\title{
CAPITAL-MARKET EFFECTS OF SECURITIES REGULATION: PRIOR CONDITIONS, IMPLEMENTATION, AND ENFORCEMENT
}

\author{
Hans B. Christensen \\ Luzi Hail \\ Christian Leuz \\ Working Paper 16737 \\ http://www.nber.org/papers/w16737 \\ NATIONAL BUREAU OF ECONOMIC RESEARCH \\ 1050 Massachusetts Avenue \\ Cambridge, MA 02138 \\ January 2011
}

This paper previously circulated as "Capital-Market Effects of Securities Regulation: The Role of Implementation and Enforcement." We appreciate the helpful comments of Cindy Alexander, Sudipta Basu, Allan Bester, Utpal Bhattacharya, Luca Enriques, Michael Erkens, Matt Gentzkow, Chris Hansen, Alexander Hellgardt, Emir Kamenica, Zachary Kaplan, Andrew Karolyi (editor), Daniel Paravisini, Jesse Shapiro, Andrei Shleifer, Jerry Zimmerman, two anonymous referees, and workshop participants at the 2011 Conference on Empirical Legal Studies, 2011 NBER Corporate Finance program meeting, 2010 PECA Conference, Bocconi University, University of Chicago, Chinese University of Hong Kong, University of Colorado Boulder, Copenhagen Business School, HEC, INSEAD, University of Manchester, University of Michigan, MIT, University of North Carolina, University of Rochester, Stockholm School of Economics, Temple University, University of Texas at Dallas, Tilburg University, Vienna University of Business and Economics, and University of Zurich. We thank several technical partners at PwC's European offices as well as several CESR members and supervisory authorities for providing institutional information, in particular Mike Birch, Oliver Burkart, Jan Fedders, and Bernd Roese. We thank Philip Jacobs, Laszlo Jakab, Maria Kamenetsky, Jeff Lam, Frank Li, Elton Lor, Russell Ruch, and Michelle Waymire for their excellent research assistance. Christian Leuz gratefully acknowledges financial support by the Sondheimer Family Charitable Foundation and the Business and Public Policy Faculty Research Fund. The views expressed herein are those of the authors and do not necessarily reflect the views of the National Bureau of Economic Research.

NBER working papers are circulated for discussion and comment purposes. They have not been peer-reviewed or been subject to the review by the NBER Board of Directors that accompanies official NBER publications.

(C) 2011 by Hans B. Christensen, Luzi Hail, and Christian Leuz. All rights reserved. Short sections of text, not to exceed two paragraphs, may be quoted without explicit permission provided that full credit, including $\odot$ notice, is given to the source. 
Capital-Market Effects of Securities Regulation: Prior Conditions, Implementation, and Enforcement Hans B. Christensen, Luzi Hail, and Christian Leuz

NBER Working Paper No. 16737

January 2011, Revised April 2016

JEL No. F36,G12,G14,G15,G38,K22,M41,M48

\begin{abstract}
$\underline{\text { ABSTRACT }}$ countries diverge more upon harmonizing regulation.

Hans B. Christensen

University of Chicago

Booth School of Business

5807 S. Woodlawn Ave

Chicago, IL 60637

hans.christensen@chicagobooth.edu

Luzi Hail

Wharton School

University of Pennsylvania

Locust Walk

Philadelphia, PA 19104

lhail@wharton.upenn.edu

Christian Leuz

Booth School of Business

University of Chicago

5807 S. Woodlawn Avenue

Chicago, IL 60637-1610

and NBER

cleuz@chicagobooth.edu
\end{abstract}

We examine the capital-market effects of changes in securities regulation in the European Union (EU) aimed at reducing market abuse and increasing transparency. To estimate causal effects for the population of EU firms, we exploit that for plausibly exogenous reasons, like national legislative procedures, EU countries adopted these directives at different times. We find significant increases in market liquidity, but the effects are stronger in countries with stricter implementation and traditionally more stringent securities regulation. The findings suggest that countries with initially weaker regulation do not catch up with stronger countries, and that 
The academic debate on the costs and benefits of securities regulation is controversial and the empirical evidence so far is mixed (see, e.g., Coffee 1984; Easterbrook and Fischel 1984; Shleifer 2005; Zingales 2009; Leuz and Wysocki 2016). Only a few studies provide causal estimates for the effects of securities regulation, but they are typically limited to specific market segments (e.g., smaller over-the-counter firms) or samples around a narrow size threshold (e.g., Greenstone, Oyer, and V issing-J orgensen 2006; Iliev 2009). M oreover, prior studies typically focus on regulatory changes in a single country. In these settings, the state of prior regulation, the new rules, their implementation and their enforcement are essentially a bundle and difficult to separate.

In this paper, we exploit major changes in securities regulation in the EU to provide causal estimates for the capital-market effects in a large population of EU firms as well as evidence on how these effects differ by prior regulatory conditions, implementation, and enforcement.

The EU setting offers several unique advantages. First, changes in securities regulation are enacted in the form of EU-wide directives. M ember states need to implement directives within a predetermined and relatively short time period, resulting in country-specific entry-into-force dates that are spread over two to three years. The variation in effective dates is plausibly exogenous within this narrow implementation window, for instance, due to differences in countries' legislative processes. Second, as EU directives apply to all member states, the regulatory act itself is held constant across countries, but its transposition (i.e., the process by which EU member states implement EU directives into national law), the design of supervision, the penalties for violations, and the actual supervision are left to the EU member states. This variation across countries allows us to analyze the role of implementation and enforcement separately from the rule change. Third, the EU setting comprises countries with different regulatory histories, which lets us analyze the interaction between a country's prior regulatory conditions and the newly introduced rules. 
Specifically, we study the capital-market effects of two EU directives that contain central el ements of securities regulation: the M arket $A$ buse Directive (M AD) concerns insider trading and market manipulation, and the Transparency Directive (TPD) addresses corporate reporting and disclosure. B oth types of regulations are intended to reduce adverse selection in capital markets. Given this regulatory intention, we focus our analysis on stock market liquidity. An extensive body of theory links market liquidity to the magnitude of information asymmetry and adverse selection in markets (e.g., Copeland and Galai 1983; Glosten and Milgrom 1985; Kyle 1985; Easley and O'Hara 1987). Furthermore, a primary purpose of securities markets is to provide liquidity to market participants, and securities regulation is frequently justified with expected improvements in market liquidity (e.g., Lamfalussy 2000; Enriques and Gatti 2008). Liquidity also has desirable features from a research design perspective: it can be measured over relatively short intervals and is "less anticipatory" in nature than other economic constructs (e.g., firm value or cost of capital). We need both features to exploit the staggered introduction of the directives. At the same time, improvements in liquidity due to reduced adverse selection should also manifest in a lower cost of capital, higher market valuations, and improved market efficiency (e.g., A mihud, M endelson, and Pedersen 2005). Thus, liquidity effects have broader capital-market implications.

Following Daske et al. (2008) and Lang, Lins, and Maffett (2012), we combine four individual proxies for information asymmetry and illiquidity (i.e., bid-ask spreads, price impact, zero returns, and total trading costs) by way of factor analysis to measure our construct of market liquidity. We estimate quarterly panel regressions with calendar-quarter fixed effects for a large sample of EU firms over a 10-year window around the two directives. The identification of the regulatory effects comes solely from within-EU variation in the effective dates of the two directives. To further tighten identification, we also estimate regressions adding country-specific linear and quadratic time trends to the model. In addition, we estimate the regulatory effects of the 
directives within-country, exploiting that some EU countries have large unregulated markets (Germany, Ireland, and the U.K.), which are not or to a lesser degree (e.g., via spillover effects) affected by the new directives. In these regressions, we allow for country-specific quarterly trends in liquidity, and the identification stems from differential liquidity effects across propensitymatched firms trading on regulated and unregulated markets in the same country.

We find that market liquidity increases when new market abuse (MAD) and transparency (TPD) regulations come into force. The estimated magnitudes for the MAD and TPD are similar and suggest an increase in liquidity around 10 percent relative to pre-directive levels. We can translate this improvement into (volume-weighted) average trading cost savings between US\$ 130,000 and US $\$ 430,000$ per year, directive, and sample firm, which implies a combined yearly benefit of both directives between 0.1 and 0.2 percent of market capitalization. ${ }^{1}$ This magnitude is economically significant, especially when considering the recurring nature of the savings and the number of sample firms. At the same time, the estimated per-stock magnitude is not too large as to be implausible. In sum, our results suggest that improving key elements of securities regulation leads to substantial economic benefits in capital markets. ${ }^{2}$

The staggered implementation of the two directives in a large number of countries mitigates many concerns that typically arise in studies of a single regulatory event. For instance, it is unlikely that unrelated shocks to liquidity line up in time with the implementation pattern across $26 \mathrm{EU}$ countries. Moreover, there are good reasons to believe that the directives' implementation timing is plausibly exogenous. First, the political decision to enact the regulation was made years

This translation provides a lower bound for the economic effects of two directives because it measures only the transaction cost savings. As discussed above, liquidity improvements indicate less adverse selection and, among other things, map into firms' cost of capital (e.g., A mihud and M endelson 1986).

2 We conduct extensive sensitivity analyses and show that our results, among other things, are robust to the introduction of firm-fixed effects, separate quarter-year fixed effects for more and less developed EU countries, controls for differences in the composition of the country samples (e.g., with respect to size or industry), the inclusion of non-EU benchmark countries, alternative proxies for market liquidity, and an analysis on the country level instead of the firm level. See the Internet A ppendix for details. 
earlier, at the EU level, mitigating the concern that our analysis picks up a market response to events giving rise to the new directives. Second, the transposition window is relatively narrow and predetermined by the EU; yet the subsequent national legislative processes are fairly lengthy and inflexible. Thus, for our findings to be spurious or to reflect other shocks, a large set of countries would have to experience differentially-timed local shocks, each prompting the national lawmaker to start the country's transposition of the directives. In addition, the lawmakers would have to choose entry-into-force dates that coincide with country-specific future liquidity improvements (or reversals) several months in advance. Such timing ability by lawmakers seems highly unlikely, even if they respond to local economic shocks or pressures by lobbyists. That being said, we conduct several tests that gauge the validity of these arguments and our identification. We provide evidence that the parallel-trends assumption holds, that liquidity responds relatively "sharply" around the event dates, and that the variation in entry-into-force dates is not explained by preimplementation liquidity shocks or by institutional features associated with cross-sectional variation in the liquidity effects. We also conduct a falsification test in the spirit of A Itonji, Elder, and Taber (2005) to specifically gauge the role of local economic shocks.

Regulatory outcomes likely not only depend on the new rules, but also on how regulation is implemented and enforced as well as on the state of prior regulation (e.g., Djankov et al. 2003a). We therefore examine whether there is heterogeneity in the treatment effects. We consider two alternative hypotheses. The first one posits that the effects of the new directives are larger in countries where prior securities regulation has been weak, effectively reducing differences across countries ("catching-up hypothesis"). But it is also possible that the same institutional, market, and political forces and constraints that limited the scope and effectiveness of securities and other regulation in the past are at play when new rules come into force ("hyster esis hypothesis"). 
We test whether the treatment effects differ depending on countries' prior regulatory conditions, and find evidence of hysteresis. That is, the liquidity benefits of the two directives are stronger in countries with higher prior regulatory quality. ${ }^{3}$ This finding may be surprising to the proponents of harmonization as it implies that imposing the same regulation on countries with disparate prior conditions could make markets diverge more, rather than converge. This hysteresis in regulatory outcomes could occur for several reasons, including lack of institutional fit, resource constraints, regulatory capture, inefficient bureaucracies, and political pressures (e.g., Demsetz 1969; Stigler 1971; Henisz 2000).

We then examine the role of differences in the implementation and enforcement of the new directives for regulatory outcomes. We create directive-specific partitioning variables using data on supervisory powers, penalties, and enforcement actions in each EU country. We also use staff growth at the securities regulator as a proxy for the extent to which countries commit resources to the implementation and enforcement of the new regulation. In a first set of tests, we show that countries with stricter implementation and enforcement experience significantly larger capitalmarket effects. When we condition on both prior regulation and implementation strength, the liquidity effects are strongest in countries with high past regulatory quality and strong implementation. There are no liquidity increases for countries with low-quality prior regulation and weak implementation. M oreover, while stricter implementation of the new directives often has an incremental effect on liquidity, this effect is significant only in countries with high past regulatory quality. This evidence further supports the existence of hysteresis in regulatory outcomes, despite regulatory harmonization.

3 W e use the regulatory quality index from K aufmann, K raay, and M astruzzi (2009) to measure a country's ability to formulate and implement sound policies and regulations. While this proxy fits our hypothesis, it is not specific to securities regulation. We find similar results using other proxies with a closer link to securities regulation (e.g., La Porta, Lopez-de-Silanes, and Shleifer 2006; Cumming, J ohan, and Li 2011). See the Internet A ppendix. 
Our paper makes several contributions to the literature. First, we provide causal evidence that the imposition of stricter securities regulation can have significant economic benefits for a broad cross-section of firms. Much of prior evidence showing such benefits stems from cross-country studies (e.g., La Porta et al. 1998 and 2006; Doidge, K arolyi, and Stulz 2004; Hail and Leuz 2006; Cumming, Johan, and Li 2011). One concern with these studies is that the evidence relies mainly on cross-sectional identification. A nother stream of studies examines major regulatory changes in a single country. Evidence from these studies often casts doubt on the existence of benefits from securities regulation, which is especially true for studies examining U.S. securities regulation in the 1930s (e.g., Stigler 1964; Benston 1969 and 1973; Jarrell 1981; M ahoney and M ei 2009). But it also holds for many studies on Regulation Fair Disclosure (e.g., Heflin, Subramanyam, and Zhang 2003; Gintschel and Markov 2004; Francis, Nanda, and Wang 2006) and the SarbanesOxley Act (e.g., Chhaochharia and Grinstein 2007; Zhang 2007; Li, Pincus, and Rego 2008; Doidge, Karolyi, and Stulz 2010; Coates and Srinivasan 2014). However, even these studies face identification challenges because they often lack a convincing control group of firms that are unaffected by the new rules (see discussions in Collver 2007; Leuz 2007; Coates and Srinivasan 2014). To get around this issue, Bushee and Leuz (2005) and Greenstone, Oyer, and VissingJorgensen (2006) examine extensions of U.S. securities regulation in specific market segments only, and Iliev (2009) exploits a size-based compliance cutoff with a regression-discontinuity design. While these designs permit causal estimates, the results apply primarily to smaller firms and offer different conclusions about the benefits. In contrast, our study estimates the liquidity benefits of securities regulation for almost the entire population of public firms in a broad set of countries using the staggered imposition of two EU directives across 26 countries. ${ }^{4}$

\footnotetext{
$4 \quad$ Papers using a similar identification strategy to ours are A grawal (2013) exploiting the staggered passage of investor protection statutes in the 1900s and K alemli-Ozcan, Papaioannou, and Peydró (2010 and 2013) using the introduction of EU directives as part of the Financial Services Action Plan (FSA P).
} 
A $n$ important second contribution of our paper is the finding that regulatory outcomes depend on countries' prior regulatory conditions as well as countries' ability and willingness to implement and enforce new rules. This evidence highlights the role of implementation and enforcement and, perhaps more surprisingly, documents substantial hysteresis in regulatory outcomes. The findings are consistent with the enforcement theory formulated in Djankov et al. (2003a) as well as its application to securities regulation in Shleifer (2005). They also provide important insights for attempts to harmonize markets globally through regulatory reforms.

Third, our findings add to the budding literature on securities law enforcement. B hattacharya and Daouk (2002) provide evidence that the first enforcement of insider trading regulation lowers firms' cost of capital. Subsequent papers using the same events demonstrate other capital-market effects associated with insider trading regulation and enforcement (e.g., Bushman, Piotroski, and Smith 2005; Ackerman, van Halteren, and Maug 2008; Hail, Tahoun, and Wang 2014). Our analysis goes beyond insider trading regulation. Moreover, prior evidence on securities law enforcement is based on ex-post measures, i.e., complaints, lawsuits, and enforcement actions. The timing of these measures raises endogeneity concerns. The EU setting allows us to provide evidence on the capital-market effects associated with changes in the legal design of enforcement regimes. ${ }^{5}$ We show that improvements of countries' supervisory regimes have immediate capitalmarket effects even before the first enforcement action took place.

While our evidence suggests substantial economic benefits, it is important to note that securities regulation also has its costs. We do not provide evidence on the costs associated with the MAD and TPD and, hence, cannot say whether the directives are net beneficial. Survey evidence suggests that direct compliance costs to firms are relatively small (Demarigny and Clerc

$5 \quad$ We also analyze (changes in) supervisory resources. In this sense, our study is related to Coffee (2007), J ackson and Roe (2009), and Cumming, Groh, and Johan (2014), which point to an association between capital-market outcomes and the level of enforcement (e.g., using staff and budgets numbers). 
2009; V roonhof and B oog 2010). But the indirect costs to firms (e.g., due to changes in corporate behavior) have not been studied yet. In addition, national governments bear one-time and ongoing administrative costs (e.g., related to enforcement). Thus, the total costs could still be substantial. As our evidence indicates, the two directives have few or no liquidity benefits in countries with weak prior regulation and implementation and could well be net costly for these countries (unless there are other benefits), which in turn could explain why these countries have committed fewer resources to implementation and enforcement.

\section{Conceptual Underpinnings, Institutional Setting, and H ypotheses}

There is a long-standing debate as to whether securities regulation is beneficial for a country's capital markets. The arguments in favor of securities regulation refer, among other things, to the existence of externalities, economy-wide cost savings, commitment problems, and insufficient private penalties (e.g., Coffee 1984; Easterbrook and Fischel 1984; Zingales 2009; Leuz and Wysocki 2016). However, these arguments often set aside the difficulties of implementing and enforcing regulation, as highlighted by Stigler (1971), Posner (1974), Peltzman (1976), and Becker (1983). Regulators face serious information problems, are often incompetent or even corrupt, and can be captured in the regulatory process. ${ }^{6}$ Private contracts are an alternative to regulation, but they rely heavily on functioning courts and private litigation, which, in practice, can be quite imperfect as well (e.g., Easterbrook and Fischel 1984; Johnson, M cM illan, and Woodruff 2002). For instance, Shleifer (2005) argues that the "inequality of weapons" between corporate insiders and promoters on one side and often unsophisticated investors on the other side makes it unlikely that private contracts combined with litigation offer an efficient solution in securities markets. $\mathrm{He}$

$6 \quad$ Illustrating that these concerns also apply to securities regulation, Carvajal and Elliott (2007) point to shortcomings in the ability of securities regulators to effectively enforce compliance with existing rules as a recurring theme in the assessment reports by the International Organization of Securities Commissions (IOSCO). 
concludes that regulation prescribing what firms have to disclose to investors could be beneficial. Consistent with this conjecture, almost all economies have extensive securities and transparency regulation. Given the above tradeoffs, the benefits of securities regulation are not a priori obvious. Djankov et al. (2003a) argue that the optimal institutional design involves tradeoffs between necessarily imperfect alternatives, which can differ greatly across countries. As a result, the benefits of securities regulation are largely an empirical matter. ${ }^{7}$

To provide empirical evidence, we examine the MAD on insider trading and market manipulation and the TPD on financial reporting and mandatory disclosure. Both directives pertain to key elements of securities regulation and are at the core of the EU's Financial Services A ction Plan (FSA P). The FSA P was established in 1999 with the goal to improve and integrate EU financial markets. As there already was prior EU and national legislation in both areas, the two directives extend and tighten existing securities regulation, harmonize differences, and, in particular, stipulate appropriate supervisory and enforcement regimes. The transposition of the MAD and TPD required amending national law(s) in all member states. We briefly describe the two directives here and provide additional details as well as a description of the EU's legislative process in A ppendix A.

The MAD was passed by the EU legislature in January 2003 and followed by several implementing directives with technical details in December 2003. Its purpose is to ensure market integrity and equal treatment of market participants by defining and prohibiting insider trading and market manipulation. A mong other things, the MAD provides a common definition of an insider and establishes transparency standards requiring people who recommend investments to disclose their relevant interests. It also requires each member state to set up an authority that is responsible

M uch of the empirical evidence in the U.S. is mixed and often negative (Leuz and Wysocki 2016 for a survey). There is also international evidence showing benefits (e.g., Glaeser, Johnson, and Shleifer 2001; Doidge, K arolyi, and Stulz 2004; Hail and Leuz 2006; La Porta, Lopez-de-Silanes, and Shleifer 2006), but it is largely from cross-sectional settings in which it is difficult to isolate the effects of securities regulation. 
for monitoring insider trading and market manipulation, and to delegate the necessary supervisory and investigative powers to this authority. ${ }^{8}$ The M AD further requires cooperation among national supervisory authorities and some, although not complete, harmonization of penalties. It replaces Directive 89/592/EEC on insider trading. Thus, while the MAD expands market abuse regulation in some areas, it is primarily intended to strengthen and harmonize the implementation and enforcement of existing EU regulation (e.g., Lamfalussy 2000; CRA 2009).

The TPD was passed by the EU legislature in December 2004 and its implementing directive was enacted in March 2007. The directive requires issuers of traded securities to ensure appropriate transparency for investors by disclosing and disseminating regulated information (e.g., periodic financial reports and ongoing information on major holdings of voting rights). However, prior EU directives, member state laws, and exchange requirements al ready stipulated annual and interim financial reports as well as the disclosure of other ongoing information. As such, the TPD does not substantially expand existing disclosure requirements, but rather focuses on (better) supervisory regimes and enforcement. For instance, the TPD stipulates that, in each member state, a supervisory authority assumes responsibility for monitoring compliance with the provisions of the directive and that this authority examines firms' regulated disclosures. Such an authority and review process did not yet exist in several EU countries and was introduced (or expanded) following the TPD. ${ }^{9}$ The TPD also requires that the authority is given appropriate enforcement tools, including the power to carry out on-site inspections.

8 For instance, the U.K.'S Financial Services A uthority (FSA) received additional powers allowing it to compel compliance with market abuse provisions and to gather evidence by requesting a search warrant. Similarly, the Portuguese regulator (Comissão do M ercado de V alores M obiliários) received additional powers to seize, freeze, seal, or inspect documents from persons and entities subject to its supervision.

9 For instance, following the TPD, the Swedish Financial Supervisory A uthority (SFSA) was charged to enforce financial reporting requirements starting in July 2007. B efore that date, the stock exchanges (and not a national supervisory body) performed reviews of the annual reports. The new regime is stricter, more extensive, and proactive. The first sanctions under the new regime were imposed in 2008 and included public disclosure of violations and corrections to the financial reports going forward. Some EU countries like the U.K. introduced such a review process al ready with the adoption of IFRS and hence, before the TPD (see Christensen at al. 2013). 
Our analysis examines the effects of the two directives in terms of market liquidity. We hypothesize that the MAD and TPD increase liquidity. However, regulatory effects likely not only depend on the new rules, but also on how regulation is implemented and enforced (e.g., Djankov et al. 2003a). In the EU setting, member states have some flexibility in how they implement the directives, for instance, with respect to penalties (Enriques and Gatti 2008). In addition, supervision is local and countries essentially determine the resources they devote to enforcement. Thus, as regulatory tradeoffs differ across countries, we expect cross-sectional variation in the implementation and enforcement of the two directives. Countries with stricter implementation and enforcement should exhibit larger liquidity effects. Moreover, countries differ in their prior regulatory conditions giving rise to two (competing) cross-sectional hypotheses. On the one hand, the effects of the new directives could be larger in countries where prior securities regulation has been weak, effectively reducing existing differences between countries ("catching-up hypothesis" ). Alternatively, the capital-market effects of the new directives could be larger in countries in which securities and other regulation has been stronger and more effective in the past ("hysteresis hypothesis"). Prior regulatory conditions likely reflect institutional, market, and political forces (or constraints) that are still at play when new rules are introduced. For instance, in countries with weak institutions and inefficient bureaucracies, new regulation is more likely to be abused and, hence, harmful (Shleifer 2005; B hattacharya and Daouk 2009). In addition, a country's past track record with respect to implementing regulation is likely revealing about its political will to put in place regulation that induces (or curbs) socially (un)desirable behavior. If such forces are persistent, we expect to see hysteresis in regulatory outcomes, rather than catching up.

A part from the MAD and TPD, the FSA P brought numerous other legislative initiatives in the area of financial market regulation. A mong the ones geared towards securities markets were the 
IAS Regulation that mandated International Financial Reporting Standards (IFRS), the Prospectus

Directive regulating disclosures during public securities offerings, the Markets in Financial Instruments Directive (MiFID) on the provision of investment services across the EU, and the Takeover Directive, which provides a framew ork for mergers and acquisitions and takeover bids. All these directives were implemented over the 2004 to 2009 period, and could potentially confound an empirical analysis of the MAD and TPD. ${ }^{10}$ We address the issue of concurrent other regulations with our identification strategy.

\section{Research Design and Data}

\subsection{E mpirical M odel and Identification Strategy}

B ased on the institutional discussion in the previous section, we predict the M AD and TPD to reduce information asymmetries and adverse selection in capital markets. We test this prediction using a quarterly panel dataset with firm-level observations of stock market liquidity. The quarterly data allow us to exploit variation in the entry-into-force dates of the MAD and TPD, but at the same time the window is long enough to reliably measure the level of liquidity. ${ }^{11}$ We estimate the following model (without firm and time subscripts):

$$
\mathrm{Liq}=\beta_{0}+\beta_{1} \mathrm{MAD}+\beta_{2} \mathrm{TPD}+\sum \beta_{\mathrm{j}} \text { Controls }_{\mathrm{j}}+\sum \beta_{\mathrm{i}} \text { Fixed Effects } \mathrm{i}+\varepsilon
$$

The dependent variable, Liq, stands for liquidity, described in more detail below. MAD and TPD, our main variables of interest, are binary indicators coded as ' 1 ' beginning in the quarter in

10 Conceptually, the M IFID is the biggest potential confound for a liquidity analysis given its focus on investment services (e.g., order handling and trade transparency). However, M iFID was passed in part by regulation, which implies that a common effective date is set by the EU (N ovember 2007). If its effect occurs around that date, it is absorbed by the quarter-year fixed effects. In addition, we use the dates by which EU countries completed the implementation of all the M iFID provisions to control for its effects.

11 Exploiting the variation in the entry-into-force dates requires an outcome variable that is not anticipatory as otherwise date variation is not relevant. For instance, firm value or the cost of capital likely responds as soon as regulatory changes are announced. We argue that liquidity is less anticipatory and, hence, suited for the analysis. Investors primarily worry about adverse selection at the time they trade. It is of course possible that investors anticipate that future regulatory changes will reduce adverse selection at the time they sell. But this anticipatory effect is likely small (consistent with the evidence in Figure 1 and Table 3, Panel A). 
which the corresponding directive comes into force in a given EU member state and ' 0 ' otherwise. Controls $\mathrm{s}_{\mathrm{j}}$ denotes a set of firm- and country-level control variables. A mong other things, we explicitly control for other FSAP directives introduced over the sample period that are less pertinent for our purposes but could affect liquidity (see Section 1). Fixed Effects; represents country, industry, and quarter-year fixed effects. The purpose of the quarter-year fixed effects is to eliminate liquidity trends and shocks common to all EU member states in a given quarter. As a result, the identification stems from within-EU variation in the entry-into-force dates of the two directives. We draw statistical inferences based on standard errors clustered by country. ${ }^{12}$

Our empirical strategy for estimating the effects of securities regulation on market liquidity is based on the following institutional features. First, after the enactment of a new EU directive, each member state must transpose the directive into national law. As a result of this legislative process, new directives come into force at different points in time across member states. For the M AD, the dates range from A pril 2004 to J anuary 2007, and for the TPD they spread from J anuary 2007 to A ugust 2009 (see Table 1). The staggered introduction allows us to use quarter-year fixed effects, which alleviates two common concerns in studies of regulatory changes (see also K alemliOzcan, Papaioannou, and Peydró 2010 and 2013). One concern is that the results could reflect general time trends or market-wide changes (e.g., macroeconomic shocks) that are concurrent with but unrelated to the regulatory change. A nother concern is that new regulation is often put in place after major economic events, such as a crisis or corporate scandal. It is likely that markets respond to these preceding events and, hence, the results could reflect this market response rather than the

12 We also conduct placebo analyses in which we randomly assign implementation dates between the first quarter of 2001 and the second quarter of 2004. This period precedes the entry-into-forces dates for the MAD in all countries, except for Lithuania. Using 500 replications, the average placebo effect is close to zero, as expected. W e use the distribution of placebo coefficients to bootstrap the significance levels in our main analyses. $N$ one of the 500 placebo regressions produced coefficients that exceed the M AD or TPD coefficients reported in Table 2. Based on this evidence, the estimated effects are clearly statistically significant and, if anything, our inferences using standard errors clustered by country are conservative. We also consider two-way clustering and clustering by economic region. See the Internet A ppendix for details. 
effects of the new regulation (e.g., Ball 1980; M ulherin 2007). In our setting, confounding events would have to be correlated with the effective dates of two directives across 26 countries, which seems unlikely.

Second, the regulatory act takes place at the EU level and, hence, the new regulation is not specific to any particular country. Member states have to transpose the directives within a specified and limited amount of time (typically about two years). This window is not particularly generous. To illustrate, the law that implemented the MAD in the U.K. was laid before the U.K. parliament in February and entered into force in J uly of 2005. The consultation period started in J une 2004 with an initial draft, so the implementation process must have started even earlier. In total, the observable part of the implementation process exceeded one year. We illustrate in Table A-1 that the length of this process is not uncommon for several EU countries. M oreover, standard due process for new EU laws implies that the transposition of the directives into national law is fairly inflexible. ${ }^{13}$ In A ppendix A, we provide more details on the legislative processes in the EU supporting the claim that they are lengthy and inflexible.

The narrow transposition window set by the EU combined with lengthy and inflexible legislative processes at the national level substantially reduce concerns about reverse causality and endogenous implementation timing. In our setting, reverse causality would imply that lawmakers can predict future liquidity changes well in advance (by a year or more) and time legislative processes and effective dates accordingly. This seems implausible. The institutional setting also mitigates the concern that the entry-into-force dates are endogenous because lawmakers start the implementation in response to local conditions (e.g., liquidity shocks) or lobbying pressures induced by local conditions. For this concern to arise in our setting, countries would have to

13 Despite the inflexibility, it is possible that timing is related to a country's willingness to implement the new laws, which could lead to heterogeneous treatment effects across countries. But such heterogeneity likely stems from the way countries implement the directives (and not the implementation timing per se). See Section 4. 
experience a series of differentially-timed local shocks, which in turn would have to prompt national lawmakers to start the country's implementation process for a directive and this legislative process would have to result in effective dates that coincide with subsequent liquidity changes. As this sequence of events seems unlikely, we argue that the directives' entry-into-force dates across countries can be viewed as plausibly exogenous (and provide further evidence in Section 3.2). We conclude that the setting is well suited to identify causal effects of securities regulation on market liquidity for a broad cross-section of firms and countries.

\subsection{Data and C onstruction of the Variables}

Our sample period starts in the first quarter of 2001, before the EU adopted the MAD and the TPD, well in advance of the first country-specific entry-into-force dates for the two directives. The sample period ends in the second quarter of 2011, which gives us a minimum of two years of post-implementation data for all EU countries. Adding additional firm-quarters beyond 2011 is unlikely to affect our results because the effects are primarily identified from liquidity changes close to the entry-into-force dates. We include all firm-quarter observations from EU countries for which we have the necessary data to estimate our basic regression in Eq. (1). Table 1, Panel A, provides an overview of the sample composition by country. ${ }^{14}$ The sample comprises 112,260 firm-quarters from 4,846 unique firms across 26 countries. We exclude firms with U.S. crosslistings as they are subject to U .S. insider trading and transparency rules. In addition, we eliminate firms trading on unregulated EU markets that are not necessarily subject to the MAD and TPD

14 The treatment sample also includes Iceland and Norway, which are not in the EU but belong to the European Economic A rea (EEA). W e include them because they have agreed, among other things, to adopt the EU capital market directives (such as the MAD and TPD) in exchange for access to the EU's single market. For simplicity, we refer to them as EU countries throughout the paper. Furthermore, we exclude Bulgaria and Romania in the empirical analysis even though they are EU member states because they adopted all EU regulations (including the MAD and TPD) upon joining the EU in January 2007. The results are not sensitive to either of those sample choices. We exclude $M$ alta as we do not have sufficient data. 
(e.g., the A Iternative Investment $\mathrm{M}$ arket in London) and very small firms with, on average, market values below US\$ 5 million. ${ }^{15}$ We further require at least four quarterly observations per firm.

Panel A of Table 1 also lists the dates when the national law(s) that implemented the MAD and TPD came into force in a country. We collect the Entry-into-F orce Dates from publications by the European Commission for the MAD and by Linklaters LLP, an international law firm, for the TPD, and validate them with the dates on which each EU member state informed the European Commission of its compliance with the directives. In case of discrepancies, we contacted the national securities regulator to resolve the issue. The MAD dates vary from A pril 2004 (Lithuania) to J anuary 2007 (Bulgaria and Romania), the TPD dates from J anuary 2007 (Bulgaria, Germany, Romania, and the U.K.) to A ugust 2009 (Czech Republic).

We also include controls for other FSAP directives that are related to securities markets, namely the Takeover Directive (TAKEOVER), the Market in Financial Instruments Directive (MiFID), the Prospective Directive (PROSP), and the IAS Regulation that mandated IFRS adoption (IF RS). Except for IF RS, we define the control variables for the other FSA P directives in the same way as for the MAD and TPD, that is, as binary variables that are coded as ' 1 ' beginning in the quarter in which the respective directive comes into force. We collect the entry-into-force dates from publications by the European Commission. For IFRS, we use a firm-specific indicator to account for the fact that a firm's fiscal-year end determines the quarter it starts reporting under IFRS. We code a binary variable that switches to ' 1 ' in the quarter after the first fiscal-year end for which IFRS reporting is mandatory (see also Christensen, Hail, and L euz 2013).

We use four liquidity proxies. The first proxy is Bid-Ask Spread, which is conceptually close to the desired construct and commonly used in empirical research to capture information

15 We impose the latter restriction because tracking listings on unregulated markets over time is difficult. For instance, Datastream provides only static exchange information. As firms trading on unregulated markets tend to be smaller, the size criterion is another way to identify such firms and to make sure that they do not enter the main analysis. We exploit firms trading on unregulated markets as a benchmark in Section 3.2. 
asymmetry (e.g., Stoll 1978; V enkatesh and Chiang 1986; Glosten and Harris 1988). We obtain the closing bid and ask prices for each day and compute the daily quoted percentage spread as the difference between the two prices divided by the mid-point. We then take the mean daily spread over the quarter for a given firm. The second proxy is Price Impact computed as the quarterly mean of the A mihud (2002) illiquidity measure (i.e., daily absolute stock return divided by US\$ trading volume). ${ }^{16}$ The third proxy is Zero Returns, defined as the proportion of trading days with zero daily stock returns out of all potential trading days per quarter. The fourth proxy, Total Trading Costs, is an estimate of the total round trip transaction costs (including bid-ask spreads, commissions, and implicit costs from short-sale constraints or taxes). We calculate Total Trading Costs based on a quarterly time-series regression of daily stock returns on the aggregate market returns (L esmond, Ogden, and Trzcinka 1999). ${ }^{17}$ To mitigate measurement errors in the individual proxies as well as differences in the relative quality of the proxies across countries, we follow Daske et al. (2008) and Lang, Lins, and M affett (2012) and aggregate the four liquidity proxies into a single Liquidity Factor using factor analysis. We use the scores from the first (and only) factor with an Eigenvalue greater than one as the dependent variable. ${ }^{18}$

As control variables, we include gross domestic product (GDP) per capita to capture differences in countries' macro-economic development and, following prior literature (e.g., Chordia, Roll, and Subrahmanyam 2000; Leuz and Verrecchia 2000), the market value of equity, share turnover, and return variability to account for firm-level differences. We measure all control

16 To avoid the misclassification of days with no or low trading activity (i.e., days potentially yielding a price impact of zero), we omit zero-return days from the computation of the quarterly means.

17 This measure, which is empirically closely related to Zero Returns, is based on the logic that informed investors do not trade when the cost of trading exceeds the value of new information. We use log-likelihood estimation to extract a proxy of total trading costs from a system of equations employing a panel of firms' daily stock returns and equal-weighted local market index returns. To reduce measurement error, we eliminate estimates below a lower bound of one basis point. See the appendix in Daske et al. (2008) for details on the estimation.

18 We provide details on the construction of the liquidity factor in Table I-2 in the Internet A ppendix. The first factor explains the vast majority of the variation in the liquidity variables. We also provide results using bid-ask spreads and zero returns as dependent variables. See Table I-1 in the Internet A ppendix. 
variables on a quarterly basis (except for GDP), and lag them by four quarters to allow for seasonal effects. The notes to Table 1 provide further details on the variable measurement. We estimate the regressions in a log-linear form taking the natural logarithm of the liquidity factor and the continuous control variables. Price and volume data are from Datastream. ${ }^{19}$ We truncate variables without natural upper and lower bounds at the first and $99^{\text {th }}$ percentile. Panel B (Panel C) of Table 1 reports descriptive statistics for (correlations between) the firm-level variables.

\section{Capital-M arket E ffects of T ighter Securities R egulation in the E U}

\subsection{A verage Liquidity E ffects}

We present the results of four specifications in Table 2. In Columns (1) and (2) we estimate the effects for each directive separately; in Column (3) we combine the two directives into one model; and in Column (4) we include controls for other EU directives in the FSA P that are related to securities markets. The explanatory power of the regressions is high with an $\mathrm{R}^{2}$ of 66 percent, suggesting that the model accounts for the main drivers of liquidity. The firm-specific control variables are significant and exhibit the expected signs. Large firms and firms with a high share turnover are more liquid, and firms with more volatile returns are less liquid. GDP per capita is insignificant. A mong the other FSA P directives only IF RS is significant. The negative coefficient on IF RS in the EU is consistent with Daske et al. (2008) and Christensen, Hail, and Leuz (2013). The insignificant coefficient on M iF ID contrasts with the liquidity results in Cumming, J ohan, and

Li (2011). One reason for this difference could be that our model provides tighter identification. It is possible that the concerns about M iFID (e.g., increased market fragmentation) are warranted

19 Our primary source of bid-ask spread data is Datastream. To increase sample size in some of the smaller EU countries (i.e., Czech Republic, Latvia, L uxembourg, R omania, Slovakia, and Slovenia) we complement this data with spreads from Bloomberg. Doing so does not materially affect the results. We also assess the effect of data availability of the four liquidity proxies on our results using an expectations-maximization (EM) algorithm to impute missing observations (see, e.g., Dempster, Laird, and Rubin 1977; K arolyi 2015, Chapter 3). Imputing missing values leaves the results largely unchanged (see Table I-1 of the Internet A ppendix). 
and that it has no liquidity effects. A Iternatively, the insignificance of M iF ID could reflect limited variation in the effective dates. As M iFID was passed in part by regulation and had a common effective date set by the EU (November 1, 2007), the demanding fixed-effects structure in our model could absorb (partially) the liquidity effect, if there is one. ${ }^{20}$

For our test variables, we find that the coefficients on both MAD and TPD are negative and statistically significant. MAD and TPD remain significant and have similar magnitudes when we jointly include them in the model and when we control for the other FSA P directives. The results imply that tighter securities regulation increases market liquidity. The estimated treatment effects are economically significant. U sing Column (4), the MAD coefficient of -0.115 suggests that, on average, liquidity increases by 11 percent. $^{21}$ For the TPD, the coefficient of -0.093 indicates an average increase in liquidity of about 9 percent. The magnitude is comparable to the liquidity changes around IFRS adoption in the EU. This finding is plausible in light of Christensen, Hail, and Leuz (2013), which suggests that the liquidity changes around IFRS adoption are also related to substantive enforcement changes (see Table I-3 in the Internet A ppendix).

As a way to further gauge the economic magnitude, we translate the percentage effects into value-weighted average savings in annual trading costs per firm. These values give us a lower bound on the capital-market effects because the economic effects of liquidity improvements go beyond trading costs. We multiply the estimated trading cost reductions with the total yearly dollar trading volume per firm and then divide by the mean market capitalization. U sing bid-ask spreads, the annual cost savings are approximately US $\$ 0.16$ and 0.13 million (or 0.053 and 0.043

20 For our analyses, we use the date by which all M iFID provisions were adopted in a given country, which slightly increases the variation in dates: one country completed the adoption of M iFID in the third quarter of 2007, 24 in the fourth quarter of 2007, one in the first, two in the second, and one in the fourth quarter of 2008 (see summary transposition tables provided by the European Commission). To assess the impact of limited variation in the effective dates, we include non-EU benchmark countries in the sample and define the quarter-year fixed effects across all countries. Thus, we identify the effect of M iFID off differential liquidity trends between EU and nonEU firms. We still find that the M iFID coefficient is insignificantly negative or, with controls, even positive.

21 We compute the average percentage change in liquidity as $\left(e^{-0.115}-1\right)=-0.108$ (or roughly $11 \%$ ). 
percent of market value) for the MAD and TPD, respectively. Using total round-trip trading costs, the annual savings are approximately US\$ 0.43 and 0.35 million (or 0.103 to 0.084 percent of market value) for the MAD and TPD. These numbers are economically significant, in particular when considering the recurring nature of the savings. ${ }^{22}$

We gauge the sensitivity of the results with respect to (i) the clustering of the standard errors, (ii) the fixed-effects structure and shocks that differentially affect firms and countries, (iii) the construction of the liquidity factor, (iv) the use of individual liquidity proxies, (v) the sample composition including the unit of analysis (firm versus country level), and (vi) the use of share turnover and market value as control variables. We report the sensitivity tests in Table I-1 in the Internet A ppendix. These analyses show that our findings and estimated magnitudes are robust to a wide variety of alternative design choices.

\subsection{Assessing Identification and R esults from W ithin-C ountry E stimation}

In this section, we further assess our empirical strategy, in particular, the notion that countries' entry-into-force dates are plausibly exogenous. If the dates provide reasonably sharp identification with respect to changes in market liquidity, then threats to identification would have to come from omitted factors that are correlated with the distribution of the entry-into-force dates within the EU and concurrent changes in market liquidity. This correlation would arise if countries chose to implement the directives in response to local liquidity shocks.

We begin by assessing the sharpness of the liquidity effects. It is a priori not obvious that the treatment effect of the directives is indeed "sharp" right at the entry-into-force date. We do not expect a similar pattern as in medical trials or educational experiments for which the timing of the treatment can be precisely controlled. For instance, investors may already respond with less

22 When interpreting the magnitudes, it is important to note that within-EU estimation with quarter-year fixed effects is very demanding and could capture some fraction of the treatment effect, particularly if (i) there is clustering of the implementation dates across countries, (ii) the dates are measured with noise, or (iii) the directives have a more gradual effect. 
insider trading shortly before the directives' effective dates because they expect countries' capabilities or willingness to pursue insider-trading violations to increase in preparation of the new directives. Thus, some response prior to the entry-into-force date is conceivable, but it should be limited (see also Footnote 11). M oreover, multiple countries (like the U.K.) implemented several TPD provisions (e.g., proactive reviews of financial statements) before the official entry-into-force date and in conjunction with IFRS adoption (Christensen, Hail, and Leuz 2013). Such a preimplementation could attenuate the TPD effects at the effective date (see Table I-3 in the Internet A ppendix for evidence of abated TPD liquidity effects when we control for early implementation). Conversely, it may take some time for the TPD enforcement bodies to become fully effective. ${ }^{23}$ Thus, there are reasons to believe that the TPD effect is less sharp than the M AD effect on either side of the entry-into-force dates.

To empirically gauge whether the implementation dates provide reasonable identification, we introduce a separate indicator variable into the model for the year leading up to the two directives (i.e., quarter $\mathrm{t}-4$ to quarter $\mathrm{t}-1$ ). The purpose of this analysis is to see whether liquidity is al ready elevated or trending ahead of the directives (in event time). We find that the liquidity effects in the year prior to the directives are small and insignificant (Table 3, Panel A). An F-test confirms that liquidity is significantly higher after the directives become effective compared to the preceding year. Thus, liquidity increases right around the time the directives enter into force. We further confirm that the effective dates are critical by counter-factually shifting the assignment of the implementation dates by one quarter at a time. Each time we re-estimate our base model noting the respective coefficient. For the MAD, the coefficients peak when using the true entry-

23 For instance, setting up a review process for financial information requires hiring and training additional staff. Descriptive evidence for Germany shows that it may take a year or two before the supervisory agency gets to a steady state (Ernstberger, Hitz, and Stich 2012). Our survey of regulators and auditors supports the notion that enforcement activities under the TPD were gradually increased over time. 
into-force dates; for the TPD the coefficients indicate a delayed reaction in liquidity (see Table I-4 in the Internet A ppendix).

To graphically illustrate the sharpness of the entry-into-force dates, we plot the liquidity effects in event time. To do so, we estimate a version of Eq. (1), in which we replace the single MAD or TPD indicator with a series of 16 separate indicator variables, each marking one quarter over the period $t-8$ to $t+8$. We omit the indicator for quarter $t-1$ so that this period serves as a benchmark (by definition, this coefficient is zero). We limit the sample to quarters $t-8$ to $t+8$ and keep only countries that have observations in all 17 periods, so that the country composition is held constant and coefficients are comparable over time. Figure 1 plots the coefficients for each relative quarter together with the $95 \%$ confidence interval. For the MAD, the liquidity effect is fairly immediate and becomes significant starting with the entry-into-force quarter $(t=0)$. The effect slightly increases in magnitude over time and remains significant through quarter $t+8$. For the TPD, the time-series pattern is less sharp, as expected, and it takes some time for the quarterly indicators to fall significantly below the benchmark period. Nonetheless, the graph suggests a clear shift in liquidity after the TPD becomes effective. For both directives, the coefficients in the pre-period (t-2 to t-8) are statistically indistinguishable from the benchmark quarter, showing that there is no pre-trend.

Given the effects occur right around the entry-into-force dates, the remainder of the section focuses on the question of whether these dates are indeed plausibly exogenous. In particular, we gauge the concern that countries choose to implement the directives in response to local liquidity shocks. We conduct five tests and present the results in Panel B of Table 3. In Column (1), we include an additional control for changes in firm-specific liquidity in quarters t- 8 to t-4, which corresponds to the period over which the national bureaucracies typically prepared the transposition of the directives (see Appendix A). This model gets at the possibility that mean 
reversion in liquidity or a response to local liquidity shocks by particular firms play into our findings. The table shows that adding lagged changes does not materially affect the estimated MAD or TPD coefficients. In addition, we test whether the relative timing of the entry-into-force dates is associated with countries' average liquidity change in the year after the directive passed at the EU level (not tabulated). For both directives, the association is insignificant ( $p=0.24$ and $p=0.39$, respectively) and, if anything, positive, which is opposite to what one would expect if liquidity shocks motivated national lawmakers to begin or accelerate the directives' implementation.

In Column (2), we add linear and quadratic trend variables for each country to the model. This specification accounts for time trends in individual EU countries on top of the quarter-fixed effects, which already control for EU-wide trends. The coefficient on MAD is hardly affected. The TPD coefficient is somewhat attenuated, which is expected given the more gradual implementation of this directive and the liquidity pattern shown in Figure 1. However, the TPD coefficient remains significant.

In Columns (3) and (4), we provide an even stricter test, but for a limited set of countries. We restrict the sample to three countries with large unregulated markets: Germany (O pen M arket), Ireland (Enterprise Securities M arket), and the U.K. (A Iternative Investment M arket A IM ). ${ }^{24}$ The idea is that the two directives are geared primarily towards regulated markets and do not apply (or only to a lesser extent) to firms trading on unregulated markets. Unless there are spillover effects (e.g., due to externalities or competition with the regulated markets), firms on unregulated markets should be less affected and, hence, provide a suitable within-country benchmark. That is, by adding unregulated market firms to the sample, we can apply within-country estimation and include separate calendar quarter fixed effects for each country. These fixed effects absorb local

24 W e do not use NY SE A Iternext in these tests because most of the M A D provisions al so cover NY SE A Iternext. 
shocks and country-specific trends in an even more flexible way than the linear and quadratic trends in Column (2). The coefficients on MAD and TPD identify the liquidity effects for regulated-market firms relative to firms trading on unregulated markets in the same country. As shown in Column (3), both MAD and TPD are significant and similar in magnitude to the estimates in Table 2. In Column (4), we go one step further and estimate the within-country specification for a balanced and propensity-matched sample to ensure that we have the same number of regulated and unregulated firms with similar characteristics. ${ }^{25}$ A gain, the coefficients on MAD and TPD remain significant and are only slightly attenuated relative to Table 2 .

In Column (5), we directly gauge the concern that the staggered dates are endogenous. Under the selection explanation, local shocks (or pressures) affect both liquidity and the timing of when lawmakers implement the directives, leading to an endogenous correlation between the two. We test this alternative explanation with a falsification exercise in the spirit of Altonji, Elder, and Taber (2005). We first re-estimate M odel 3 of Table 2, but exclude the M AD and TPD variables and instead add several proxies for local economic conditions and political forces. These forces have the potential to influence the timing of when lawmakers implement the directives and could be correlated with liquidity changes. Specifically, we regress the liquidity factor on a series of election dummies capturing the time to the next national elections (i.e., quarter $t-4$ to $t=0$ ) as well as macroeconomic variables for annual inflation, GDP growth, gross domestic savings, net portfolio equity inflows, and the net capital account (all scaled by GDP). This first-stage regression generates predicted liquidity values conditional on observable candidates for selection. We then use these predicted values as dependent variable in our main model. Under the

25 W e conduct the propensity matching within each country based on the following firm characteristics (measured in the quarter before the MAD came into force): total assets, return on assets, book-to-market, asset growth, quarterly stock returns, and annual standard deviation of daily stock returns. For each matching variable, we ensure that there are no statistically significant differences between regulated and unregulated firms. We further require that firms exist before and after the MAD and TPD became effective. 
alternative explanation that local conditions and shocks induce our results, we should find coefficients that are similar to those in Table 2. However, as Column (5) shows, the coefficients on MAD and TPD are statistically insignificant, and their magnitudes are small in an absolute and relative sense. Given that a model with selection on observables does not come close to explaining our findings, selection on (time-variant) unobservables would have to be huge (and largely unrelated to the observables that we control for) if it were to explain our results.

Finally, we analyze countries' relative transposition timing across directives. We find that the relative timing is persistent (i.e., countries are consistently early or late) and driven by features of the national legislative process such as having a bicameral legislature, which supports the notion that the entry-into-force dates are plausibly exogenous (see Table I-5 in the Internet A ppendix).

\section{Role of Prior R egulation and Differential Implementation of Securities R egulation}

\subsection{Partitioning V ariables to Test for H eterogeneity in the Treatment E ffects}

Our analyses up to this point suggest that the imposition of tighter securities regulation, on average, has a causal effect on market liquidity. In this section, we examine heterogeneity in the treatment effects, in particular, due to differences in prior regulatory conditions as well as in the ex post implementation and enforcement. These analyses allow us to explore the catching-up and hysteresis hypotheses. To test for cross-sectional differences, we introduce two (non-overlapping) partitioning variables, one for high levels and one for low levels, into the base model:

$$
\begin{aligned}
& \mathrm{Liq}=\beta_{0}+\beta_{1} \mathrm{MAD}(\mathrm{TPD}) \times \mathrm{P} \text { artitioning Variable } \mathrm{e}_{\mathrm{High}}+\beta_{2} \mathrm{MAD}(\mathrm{TPD}) \times \\
& \text { Partitioning Variable } \mathrm{L}_{\mathrm{Lw}}+\sum \beta_{\mathrm{j}} \text { Controls }_{\mathrm{j}}+\sum \beta_{\mathrm{i}} \mathrm{F}_{\text {ixed Effects }}+\varepsilon \text {. }
\end{aligned}
$$

The Partitioning Variables are binary indicators set to ' 1 ' for the group of EU countries with high/low realizations of several institutional characteristics, respectively, and to ' 0 ' otherwise. We then test for significant differences between the coefficients $\beta_{1}$ and $\beta_{2}$ to assess whether the 
liquidity effects of the directives differ within the EU. Everything else is defined as in our base specification (see Model 4 in Table 2). We partition EU countries with regard to the quality of prior regulation and the strength with which the MAD and TPD are implemented and enforced. Thus, the analyses examining the heterogeneity in the treatment effects rely solely on crosssectional differences across countries. Such variation is subject to standard correlated omitted variable concerns and cannot provide causal evidence on the precise reasons for the heterogeneity in the treatment effects, despite the fact that the average treatment effect is well identified.

Table 4 provides a by-country overview of the partitioning variables (together with the binary indicators). For Regulatory Q uality, we use an index taken from K aufmann, K raay, and M astruzzi (2009) that measures "the government's ability to formulate and implement sound policies and regulations that permit and promote private sector development." This variable is conceptually close to the construct we have in mind for our tests and should broadly capture the effectiveness of prior regulation (not just in the area of securities markets). ${ }^{26} \mathrm{Higher}$ index values indicate better prior regulatory quality. We use the values as of 2003 in the analysis, that is, before the two directives came into force, and split the sample by the median of the 34 member countries of the Organization for Economic Co-operation and Development (OECD). The use of the OECD median, which includes countries like Canada and the U.S.A., allows for a broader benchmarking of the institutional features among a group of countries with a certain minimum level of market development and quality of legal institutions and procedures (but the results are similar when we split by the EU median instead).

26 W e get similar results for al ternative proxies of prior regulatory quality with a closer link to securities regulation: (i) the rule of law index from K aufmann, K raay, and M astruzzi (2009), (ii) the public enforcement index from La Porta, Lopez-de-Silanes, and Shleifer (2006), (iii) the anti-self-dealing index from Djankov et al. (2008), (iv) an index measuring the quality of a country's auditing and reporting standards from the Global Competitiveness Report, and (v), in the spirit of K arolyi (2015, Chapter 8), a Regulatory Quality F actor we derive from all our country-level proxies using factor analysis. See Tables I-6 and I-7 in the Internet A ppendix for details. 
Next, we develop directive-specific measures for the implementation and enforcement of the MAD and TPD across EU member states: (i) Maximum $F$ ine $_{M A D}$ is the maximum monetary penalty that the supervisory authority can impose on security issuers for violations of A rticle 2 of the MAD (CESR 2008). A rticle 2 deals with insider trading, and prohibits any person who possesses inside information from using that information in trading securities, for his own account or the account of a third party. (ii) Supervisory Powers $S_{M D}$ equals the number of positive answers (out of 86 possible) by the supervisory authority in each EU member state to a questionnaire on the existence of specific supervisory powers regarding the transposition of the MAD into national law (CESR 2007). ${ }^{27}$ Higher values imply more supervisory powers. (iii) Shift in Enforcement $\mathrm{MAD}_{\text {AD }}$ indicates EU countries that have taken at least a single enforcement action regarding violations of the MAD by 2009 (e.g., imposed a fine). We establish whether enforcement actions were taken based on CESR (2010), a review report that summarizes the enforcement actions in the EU since the introduction of the MAD. (iv) Maximum Fine supervisory authority can impose on security issuers for violations of A rticles 4 to 6 of the TPD on periodic reporting requirements (CESR 2009a). ${ }^{28}$ (v) Supervisory PowerSTPD represents the subset of EU countries that by the end of 2008 fully comply with all the enforcement principles proposed in the Committee of European Securities Regulators (CESR) Standard N 0. $1^{29}$ (vi) Shift in Enforcement $T_{T P D}$ indicates a substantial change in the enforcement of financial reporting rules around the entry-into-force of the TPD. We construct this variable based on a survey that we sent

27 The survey covers MAD A rticles 1.5 to 16.4. For instance, the question for A rticle 2 on insider information is: "D oes your authority have the power to establish whether or not an individual has access to insider information?" For A rticle 3 on third-party tipping they ask: "D oes your authority have the power to evaluate the application of the provisions of M AD related to the disclosure of inside information to third parties?" A rticle 4 requires the release of an annual report within four months of the fiscal-year end. A rticle 5 regulates the publication of semi-annual reports. Article 6 requires that issuers make a public announcement during both the first and the second half of the fiscal year about the financial position and performance of the firm.

29 Standard N 0.1 comprises 21 principles on how each EU member state should enforce the provision of financial information. In 2009, CESR released a report on whether or not its principles were met. Because many of the principles in Standard N o. 1 essentially became law with the TPD, we use this report to construct a variable that measures the extent to which a country enforces the provisions of the TPD (CESR 2009b). 
to the authority in charge of supervising compliance with accounting standards and the technical departments of PricewaterhouseC oopers, an international audit firm, in each EU country. ${ }^{30}$

The last partitioning variable applies to both the MAD and TPD, and focuses on the resources that countries commit to enforcing the directives (see also Enriques and Gatti 2008). We measure Staff Growth as the percentage change in the number of full-time employees working for the supervisory authority in charge of securities regulation from 2004 to $2009 .{ }^{31}$ Staff numbers are more readily available and easier to compare across countries than budgets. To make staff numbers comparable, we scale them by the number of publicly listed firms per country. In line with Jackson and Roe (2009), we assume that a higher rate of staff growth indicates stronger implementation and enforcement. For the analyses, we transform all continuous implementation proxies into binary partitioning variables splitting by the EU median.

\subsection{Differential Liquidity E ffects within the E U}

In this section, we report findings on the heterogeneity in the treatment effects. For brevity, we tabulate only the coefficients (and t-statistics) for the main variables of interest from estimating Eq. (2) in Table 5. We begin each panel with splits for prior regulatory conditions for the MAD (Panel A) and the TPD (Panel B ). Thereafter, we present splits using the directive-specific proxies for the way in which EU countries implement and enforce the directives. The table also reports $\mathrm{p}$ values for the tests of differences in the coefficients across groups.

Using Regulatory Quality in 2003 to partition the EU countries, we find that the coefficients on MAD and TPD are negative and significant when prior regulatory quality is strong (relative to

30 We set the variable to ' 1 ' if the local authority indicated that it newly implemented a proactive comment and review process for compliance with accounting standards and the audit firm replied that there was a significant shift in enforcement intensity between 2004 and 2009 (see also Christensen, Hail, and L euz 2013, A ppendix A).

31 We use annual reports of the national securities regulators and the numbers in Central Banking Publications (2009) to gather data on full-time supervisory staff. If data are missing in a given year, we interpolate from adjacent years. We use the growth of staff specifically assigned to the oversight of securities regulation and include the staff growth from separate monitoring bodies to review financial reports (e.g., in Germany and the U.K.), if applicable. If the sources provide data only for a joint regulator (including banking and insurance), we allocate staff to securities regulation based on the market capitalization of the respective sectors. 
the OECD benchmark). In countries with weaker prior regulation, the coefficients are insignificant and close to zero. The liquidity effects are statistically different across the two groups. The results indicate that the effects are concentrated in countries with stronger prior regulation, which supports hysteresis rather than the catching up hypothesis.

The tenor of the results using the directive-specific variables is very similar across partitions. The MAD and TPD coefficients are al ways negative and significant for the subset of EU countries that implement and enforce the directives relatively strongly. The coefficients are much smaller and, with one exception, not significant for countries with weak implementation. The liquidity improvements are concentrated in countries that impose higher monetary fines for violations, confer more supervisory powers to national regulators, shifted to a stronger enforcement regime when the directives came into force, and allocated more resources to the supervisory authority. ${ }^{32}$ The (two-sided) p-values for the differences between strong and weak implementation countries are often not significant at conventional levels, but the reason is likely power (see also our bootstrapping exercise in Footnote 12, which suggests that we tabulate rather conservative standard errors). The relative coefficient magnitude across all eight specifications supports the notion that the liquidity effects of the two EU directives are concentrated in countries with stronger implementation and enforcement.

An alternative explanation for the observed heterogeneity in the liquidity effects is that the implementation of the directives in the early countries creates spillover effects in the late countries that have not yet implemented the directives. These spillover effects, in turn, imply weaker liquidity effects at the later entry-into-force dates. The analyses presented in Section 3.2 al ready mitigate this concern as they show that the liquidity effects occur relatively sharply around the

32 The results for $M A D$ are very similar when we partition countries based on the price manipulation index or the market manipulation index from Cumming, Johan, and Li (2011), or the number of detected offenses in 2008 from Cumming, Groh, and Johan (2014). However, except for detected offences, these indices are available for only 13 of our sample countries. 
entry-into-force dates. In additional tests (not tabulated), we find no evidence of liquidity benefits prior to the entry-into-force dates for countries that adopt the MAD (TPD) late, which is inconsistent with the existence of spillover effects. ${ }^{33}$ M oreover, Table I-8 in the Internet A ppendix shows that there is essentially no correlation between a variable splitting countries into 'early' and 'late' depending on their relative implementation timing and the cross-sectional partitioning variables. Thus, relative timing and spillover effects are unlikely to explain the heterogeneity in the treatment effects presented in Table 5. In addition, the lack of correlation between countries' implementation timing and the partitioning variables lends further support to our earlier conclusion that the entry-into-force dates are not selected with liquidity in mind.

\subsection{Conditioning on Prior Regulation and Implementation Strength}

To further examine the hysteresis and catching-up hypotheses, we condition on both prior regulatory quality and implementation (or enforcement) of the two directives. We combine the binary Regulatory Quality indicator (high vs. low) with each of the implementation variables (strong vs. weak), and report results in Table 6. These two-way partitions sort the post-M AD and post-TPD observations into four distinct bins, for which we estimate the liquidity effects using a slightly extended version of the model in Eq. (2). Specifically, we introduce a variable labeled High RQ/Strong IS in the model, which represents the liquidity effects of the directives in countries with high quality prior regulation and strong implementation. Low RQ/Weak IS stands for the opposite end of the spectrum, i.e., countries with low prior regulatory quality and weak implementation. High RQ/Weak IS and Low RQ/Strong IS capture the two interim cases.

The table presents only the coefficient estimates and t-statistics of the four distinct groups of EU countries, but the model includes all controls and fixed effects from our base specification.

33 Without spillover effects, countries' relative implementation timing should have no implication for the (relative) magnitude of the liquidity effects across countries. Our empirical model accounts for general liquidity trends in a flexible manner. Thus, implementing the directives a quarter earlier or later should have no systematic effect. 
The analyses indicate that countries with a strong track record of past regulation and a strict implementation and enforcement of the new directives have the largest liquidity improvements. The coefficients in the High RQ/Strong IS bins are always significantly negative. The coefficients indicate that liquidity increases by more than 20 percent relative to the pre-MAD or pre-TPD period. Thus, for countries with high quality prior regulation and strong implementation and enforcement the effect doubles relative to the average liquidity effect we report in Section 3.1.

The liquidity effects for this sub-set of EU countries are statistically different from any other group in all but two cases. The coefficients going from the High RQ/Strong IS bin to the Low RQ/Weak IS bin are monotonically ranked in general. Holding regulatory quality constant, the liquidity effects in strong implementation countries are always larger in magnitude than in weak implementation countries when prior regulatory quality is high, and the differences between the two groups are significant in six out of eight cases. The liquidity effects are still significant in four cases with weak implementation. In contrast, for low prior regulatory quality countries, the effects are generally insignificant and close to zero, irrespective of implementation strength. Holding implementation strength fixed, the liquidity effects generally become larger in magnitude when going from low to high prior regulatory quality.

The evidence does not support the catching-up hypothesis for countries with weaker prior conditions. Instead, liquidity differences widen across EU countries as a result of the directives. These findings imply that imposing the same regulation in countries with different prior regulatory conditions can result in countries drifting further apart, rather than moving them closer together. Put differently, there is considerable hysteresis in regulatory outcomes. One explanation is that the same forces that limited the extent and effectiveness of securities regulation in the past are again at play when new rules are introduced. Consistent with this explanation, post-directive reviews conducted by CESR confirm that countries with strong prior regulation, such as the U.K., made 
multiple and substantial changes to the oversight and enforcement procedures following the implementation of the MAD and TPD (CESR 2009a and 2010).

The implication is that history and countries' prior institutional conditions matter greatly for regulatory outcomes. Differences in these prior conditions pose a major obstacle for regulatory harmonization. These differences are not easily overcome by new regulation in an isolated area such as securities regulation, but instead may require a concerted effort across several areas due to the complementarities among many institutions that make up the nexus of countries' institutional infrastructures (see also Leuz and W ysocki, 2016).

\section{Conclusion}

In this paper, we examine the capital-market benefits of securities regulation. We exploit that the staggered imposition of two EU directives aimed at reducing market abuse and increasing transparency gave rise to plausibly exogenous variation in the effective dates, allowing us to estimate the causal effects on market liquidity for almost the entire population of publicly traded firms in a large number of countries.

We document that the new market abuse and transparency directives significantly increase the liquidity of share markets, on average. We conduct extensive sensitivity analyses, including within-country estimation and several tests gauging the validity of our identification strategy. Overall, our analysis indicates that stronger securities regulation can have significant economic liquidity benefits by reducing information asymmetries and adverse selection in capital markets.

However, we also show that the benefits of securities regulation differ across countries. We find evidence of substantial hysteresis in regulatory outcomes. The liquidity effects of the two directives are stronger in countries with a history of higher regulatory quality. The effects are also stronger with stricter implementation and enforcement, but primarily in countries with higher 
regulatory quality in the past. These findings are consistent with early work on the economics of regulation that highlights the difficulties of implementing and enforcing new rules (e.g., Stigler 1971; Posner 1974; Peltzman 1976; Becker 1983) as well as the enforcement theory by Djankov et al. (2003a). But they also pose a conundrum: what can low past regulatory quality countries do to catch up? The hysteresis results suggest that strict implementation and enforcement is not enough. Prior regulatory conditions matter. But then, how did the countries with high regulatory quality get to where they are? One potential explanation is that the same forces that limited the effectiveness of regulation in the past are still at work when new securities regulation is introduced. These forces could span a wide range, including lack of institutional fit, resource constraints, political pressures, and inefficient bureaucracies. To catch up, countries with low quality prior regulation would have to make a series of institutional changes, rather than merely strengthen securities regulation.

In sum, our findings support a causal link between stricter securities regulation and market liquidity. They also support the notion that the success of new regulation depends critically on how it is implemented and enforced. Our finding that countries with weaker securities regulation do not catch up with stronger countries illustrates the difficulty of harmonizing capital markets through regulatory reforms. It implies that imposing the same regulation on countries with disparate initial conditions can have the unintended consequence of making countries diverge more, not less. A n important caveat of our study is that the analysis does not include the costs of regulation. Thus, despite the fact that the results suggest substantial economic benefits, we cannot show that the directives are beneficial, net of costs. For the same reason, our results do not imply that countries with weaker implementation and enforcement of securities regulation "leave money on the table." We need more research to assess these issues and establish welfare consequences. 


\section{Appendix A}

\section{Overview of the M arket A buse and Transparency Directives in the E U}

In this appendix, we describe the institutional background on what motivated the enactment of the M AD and TPD, discuss the legislative and administrative procedures associated with the implementation of EU directives, both in the European Parliament and the individual member states, and provide more details on the regulatory changes due to the two directives.

\section{A.1 Financial Services Action Plan}

In 1999, the EU initiated the Financial Services Action Plan (FSAP) because EU regulation was perceived to be insufficient and lagging behind the U nited States (Lamfalussy 2000). In addition, the FSA P is a crucial part of the EU's attempt to create a single financial market. The FSA P's stated aims are to improve market confidence and eliminate capital-market fragmentation, and thereby to reduce the cost of raising capital on EU markets (FSAP 1999, p. 3). The FSA P introduced 42 different measures, each with its own specific objective (CRA 2009). The four so-called Lamfalussy Directives form the core of the FSAP in the area of securities regulation: the MAD, the TPD, the Prospectus Directive (PROSP), and the M arkets in Financial Instruments Directive (M iFID). Our empirical analysis focuses on the M AD and TPD because they are conceptually most clearly related to secondary-market outcomes like market liquidity. The PROSP pertains to securities offerings in the primary market. The MiFID's main objective is to increase competition and consumer protection in investment services. Nevertheless, we control for the introduction of the PROSP and M iFID in our analyses (see M odel 4 in Table 2).

\section{A.2 Legislative and Administrative Process in the EU and the M ember States}

We describe the main institutional features of the legislative and administrative process for EU directives in Section 1. Below, we provide additional details and illustrate why the directives' entry-intoforce dates make our setting well suited for the identification of causal effects. EU directives are unusual in the sense that they require member states to implement certain rules but do not prescribe the means by which to implement them (see Article 288 of the Treaty on the Functioning of the European Union). 
Moreover, as EU directives have to go through the EU institutions as well as the national parliaments of each member state, the legislative process from the initial proposal to the final effective date is lengthy and depends on national political institutions and rules. Directives do not always require new laws, but in the case of the MAD and TPD the changes were substantial enough to require at least one new law in each EU member state. We first explain the administrative process at the EU level and then describe the enactment process in the member states.

A.2.1 Enactment at the Supranational Level of the EU. The EU has a bicameral legislature consisting of the European Parliament (elected by the citizens of the EU) and the Council of M inisters, comprising one minister per member state. The specific minister depends on the topic under consideration, but he or she always represents the respective national government. $\mathrm{N}$ ational governments also exert influence through the appointment of the European Commission, the EU's executive body, which proposes legislation, implements decisions, and is responsible for the day-to-day running of the EU. The heads of the EU member states initiated the FSA P-project in J une 1998 at the Cardiff European Council.

Some FSAP directives, e.g., the Takeover Directive, were controversial and required extensive political negotiation ultimately delaying their adoption (see Hix, Noury, and Roland 2007). This was not the case for the MAD and TPD. The MAD was passed as originally scheduled in the FSAP. The TPD was delayed by two years but for reasons unrelated to the directive itself. The E uropean Parliament passed both directives without substantive amendments and with overwhelming majorities across party lines and nationalities. The European Parliament adopted the MAD on October 24,2002 , without a roll-call vote. ${ }^{34}$ There was (only) one roll-call vote when the TPD was debated, and it was adopted by the European Parliament on M arch 30, 2004, with 380 members of the parliament voting yes, 8 voting no, and 102 abstaining. A fter the European Parliament has adopted a directive, it is sent to the European Council of M inisters for final approval and adoption.

34 Only roll-call votes, which require a request from approximately a fifth of the parliament members, are recorded in the minutes of the meetings of the European Parliament. A lack of a roll-call vote indicates that there is little disagreement regarding a directive. See Hix, Noury, and Roland (2007) for details. 
For the purpose of identification, it is beneficial that the political decision to adopt the FSA P was made at the EU level and precedes our sample period by several years. This extended timeline makes it unlikely that economic or political events that played into the adoption of the FSAP affect our analysis. Furthermore, the fact that the two directives were fairly uncontroversial makes it more likely that procedural features of countries' legislative systems rather than political considerations determined the timing of the directives' transposition into national law.

A.2.2 Transposition into National Law in EU M ember States. When adopted by the EU, directives give member states a common deadline for the transposition into national law. The respective deadlines were October 12, 2004 (MAD), and January 20, 2007 (TPD), giving member states about two years for national implementation. But as the relevant regulatory details and technical standards for the two directives, the so-called Level 2 directives, were issued relatively late, especially for the TPD, the actual implementation window for member states was closer to three years.

The implementation process in the member states follows the national rules of enacting laws, generally laid out in countries' constitutions, and hence is fairly inflexible. It typically involves drafting the national law (s) required to accomplish the result mandated by the directive, a consultation period, multiple readings in the various chambers of parliament, signing by the head of state, and public notification. As a result, the process is lengthy and inflexible. To illustrate this point, Table A-1 describes the national transposition timeline for the MAD and TPD in five large EU countries. For the two directives, it takes on average 13 months from the public release of the initial draft of the new law to its entry-into-force date. This time span understates the true length of the legislative process because we observe only when governments publish the initial draft but not when they initiate the process and start drafting the law. Thus, it is fairly safe to assume that the national transposition starts more than one year before the eventual entry-into-force date. Given the length of this process, the EU's transposition deadlines are rather tight. Consistent with relatively little legislative flexibility, the standard deviation of the time between countries' entry-into-force 
dates and the transposition deadlines is only 2.5 (3) quarters for the M AD (TPD). ${ }^{35}$ Thus, it is unlikely that lawmakers could respond (strategically and quickly) to local conditions (e.g., a sudden decline in market liquidity) by accelerating or delaying the implementation of the directives. These features of the legislative process considerably mitigate concerns about reverse causality and endogenous timing.

As directives have to be implemented by virtue of being a member of the $E U$, the transposition into national law is rarely controversial. At this stage, the main political decisions have already been made. Political battles over a directive have to occur earlier, at the EU level. For this reason, national parliaments monitor the legislative initiatives and processes of the EU and authorize the national governments to exert their influence through the Council of M inisters. ${ }^{36}$ That being said, member states do have some flexibility in how they implement the directives, for instance, with respect to the penalties they impose or the resources they devote. We analyze this variation in Section 4.

\section{A.3 Changes in Securities R egulation due to the M AD and TPD}

A.3.1 M arket Abuse Directive. The MAD aims to prevent insider trading and market manipulation. It contains three key elements: (i) disclosure rules designed to reduce the scope of inside information, (ii) ex-post sanctions for insider trading or market manipulation, and (iii) tightened enforcement of compliance with insider trading and market manipulation rules. The core disclosure rule in the M A D requires issuers of financial instruments to inform the public as soon as possible of inside information (A rticle 6). M oreover, executives must disclose the transactions in the securities of the firm they manage in a quick and transparent manner. The MAD also aims to harmonize sanctions for the violation of insider trading rules across EU member states. However, the requirement is generic, and it is the member states, not the EU, that set penalties. For instance, A rticle 14 states that "member states shall ensure, in conformity with their national law, that the appropriate administrative measures can be taken or administrative sanctions be

35 A s shown in Panel A of Table 1, only a few member states transposed the M AD and TPD in time. A small delay is common practice in the EU. On average, FSAP directives became effective 1.7 quarters after their respective deadlines. In this sense, the transposition deadline is somewhat flexible but delay is limited. If a directive is not implemented or significantly delayed, the Commission (or member states) can bring a case to the European Court of J ustice, which can impose financial penalties. For the M AD and TPD, no such penalties were applied.

36 For instance, in the U.K., the House of Lords and the House of Commons both have European Scrutiny Committees. The two committees approved an explanatory memorandum on the MAD in December 2001 and $M$ arch 2002, respectively, which is well ahead of the directive's passage at the EU level. 
imposed against the persons responsible where the provisions adopted in the implementation of this Directive have not been complied with."

W ith respect to enforcement, the MAD requires member states to designate a single national authority with the competence of ensuring the application of the insider trading provisions (A rticle 11). The MAD further prescribes a number of specific powers for the authority, for instance, the right to carry out on-site inspections and to demand information from any person. However, apart from a generic statement in A rticle 12, that "the competent authority shall be given all supervisory and investigatory powers necessary for the exercise of its functions," the directive is silent on the resources necessary for the authority to fulfill its task, again giving significant discretion to the member states.

The M A D replaced an older directive from 1989 banning insider trading. Thus, it should be view ed as improving and tightening existing insider trading regulation, particularly with respect to enforcement. According to the British Institute of International and Comparative Law (2005), EU member states followed the directive's exact language closely when implementing it into national law. The MAD led to many substantial changes in all EU countries (see CESR 2007, 2008, and 2010 for details). For example, many countries increased the powers of the national supervisory authority to seize and retain documents and data that may further an investigation into insider trading.

A.3.2 Transparency Directive. The TPD aims to ensure transparency for investors through a regular flow of information. It uses two regulatory tools to improve transparency: (i) a set of disclosure requirements, and (ii) tightened enforcement of compliance with the disclosure provisions. The TPD includes provisions for ongoing disclosures (e.g., the filing of annual and semi-annual reports in accordance with IFRS) and requirements that ensure the disclosure of significant events (e.g., significant holdings by shareholders). However, IFRS reporting was already mandated by older EU regulation (Regulation No. 1606/2002) and most exchanges al ready required the filing of semi-annual reports and the disclosure of significant events. Hence, the TPD did not significantly expand existing disclosure requirements. $Y$ et, it stipulated major changes to the supervisory regime and the enforcement of corporate reporting and disclosure rules. 
To mention a few specific changes, the TPD requires each member state to designate a competent supervisory authority. ${ }^{37}$ This authority is in charge of monitoring compliance with the reporting and disclosure requirements set out in the directive, and it must be given appropriate powers to enforce these requirements. Similar to the MAD, the TPD stipulates that the authority is given certain supervisory powers (A rticle 24). It must examine and monitor required disclosures and, if infringements are discovered, take appropriate action (e.g., issue a fine). When investigating compliance, the authority must be able to request information from auditors and shareholders, and to carry out on-site inspections. The requirement to monitor and enforce compliance with existing disclosure rules represents a significant change because most member states had no, or very limited, monitoring and enforcement of corporate disclosures by a securities regulator prior to the TPD.

In addition, the TPD increases access to regulated information. The directive requires member states to set up an Officially A ppointed M echanism (OAM) in which regulated information is centrally stored and through which investors can access the information fast and free of charge (A rticle 21). In practice, the member states have produced online databases that allow the public to search for all required information, similar to the EDGAR database set up by the U.S. Securities and Exchange Commission. Such central repositories are expected to aid the accessibility and dissemination of financial information.

37 For instance, in Sweden, the supervision and enforcement of periodic financial reporting requirements was transferred from the Swedish stock exchange to the national supervisory authority (Finansinspektionen), which also received better means of imposing sanctions (CESR 2009a). For further details and examples, see CESR (2009a) and Demarigny and Clerc (2009). 


\section{References}

Ackerman, A., J. van Halteren, and E. Maug. 2008. Insider trading legislation and acquisition announcements: Do laws matter? W orking paper, U niversity of M annheim.

A grawal, A. 2013. The impact of investor protection law on corporate policy and performance: Evidence from the blue sky laws. J ournal of F inancial E conomics 107:417-35.

Altonji, J., T. Elder, and C. Taber. 2005. Selection on observed and unobserved variables: A ssessing the effectiveness of catholic schools. J ournal of Political Economy 113:151-84.

A mihud, Y . 2002. Illiquidity and stock returns: cross-section and time-series effects. J ournal of Financial M arkets 5:31-56.

A mihud, $Y_{\text {., }}$ and H. Mendelson. 1986. A sset pricing and the bid-ask spread. Journal of Financial Economics 17:223-49.

A mihud, Y., H. M endelson, and L. Pedersen. 2005. Liquidity and asset prices. Foundations and Trends in Finance 1:269-364.

Ball, R. 1980. Discussion of accounting for research and development costs: The impact on research and development expenditures. J ournal of Accounting Research 18:27-37.

Becker, G. 1983. A theory of competition among pressure groups for political influence. Quarterly J ournal of E conomics 98:371-400.

Bekaert, G., and C. Harvey. 2000. Foreign speculators and emerging equity markets. Journal of F inance 55:565-613.

Bekaert, G., C. Harvey, and C. Lundblad. 2007. Liquidity and expected returns: Lessons from emerging markets. Review of F inancial Studies 20:1783-831.

Benston, G. 1969. The value of the SEC's accounting disclosure requirements. Accounting Review 44:51532.

Benston, G. 1973. Required disclosure and the stock market: A n evaluation of the Securities Exchange Act of 1934. American Economic Review 63:132-55.

Bertrand, M., E. Duflo, and S. Mullainathan. 2004. How much should we trust differences-in-differences estimates? Q uarterly J ournal of E conomics 119:249-75.

B hattacharya, U., and H. Daouk. 2002. The world price of insider trading. J ournal of F inance 57:75-108.

Bhattacharya, U., and H. Daouk. 2009. When no law is better than a good law. Review of Finance 13:577627.

British Institute of International and Comparative Law. 2005. Comparative implementation of EU directives (I): Insider dealing and market abuse. City Research Series no. 8, L ondon.

Bushee, B., and C. L euz. 2005. Economic consequences of SEC disclosure regulation: Evidence from the OTC Bulletin B oard. J ournal of Accounting and Economics 39:233-64.

B ushman, R., J. Piotroski, and A. Smith. 2005. Insider trading restrictions and analysts' incentives to follow firms. J ournal of F inance 60:35-66.

Campbell, J. 1996. Understanding risk and return. J ournal of Political Economy 104:298-345.

Carvajal, A., and J. Elliott. 2007. Strengths and weaknesses in securities market regulation: A global analysis. IM F W orking paper W P/07/259.

Central B anking Publications. 2009. How countries supervise their banks, insurers and securities markets 2010. London.

CESR . 2007. Report on CESR members' powers under the M arket $A$ buse Directive and its implementing measures, \#CESR/07-380. Committee of European Securities R egulators, Paris.

CESR . 2008. R eport on administrative measures and sanctions as well as the criminal sanctions available in member states under the M arket Abuse Directive (MAD), \#CESR/07-693. Committee of European Securities R egulators, Paris. 
CESR. 2009a. CESR report on the mapping of supervisory powers, administrative and criminal sanctioning regimes of member states in relation to the Transparency Directive (TD), \#CESR/09-058. Committee of European Securities Regulators, Paris.

CESR. 2009b. Final report of the review panel concerning the updated self assessment and peer review of CESR's Standard No.1 on financial information, \#CESR/09-374. Committee of European Securities Regulators, Paris.

CESR. 2010. Review panel report: MAD options and discretions 2009, \#CESR/09-1120. Committee of European Securities Regulators, Paris.

Chhaochharia, V., and Y. Grinstein. 2007. Corporate governance and firm value: The impact of the 2002 governance rules. J ournal of $F$ inance 62:1789-825.

Chordia, T., R. Roll, and A. Subrahmanyam. 2000. Co-movements in bid-ask spreads and market depth. Financial Analysts J ournal 56:23-7.

Christensen, H., L. Hail, and C. Leuz. 2013. M andatory IFRS reporting and changes in enforcement. J ournal of Accounting and Economics 56:147-77.

Coates, J., and S. Srinivasan. 2014. SOX after ten years: A multidisciplinary review. Accounting Horizons 28:627-71.

Coffee, J. 1984. Market failure and the economic case for a mandatory disclosure system. Virginia Law Review 70:717-53.

Coffee J. 2007. Law and the market: The impact of enforcement. University of Pennsylvania Law Review 156:229-311.

Collver, D. 2007. Is there less informed trading after regulation fair disclosure? J ournal of Corporate Finance 13:270-81.

Copeland, T., and D. Galai. 1983. Information effects on the bid-ask spread. J ournal of $F$ inance 38:145769.

CRA. 2009. Evaluation of the economic impacts of the Financial Services Action Plan, Final report prepared for the E uropean Commission. CRA International, L ondon.

Cumming, D., A. Groh, and S. Johan. 2014. Same rules, different enforcement: M arket abuse in Europe. W orking paper, Y ork U niversity.

Cumming, D., S. Johan, and D. Li. 2011. Exchange trading rules and stock market liquidity. J ournal of Financial Economics 99:651-71.

Daske, H., L. Hail, C. Leuz, and R. Verdi. 2008. M andatory IFRS reporting around the world: Early evidence on the economic consequences. J ournal of Accounting Research 46:1085-142.

Demarigny, F., and C. Clerc. 2009. Transparency Directive A ssessment Report. Paris: M azars.

Dempster, A., N. Laird, and D. Rubin. 1977. Maximum likelihood from incomplete data via the EM algorithm. J ournal of the Royal Statistical Society 39:1-38.

Demsetz, H. 1969. Information and efficiency: A nother viewpoint. J ournal of Law and Economics 12:1-22.

Djankov, S., E. Glaeser, R. La Porta, F. Lopez-de-Silanes, and A. Shleifer. 2003a. The new comparative economics, J ournal of Comparative E conomics 31:595-619.

Djankov, S., R. La Porta, F. Lopez-de-Silanes, and A. Shleifer. 2003b. Courts. Quarterly Journal of Economics 118:453-517.

Djankov, S., R. La Porta, F. Lopez-de-Silanes, and A. Shleifer. 2008. The law and economics of selfdealing. J ournal of $F$ inancial E conomics 88:430-65.

Doidge, C., G.A. K arolyi, and R. Stulz. 2004. W hy are foreign firms listed in the U.S. worth more? J ournal of $F$ inancial E conomics 71:205-38.

Doidge, C., G.A. K arolyi, and R. Stulz. 2010. Why do foreign firms leave U.S. equity markets? J ournal of Finance 65:1507-53.

Easley, D., and M. O'Hara. 1987. Price, trade size, and information in securities markets. Journal of Financial Economics 19:69-90. 
Easterbrook, F., and D. Fischel. 1984. M andatory disclosure and the protection of investors. Virginia Law Review 70:669-715.

Enriques, L., and M. Gatti. 2008. Is there a uniform EU securities law after the Financial Services Action Plan? Stanford J ournal of Law, Business and F inance 14:43-81.

Ernstberger, J., J. Hitz, and M. Stich. 2012. Enforcement of accounting standards in Europe: Capitalmarket-based evidence for the two-tier mechanism in Germany. European Accounting Review 21:25381.

Francis, J., D. Nanda, and X. Wang. 2006. Re-examining the effects of regulation fair disclosure using foreign listed firms to control for concurrent shocks. J ournal of Accounting and Economics 41:271-92.

Gintschel, A., and S. Markov. 2004. The effectiveness of Regulation FD. Journal of Accounting and Economics 37:293-314.

Glaeser, E., S. Johnson, and A. Shleifer. 2001. Coase vs. the Coasians. Quarterly Journal of Economics 116:853-99.

Glosten, L., and L. Harris. 1988. Estimating the components of the bid/ask spread. J ournal of Financial Economics 21, 123-142.

Glosten, L., and P. Milgrom. 1985. Bid, ask and transaction prices in a specialist market with heterogeneously informed traders. J ournal of F inancial E conomics 14:71-100.

Greenstone, M., P. Oyer, and A. V issing-J orgensen. 2006. M andated disclosure, stock returns, and the 1964 Securities A cts amendments, Q uarterly J ournal of E conomics 1221:399-460.

Hail, L., and C. Leuz. 2006. International differences in the cost of equity capital: Do legal institutions and securities regulation matter? J ournal of Accounting Research 44:485-531.

Hail, L., A. Tahoun, and C. W ang. 2014. Dividend payouts and information shocks. J ournal of Accounting Research 52:403-56.

Heflin, F., K. Subramanyam, and Y. Zhang. 2003. Regulation FD and the financial information environment: early evidence. Accounting Review 78:1-37.

Henisz, W. 2000. The institutional environment for economic growth. Economics and Politics 12:1-31.

Hix, S., A. Noury, and G. Roland. 2007. Democratic politics in the European parliament. Cambridge: Cambridge U niversity Press.

Iliev, P. 2009. The effect of SOX Section 404: Costs, earnings quality, and stock prices. J ournal of F inance 65:1163-96.

Jackson, H., and M. Roe. 2009. Public and private enforcement of securities laws: Resource-based evidence. J ournal of F inancial E conomics 93:207-38.

Jarrell, G. 1981. The economic effects of federal regulation of the market for new security issues. J ournal of Law and E conomics 24:613-75.

Johnson, S., J. M cM illan, and C. W oodruff. 2002. Property rights and finance. American Economic Review 92:1335-56.

K alemli-Ozcan, S., E. Papaioannou, and J. Peydró. 2010. W hat lies beneath the Euro's effect on financial integration? Currency risk, legal harmonization or trade. J ournal of International Economics 81:7588.

Kalemli-Ozcan, S., E. Papaioannou, and J. Peydró. 2013. Financial regulation, financial globalization, and the synchronization of economic activity. J ournal of $F$ inance 68:1179-228.

K arolyi, G.A. 2015. C racking the emerging markets enigma. Oxford: Oxford University Press.

K aufmann, D., A. K raay, and M. M astruzzi. 2009. Governance matters VIII: Governance indicators for 1996-2008. W orld B ank Policy Research, W ashington, D.C.

K yle, A . 1985. Continuous auctions and insider trading. E conometrica 53:1315-35.

Lamfalussy, A. (Chairman). 2000. Initial report of the Committee of $W$ ise $M$ en on the regulation of the European securities markets. November 9 , B russels. 
Lang, M., K. Lins, and M. M affett. 2012. Transparency, liquidity, and valuation: International evidence on when transparency matters most. J ournal of Accounting Research 50:729-74.

La Porta, R., F. Lopez-de-Silanes, and A. Shleifer. 2006. What works in securities laws? Journal of Finance 61:1-32.

La Porta, R., F. Lopez-de-Silanes, A. Shleifer, and R. Vishny. 1998. Law and finance. J ournal of Political Economy 106:1113-55.

Lesmond, D., J. Ogden, and C. Trzcinka. 1999. A new estimate of transaction costs. Review of Financial Studies 12:1113-41.

Leuz, C. 2007. W as the Sarbanes-0xley A ct of 2002 really this costly? A discussion of evidence from event returns and going-private decisions. J ournal of Accounting and E conomics 44:146-65.

Leuz, C., and R. Verrecchia. 2000. The economic consequences of increased disclosure. Journal of Accounting Research 38:91-124.

Leuz, C., and P. W ysocki. 2016. The economics of disclosure and financial reporting regulation: Evidence and suggestions for future research. J ournal of Accounting Research, forthcoming.

$\mathrm{Li}, \mathrm{H}$., M. Pincus, and S. Rego. 2008. Market reaction to events surrounding the Sarbanes-Oxley Act of 2002 and earnings management. J ournal of Law and E conomics 51:111-34.

M ahoney, P., and J. M ei. 2013. M andatory vs. contractual disclosure in securities markets: Evidence from the 1930s. W orking paper, U niversity of V irginia.

Mulherin, J. 2007. M easuring the costs and benefits of regulation: Conceptual issues in securities markets. J ournal of Corporate F inance 13:421-37.

Peltzman, S. 1976. Towards a more general theory of regulation. J ournal of Law and Economics 19:21140.

Posner, R. 1974. Theories of economic regulation. Bell J ournal of Economics and Management Science 5:335-58.

Shleifer, A . 2005. U nderstanding regulation. European F inancial M anagement 11:439-51.

Stigler, G. 1964. Public regulation of the securities markets. J ournal of Business 37:117-42.

Stigler, G. 1971. The theory of economic regulation. Bell J ournal of Economics and M anagement Science 2:3-21.

Stoll, H. 1978. The supply of dealer services in securities markets. J ournal of $F$ inance 33:1133-51.

V enkatesh, P., and R. Chiang. 1986. Information asymmetry and the dealer's bid-ask spread: A case study of earnings and dividend announcements. J ournal of F inance 41:1089-102.

V roonhof, P., and J. Boog. 2010. Effects of possible changes to the M arket A buse Directive: impact on administrative burdens of enterprises in the EU. A msterdam: EIM.

Zhang, I. 2007. Economic consequences of the Sarbanes-Oxley A ct of 2002. J ournal of Accounting and E conomics 44:74- 115 .

Zingales, L. 2009. The future of securities regulation. J ournal of Accounting Research 47:391-425. 


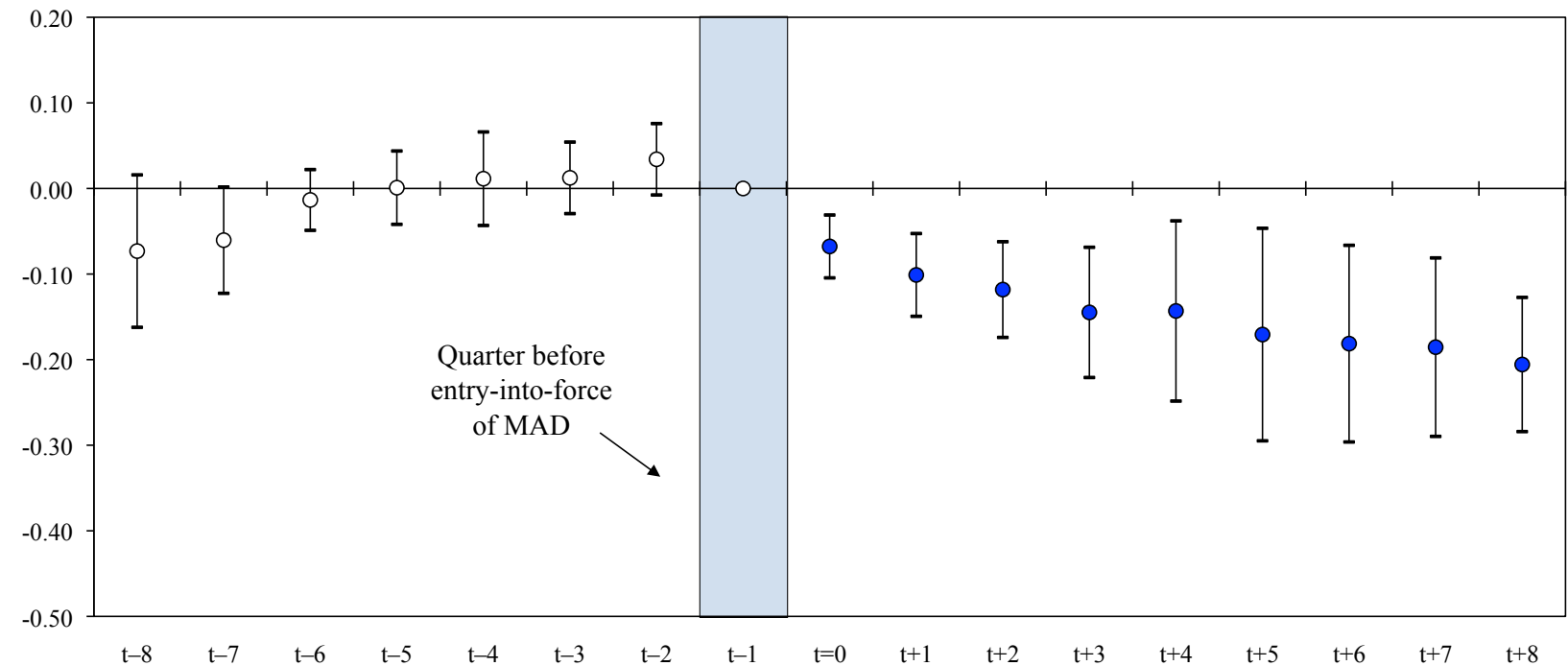

O MAD liquidity coefficients relative to period $t-1$, i.e., the quarter before entry-into-force (together with $95 \%$ confidence interval; $O$ if significantly different from zero)

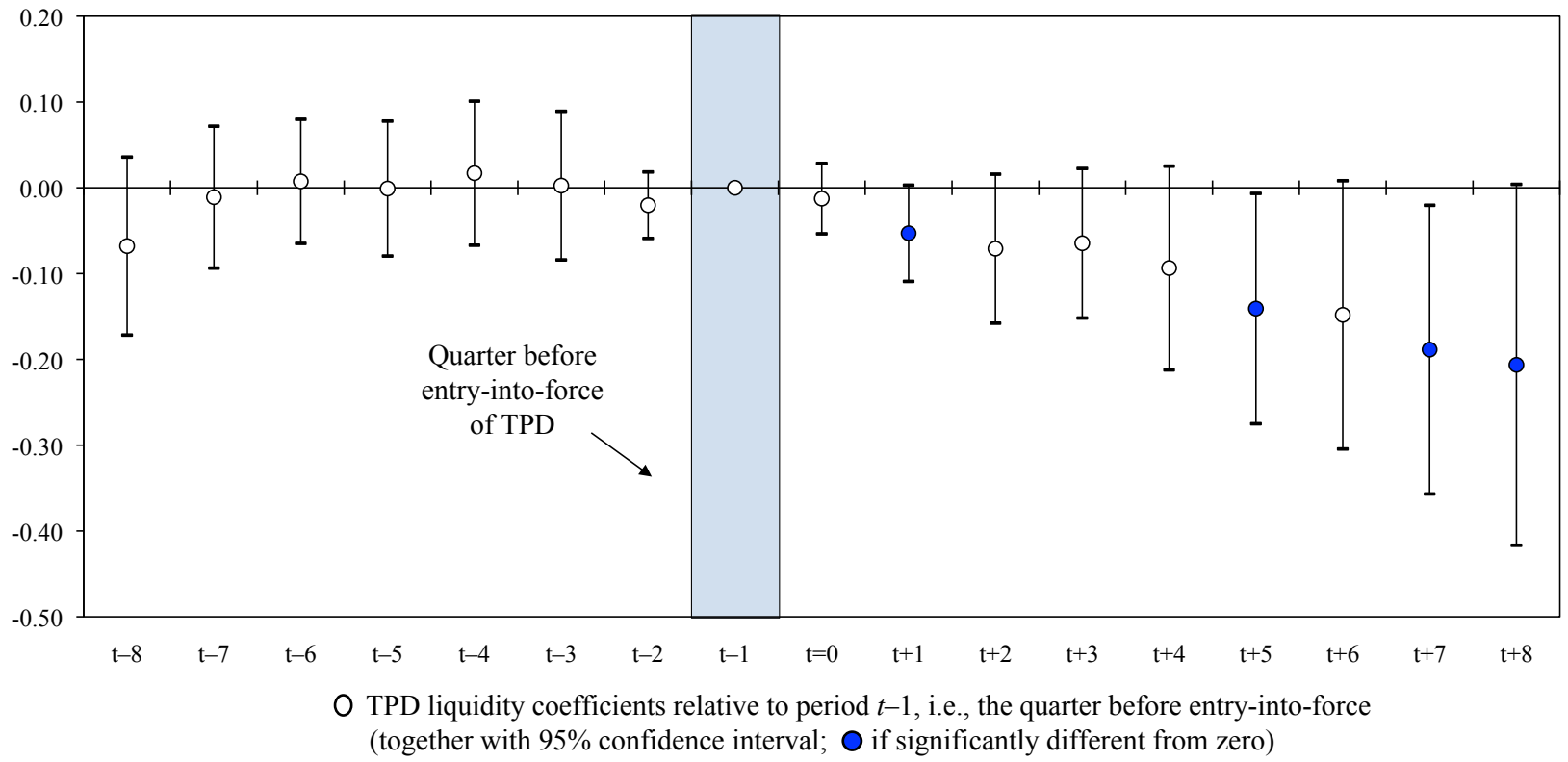

Figure 1

Liquidity patterns around the entry-into-force dates of the M AD and TPD (in event time)

We estimate Eq. (1) but replace the M AD or TPD coefficient with 16 separate indicator variables, each marking one quarter over the $t-8$ to $t+8$ period relative to the quarter before the entry-into-force of the respective directive (t- 1$)$. W e omit the indicator for period t-1. It therefore serves as benchmark, and has a coefficient value of zero (and no confidence interval). The figure plots the coefficient estimates of the 16 quarters together with their $95 \%$ confidence intervals for M AD (upper panel) and TPD (lower panel). To balance the sample through time and by country, we use all firm-quarter observations from the EU treatment sample over the $t-8$ to $t+8$ period, and require at least one observation per country and quarter. We use the Liquidity Factor as the dependent variable (see Table 1), and the control variables and fixed effects correspond to M odels 1 and 2 in Table 2. 
Table 1

Sample composition and descriptive statistics

Panel A: Sample composition and entry-into-force dates of the M AD and TPD

\begin{tabular}{|c|c|c|c|c|}
\hline Country & $\begin{array}{l}\text { Unique } \\
\text { firms }\end{array}$ & $\begin{array}{l}\text { Observations } \\
\text { (N) }\end{array}$ & $\begin{array}{c}\text { MAD } \\
\text { entry-into- } \\
\text { force dates }\end{array}$ & $\begin{array}{c}\text { TPD } \\
\text { entry-into- } \\
\text { force dates }\end{array}$ \\
\hline A ustria & 73 & 1,343 & Jan-05 & A pr-07 \\
\hline B elgium & 155 & 4,145 & Sep-05 & Sep-08 \\
\hline Bulgaria & 18 & 305 & Jan-07 & Jan-07 \\
\hline Cyprus & 98 & 1,329 & Sep-05 & M ar-08 \\
\hline Czech Republic & 6 & 162 & Feb-06 & A ug-09 \\
\hline Denmark & 203 & 5,437 & A pr-05 & Jun-07 \\
\hline Estonia & 19 & 286 & M ar-05 & Dec-07 \\
\hline Finland & 138 & 4,455 & Jul-05 & Feb-07 \\
\hline France & 729 & 19,461 & Jul-05 & Dec-07 \\
\hline Germany & 383 & 9,018 & Oct-04 & Jan-07 \\
\hline Greece & 191 & 1,243 & Jul-05 & Jul-07 \\
\hline Hungary & 36 & 789 & Jul-05 & Dec-07 \\
\hline Iceland & 12 & 91 & Jul-05 & Nov-07 \\
\hline Ireland & 31 & 772 & Jul-05 & J un-07 \\
\hline Italy & 346 & 9,038 & M ay-05 & A pr-09 \\
\hline Latvia & 12 & 285 & Jul-05 & A pr-07 \\
\hline Lithuania & 38 & 530 & A pr-04 & Feb-07 \\
\hline L uxembourg & 1 & 5 & M ay -06 & Jan-08 \\
\hline M alta & n.a. & n.a. & A pr-05 & Oct-07 \\
\hline The N etherlands & 143 & 4,039 & Oct-05 & Jan-09 \\
\hline Norway & 264 & 5,422 & Sep-05 & Jan-08 \\
\hline Poland & 347 & 7,455 & 0 ct-05 & M ar-09 \\
\hline Portugal & 56 & 1,528 & A pr-06 & Nov-07 \\
\hline Romania & 35 & 346 & Jan-07 & Jan-07 \\
\hline Slovakia & 4 & 59 & Jan-05 & M ay-07 \\
\hline Slovenia & 32 & 401 & A ug-04 & Sep-07 \\
\hline Spain & 151 & 3,849 & Nov-05 & Dec-07 \\
\hline Sweden & 359 & 9,658 & Jul-05 & Jul-07 \\
\hline U nited K ingdom & 966 & 21,460 & Jul-05 & Jan-07 \\
\hline
\end{tabular}


Table 1

Continued

Panel $B$ : Descriptive statistics for variables used in the liquidity regressions

\begin{tabular}{|c|c|c|c|c|c|c|c|}
\hline$(\mathrm{N}=112,260)$ & M ean & Std. dev. & P1 & P25 & M edian & P75 & P99 \\
\hline \multicolumn{8}{|l|}{ D ependent variables: } \\
\hline B id-ask spread & 0.027 & 0.031 & 0.001 & 0.008 & 0.017 & 0.033 & 0.156 \\
\hline Zero returnst & 0.240 & 0.226 & 0.000 & 0.062 & 0.156 & 0.379 & 0.800 \\
\hline Price impact $t_{t}$ & 4.976 & 14.942 & 0.000 & 0.040 & 0.387 & 2.600 & 82.720 \\
\hline Total trading costst & 0.039 & 0.039 & 0.010 & 0.013 & 0.025 & 0.049 & 0.191 \\
\hline $\begin{array}{l}\text { Liquidity factor } \mathrm{r}_{\mathrm{t}} \\
\text { Independent variables: }\end{array}$ & -0.054 & 0.799 & -0.748 & -0.594 & -0.336 & 0.180 & 2.999 \\
\hline$M$ arket value $e_{t-4}$ & 828 & 2,733 & 3 & 41 & 144 & 556 & 11,324 \\
\hline Share turnover $\mathrm{r}_{\mathrm{t}-4}$ & 0.001 & 0.002 & 0.000 & 0.000 & 0.001 & 0.002 & 0.011 \\
\hline R eturn variability ${ }_{t-4}$ & 0.024 & 0.012 & 0.007 & 0.016 & 0.022 & 0.031 & 0.061 \\
\hline GDP per capitat-4 & 23.647 & 7.780 & 4.600 & 21.775 & 24.323 & 28.146 & 41.400 \\
\hline
\end{tabular}

Panel C: Pearson's correlation coefficients betw een variables used in the liquidity regressions

\begin{tabular}{lcccccccc}
\hline (N =112,260) & $\begin{array}{c}\text { Zero } \\
\text { returns }\end{array}$ & $\begin{array}{c}\text { Price } \\
\text { impact }\end{array}$ & $\begin{array}{c}\text { Total trad- } \\
\text { ing costs }\end{array}$ & $\begin{array}{c}\text { Liquidity } \\
\text { factor }\end{array}$ & $\begin{array}{c}\text { M arket } \\
\text { value }\end{array}$ & $\begin{array}{c}\text { Share } \\
\text { turnover }\end{array}$ & $\begin{array}{c}\text { Return } \\
\text { variability }\end{array}$ & $\begin{array}{c}\text { GDP per } \\
\text { capita }\end{array}$ \\
\hline Bid-ask spread & 0.589 & 0.584 & 0.792 & 0.893 & -0.189 & -0.199 & 0.291 & 0.060 \\
Zero returns & & 0.371 & 0.704 & 0.774 & -0.231 & -0.306 & 0.029 & 0.069 \\
Price impact & & & 0.586 & 0.683 & -0.095 & -0.138 & 0.264 & -0.102 \\
Total trading costs & & & & 0.964 & -0.186 & -0.167 & 0.307 & 0.083 \\
Liquidity factor & & & & & -0.208 & -0.220 & 0.287 & 0.059 \\
M arket value & & & & & & 0.176 & -0.107 & 0.002 \\
Share turnover & & & & & & & 0.157 & 0.084 \\
R eturn variability & & & & & & & & 0.006 \\
\hline
\end{tabular}

The sample consists of all countries in the European Union (EU) except for Bulgaria and Romania, which did not join the EU until 2007, and M alta, for which we do not have the necessary liquidity data. We also include Iceland and Norway from the European Economic A rea (EEA) as explained in the main text. We have 112,260 quarterly observations from 4,846 firms beginning in the first quarter of 2001 through the second quarter of 2011 with financial data in Worldscope and price/volume data in Datastream. The table presents the number of unique firms and firm-quarter observations per country and the calendar months when the $M$ arket $A$ buse Directive (M AD) and the Transparency Directive (TPD) came into force (Panel A), as well as distributional characteristics (Panel B) and Pearson's correlation coefficients (Panel $C$ ) for the variables used in the regression analyses. The dependent variables are: (1) The Bid-ask spread is the quarterly mean quoted spread (i.e., difference between the bid and ask price divided by the mid-point and measured at the end of each trading day). (2) Zero returns is the proportion of trading days with zero daily stock returns out of all potential trading days in a given quarter. (3) Price impact is the quarterly mean of the A mihud (2002) illiquidity measure (i.e., daily absolute stock return divided by US\$ trading volume). (4) Total trading costs is a quarterly estimate of total round-trip transaction costs inferred from the timeseries of daily security and aggregate market returns (Lesmond, Ogden, and Trzcinka, 1999). (5) The Liquidity factor is an aggregate liquidity measure and represents the scores of a single factor obtained from factor analysis with the four liquidity variables. The continuous independent variables are: Market value is stock price times the number of shares outstanding (in US\$ million) measured at the end of the quarter. Share turnover is the quarterly mean of the daily turnover (i.e., US\$ trading volume divided by the market value at the end of each trading day). We compute Return variability as the standard deviation of daily stock returns in a given quarter. A nnual GDP per capita is from the World Bank (in constant US\$ as of 2000). All correlation coefficients are significant at the $1 \%$ level (except for GDP per capita and the correlation between Market value and Return variability). All variables (except GDP per capita) are truncated at the $1^{\text {st }}$ and $99^{\text {th }}$ percentile. The subscript $t$ indicates the cal endar quarter of variable measurement. 
Table 2

Liquidity effects from tighter $\mathrm{E}$ securities regulation

\begin{tabular}{|c|c|c|c|c|}
\hline \multirow[b]{2}{*}{$(\mathrm{N}=112,260)$} & \multicolumn{4}{|c|}{$\mathrm{L} n($ Liquidity factor +1$)$ as dependent variable } \\
\hline & $\begin{array}{c}\text { MAD } \\
(1)\end{array}$ & $\begin{array}{c}\text { TPD } \\
(2)\end{array}$ & $\begin{array}{l}\text { B oth directives } \\
\text { combined } \\
\text { (3) }\end{array}$ & $\begin{array}{c}\text { Plus other } \\
\text { directives } \\
\text { (4) }\end{array}$ \\
\hline \multicolumn{5}{|l|}{ Test variables: } \\
\hline MAD & $\begin{array}{l}-0.111 * * * \\
(-3.73)\end{array}$ & - & $\begin{array}{l}-0.116 * * * \\
(-3.70)\end{array}$ & $\begin{array}{l}-0.115^{* * *} \\
(-3.61)\end{array}$ \\
\hline TPD & - & $\begin{array}{l}-0.085^{*} \\
(-1.84)\end{array}$ & $\begin{array}{l}-0.087 * \\
(-1.87)\end{array}$ & $\begin{array}{l}-0.093^{* *} \\
(-2.20)\end{array}$ \\
\hline \multicolumn{5}{|l|}{ Control variables: } \\
\hline $\mathrm{Ln}\left(\mathrm{M}\right.$ arket value $\left.\mathrm{e}_{-4}\right)$ & $\begin{array}{l}-0.250 * * * \\
(-13.47)\end{array}$ & $\begin{array}{l}-0.250 * * * \\
(-13.52)\end{array}$ & $\begin{array}{l}-0.250 * * * \\
(-13.52)\end{array}$ & $\begin{array}{l}-0.248 * * * \\
(-13.48)\end{array}$ \\
\hline $\mathrm{Ln}\left(\right.$ Share turnover $\left._{\mathrm{t}-4}\right)$ & $\begin{array}{l}-0.155^{* * *} \\
(-18.92)\end{array}$ & $\begin{array}{l}-0.155^{* * *} \\
(-19.18)\end{array}$ & $\begin{array}{l}-0.155^{* * *} \\
(-19.11)\end{array}$ & $\begin{array}{l}-0.155^{* * *} \\
(-18.63)\end{array}$ \\
\hline $\operatorname{Ln}\left(\right.$ Return variability $\left.\mathrm{t}_{-4}\right)$ & $\begin{array}{l}0.172^{* * *} \\
(4.60)\end{array}$ & $\begin{array}{l}0.172^{* * *} \\
(4.61)\end{array}$ & $\begin{array}{l}0.172^{* * *} \\
(4.63)\end{array}$ & $\begin{array}{l}0.172 * * * \\
(4.67)\end{array}$ \\
\hline Ln(GDP per capitat-4) & $\begin{array}{l}-0.053 \\
(-0.09)\end{array}$ & $\begin{array}{l}-0.019 \\
(-0.03)\end{array}$ & $\begin{array}{l}-0.013 \\
(-0.02)\end{array}$ & $\begin{array}{l}-0.046 \\
(-0.08)\end{array}$ \\
\hline M iFID & - & - & - & $\begin{array}{c}0.033 \\
(0.51)\end{array}$ \\
\hline PROSP & - & - & - & $\begin{array}{l}-0.013 \\
(-0.56)\end{array}$ \\
\hline TAKEOVER & - & - & - & $\begin{array}{c}0.003 \\
(0.20)\end{array}$ \\
\hline IFRS & - & - & - & $\begin{array}{l}-0.101 * * \\
(-2.33)\end{array}$ \\
\hline \multicolumn{5}{|l|}{ F ixed effects: } \\
\hline Country & Y es & Y es & Y es & Y es \\
\hline Industry & Yes & Y es & Yes & Yes \\
\hline Quarter-year & Yes & Yes & Yes & Y es \\
\hline R-squared & 0.658 & 0.658 & 0.658 & 0.659 \\
\hline
\end{tabular}

$M A D$ and TPD are binary indicator variables that take on the value of ' 1 ' beginning in the quarter when the MAD or the TPD came into force. For further details on the sample and a description of the dependent and control variables see Table 1. In M odel 4 we also include binary indicator variables for other regulatory changes in the EU, i.e., the $M$ arkets in Financial Instruments Directive (M iFID), the Prospectus Directive (PROSP), the Takeover Directive (TAKEOVER), and the mandatory adoption of International Financial Reporting Standards (IFRS). For MiFID, PROSP, and TAKEOVER we set the indicator variables to ' 1 ' beginning in the respective entry-into-force quarter. IF RS takes on the value of ' 1 ' beginning in the calendar quarter immediately following a firm's first fiscal-year end with mandatory IFRS reporting. We identify firms' accounting policy based on the "accounting standards followed" field in Worldscope (field 07536). If indicated, we use the natural log of the raw values (plus one), and lag the variables by four quarters. We include country-, Campbell (1996) industry-, and quarter-year-fixed effects in the regressions, but do not report the coefficients. The table reports OLS coefficient estimates and (in parentheses) tstatistics based on robust standard errors that are clustered by country. $* * *, * *$, and $*$ indicate statistical significance at the $1 \%, 5 \%$, and $10 \%$ levels (two-tailed). 
Table 3

A ssessing identification of the liquidity effects from tighter $E \mathrm{U}$ securities regulation

Panel A: A nalysis of the liquidity effects in the year leading up to the M AD and TPD

\begin{tabular}{|c|c|c|c|c|}
\hline \multirow[b]{3}{*}{$(\mathrm{N}=112,260)$} & \multicolumn{4}{|c|}{ Ln(L iquidity factor +1$)$ as dependent variable } \\
\hline & \multicolumn{2}{|c|}{ MAD } & \multicolumn{2}{|c|}{ TPD } \\
\hline & Coefficient & t-stat & Coefficient & t-stat \\
\hline $\begin{array}{l}\text { Period relative to entry-into-force date }(t=0) \text { : } \\
\text { Y ear leading up to M AD (t- } 4 \text { to } t-1)\end{array}$ & 0.010 & $(0.39)$ & - & - \\
\hline MAD ( $t=0$ and onwards) & $-0.104 *$ & $(-1.90)$ & $-0.115^{* * *}$ & $(-3.63)$ \\
\hline Y ear leading up to TPD (t- 4 to $t-1$ ) & - & - & -0.010 & $(-0.59)$ \\
\hline TPD ( $\mathrm{t=0}$ and onwards) & $-0.093 * *$ & $(-2.18)$ & $-0.103^{* *}$ & $(-2.51)$ \\
\hline $\begin{array}{l}\text { F-test for differences across coefficients ( } p \text {-value): } \\
\text { (t- } 4 \text { to } t-1)=\text { M AD or TPD }\end{array}$ & 0.002 & & 0.037 & \\
\hline
\end{tabular}

Panel B: Controlling for various time trends and unobservable factors

\begin{tabular}{|c|c|c|c|c|c|}
\hline \multirow[b]{2}{*}{$\begin{array}{l}\operatorname{Ln}(\text { L iquidity factor }+1) \\
\text { as dependent variable }\end{array}$} & \multicolumn{2}{|c|}{$\begin{array}{l}\text { Controlling for } \\
\text { time trends }\end{array}$} & \multicolumn{2}{|c|}{$\begin{array}{l}\text { Within-Country Estimation } \\
\text { (Germany, Ireland, U.K.) }\end{array}$} & \multirow{2}{*}{$\begin{array}{c}\text { Falsification } \\
\text { Test } \\
\text { Selection on } \\
\text { observables } \\
\text { (first stage } \\
\text { prediction } \\
\text { model) } \\
\text { (5) }\end{array}$} \\
\hline & $\begin{array}{l}\text { Including } \\
\text { lagged } \\
\text { changes in } \\
\text { liquidity } \\
(1)\end{array}$ & $\begin{array}{l}\text { Including } \\
\text { linear and } \\
\text { quadratic } \\
\text { time trend } \\
\text { (2) }\end{array}$ & $\begin{array}{c}\text { Regulated \& } \\
\text { unregulated } \\
\text { markets } \\
\text { (all firms) } \\
\text { (3) }\end{array}$ & $\begin{array}{c}\text { Regulated \& } \\
\text { unregulated } \\
\text { markets } \\
\text { (matched and } \\
\text { balanced panel) } \\
\text { (4) }\end{array}$ & \\
\hline \multicolumn{6}{|l|}{ Test variables: } \\
\hline MAD & $\begin{array}{l}-0.128 * * * \\
(-4.14)\end{array}$ & $\begin{array}{l}-0.091 * * * \\
(-3.75)\end{array}$ & - & - & $\begin{array}{l}-0.011 \\
(-1.42)\end{array}$ \\
\hline TPD & $\begin{array}{l}-0.104^{* *} \\
(-2.19)\end{array}$ & $\begin{array}{l}-0.058 * \\
(-1.91)\end{array}$ & - & - & $\begin{array}{l}-0.011 \\
(-1.04)\end{array}$ \\
\hline$M A D_{\text {regulated vs. unregulated firms }}$ & - & - & $\begin{array}{l}-0.127 * * * \\
(-5.54)\end{array}$ & $\begin{array}{l}-0.096 * * * \\
(-3.21)\end{array}$ & - \\
\hline$T P D_{\text {regulated vs. unregulated firms }}$ & - & - & $\begin{array}{l}-0.121 * * * \\
(-5.03)\end{array}$ & $\begin{array}{l}-0.071^{* * *} \\
(-2.58)\end{array}$ & - \\
\hline \multicolumn{6}{|l|}{ Control variables: } \\
\hline From base specification & Y es & Y es & Y es & Y es & Yes \\
\hline$\Delta \mathrm{Ln}(\text { L iquidity factor }+1)_{\mathrm{t}-8 \text { to }-4}$ & Y es & - & - & - & - \\
\hline Country*time trend & - & Y es & - & - & - \\
\hline Country*time trend ${ }^{2}$ & - & Yes & - & - & - \\
\hline \multicolumn{6}{|l|}{ Fixed effects: } \\
\hline Country & Yes & Yes & - & - & Y es \\
\hline Industry & Y es & Yes & Y es & Y es & Yes \\
\hline Quarter-year & Yes & Yes & - & - & Y es \\
\hline Country-quarter & - & - & Y es & Yes & - \\
\hline Unregulated market indicators & - & - & Y es & Yes & - \\
\hline$N$ & 67,735 & 112,260 & 53,736 & 12,684 & 112,260 \\
\hline
\end{tabular}




\section{Table 3}

\section{Continued}

For details on the sample and a description of the dependent and control variables see Table 1 . If not stated differently, we use M odel 4 in Table 2 as our base specification. In Panel A, we include a separate indicator variable marking the four quarters leading up to the entry-into-force quarter of the MAD or TPD (i.e., the period t- 4 to t- 1 relative to the entry-into-force date in $t=0$ ). We also report $p$-values from $W$ ald tests assessing the statistical significance of differences in the coefficients across periods. In Panel $B$, we estimate the following specifications: (1) we include lagged seasonal changes $(\Delta)$ in the liquidity factor as control. (2) We include a linear and quadratic time trend variable, and interact each trend variable with the country fixed effects. (3) We estimate within-country regressions. Doing so, we add firms trading on the three largest unregulated security markets in the EU to the sample (i.e., Germany's O pen M arket, Ireland's Enterprise Securities M arket, and the A Iternative Investment M arket A IM in the U.K.). We include a separate Unregulated market indicator for each market (equal to ' 1 ' for unregulated market firms). We further replace the country and calendar quarter fixed effects with separate quarter-year fixed effects per country. The MAD and TPD coefficients represent the incremental effects of regulated firms relative to unregulated firms (as indicated by the subscripts). In (4), we use a propensity-matched and balanced sample. We conduct the matching in the quarter before MAD came into force and use the following criteria: total assets, return on assets, book-to-market, asset growth, quarterly stock returns, and the annual standard deviation of daily stock returns. We further ensure that, in each country, the number of regulated and unregulated firms is the same, and require firms to be present before and after $t=0$. (5) We provide a falsification test in the spirit of A Itonji, Elder, and Taber (2005). We first estimate Model 3 in Table 2, but exclude the variables of interest (MAD and TPD) and instead add several variables potentially capturing local factors to which lawmakers might respond when implementing the two directives. Specifically, we include gross domestic savings, the net capital account, portfolio equity inflows, annual growth in GDP per capita, yearly inflation, and five binary indicator variables for the closeness to national elections in a country (for quarters $t-4$ to $t=0$ relative to the election quarter). We scale the raw variables by GDP and lag them by four quarters. Macroeconomic data are from the World Bank and the IMF, election dates are from the national archives. We then use the predicted values from this first-stage regression as the dependent variable in our base specification and report the MAD and TPD coefficients from this falsification test in the table. Insignificant coefficients indicate that local factors cannot explain the estimated effects obtained in Table 2. Throughout the table, we only report OLS coefficient estimates (t-statistics) for the main variables. We compute tstatistics based on robust standard errors clustered by country, except in M odels 3 and 4, Panel B, in which we apply tw 0 -way clustering by firm and quarter-year. $* * *, * *$, and * indicate statistical significance at the $1 \%, 5 \%$, and $10 \%$ levels (two-tailed). 


\section{Table 4}

\section{Prior regulation and implementation variables by EU country}

\begin{tabular}{|c|c|c|c|c|c|c|c|c|c|c|c|c|c|}
\hline \multirow{3}{*}{$\begin{array}{l}\text { Country } \\
\text { A ustria }\end{array}$} & \multirow{2}{*}{\multicolumn{2}{|c|}{$\begin{array}{c}\begin{array}{c}\text { Prior } \\
\text { regulation }\end{array} \\
\\
\text { Regulatory } \\
\text { quality } 2003\end{array}$}} & \multicolumn{5}{|c|}{ MAD implementation strength } & \multicolumn{4}{|c|}{ TPD implementation strength } & \multirow{2}{*}{\multicolumn{2}{|c|}{$\begin{array}{c}\begin{array}{c}\text { Supervisory } \\
\text { resources }\end{array} \\
\text { Staff growth } \\
\text { (2004 to 2009) }\end{array}$}} \\
\hline & & & \multicolumn{2}{|c|}{$\begin{array}{l}\text { M aximum } \\
\text { fine } \\
\text { (EUR AD } 000)\end{array}$} & \multicolumn{2}{|c|}{$\begin{array}{l}\text { Supervisory } \\
\text { powers }\end{array}$} & \multirow{2}{*}{$\begin{array}{c}\begin{array}{c}\text { Shift in en- } \\
\text { forcement } \\
\text { MAD }\end{array} \\
1\end{array}$} & \multicolumn{2}{|c|}{$\begin{array}{l}\text { M aximum } \\
\text { fine } \\
\text { (EUR } 000)\end{array}$} & \multirow{2}{*}{$\begin{array}{c}\begin{array}{c}\text { Supervisory } \\
\text { powerSTPD }\end{array} \\
0\end{array}$} & \multirow{2}{*}{$\begin{array}{c}\begin{array}{c}\text { Shift in en- } \\
\text { forcement } \\
\text { ToD }^{-}\end{array} \\
0\end{array}$} & & \\
\hline & 1.52 & (1) & No fine & (0) & 70 & (0) & & 30 & (0) & & & 2.08 & (1) \\
\hline Belgium & 1.36 & (0) & Profit-based & (1) & 69 & (0) & 0 & 2,500 & (1) & 1 & 0 & -0.27 & (0) \\
\hline Bulgaria & 0.59 & (0) & 50 & (0) & 69 & (0) & 0 & 5,112 & (1) & 0 & 0 & 0.13 & (0) \\
\hline Cyprus & 1.20 & (0) & 1,710 & (0) & 68 & (0) & 0 & 341 & (0) & 0 & 0 & 0.07 & (0) \\
\hline Czech Republic & 1.12 & (0) & 350 & (0) & 64 & (0) & 0 & 400 & (0) & 0 & 0 & 0.93 & (1) \\
\hline Denmark & 1.79 & (1) & No fine & (0) & 60 & (0) & 0 & No limit & (1) & 1 & 0 & 0.23 & (0) \\
\hline Estonia & 1.40 & (1) & No fine & (0) & 60 & $(0)$ & 1 & 16,000 & (1) & 0 & 0 & -0.01 & (0) \\
\hline Finland & 1.90 & (1) & 200 & (0) & 63 & (0) & 0 & 200 & (0) & 1 & 1 & -0.20 & (0) \\
\hline France & 1.18 & $(0)$ & Profit-based & (1) & 75 & (1) & 1 & 10,000 & (1) & 1 & 0 & 0.06 & (0) \\
\hline Germany & 1.51 & (1) & Profit-based & (1) & 64 & (0) & 1 & 200 & (0) & 0 & 1 & 0.25 & (1) \\
\hline Greece & 1.01 & $(0)$ & 6,000 & (0) & 60 & $(0)$ & 0 & 1,000 & (1) & 0 & 0 & 0.16 & (0) \\
\hline Hungary & 1.08 & $(0)$ & Profit-based & (1) & 73 & (1) & 0 & 24 & (0) & 0 & 1 & 0.81 & (1) \\
\hline Iceland & 1.67 & (1) & 10,000 & (0) & 60 & $(0)$ & 1 & 300 & (0) & 0 & 1 & 1.15 & (1) \\
\hline Ireland & 1.66 & (1) & 588 & (0) & 73 & (1) & 0 & 2,500 & (1) & 1 & 1 & 0.30 & (1) \\
\hline Italy & 1.02 & (0) & Profit-based & (1) & 70 & (0) & 1 & 620 & (1) & 1 & 0 & 0.58 & (1) \\
\hline Latvia & 1.03 & (0) & Profit-based & (1) & 80 & (1) & 1 & 14 & (0) & 1 & 1 & 0.25 & (1) \\
\hline Lithuania & 1.10 & (0) & Profit-based & (1) & 70 & (0) & 0 & 29 & (0) & 0 & 1 & -0.04 & (0) \\
\hline Luxembourg & 1.94 & (1) & Profit-based & (1) & 80 & (1) & 0 & 125 & (0) & 0 & 1 & 2.36 & (1) \\
\hline M alta & 1.27 & (0) & Profit-based & (1) & 75 & (1) & 1 & 466 & (0) & 0 & 0 & 0.18 & (0) \\
\hline The N etherlands & 1.76 & (1) & Profit-based & (1) & 67 & $(0)$ & 1 & 120 & (0) & 0 & 1 & 0.25 & (1) \\
\hline Norway & 1.39 & $(0)$ & Profit-based & (1) & 59 & (0) & 1 & No limit & (1) & 1 & 1 & 0.32 & (1) \\
\hline Poland & 0.61 & $(0)$ & 1,250 & (0) & 70 & (0) & 0 & 1,389 & (1) & 1 & 0 & 1.59 & (1) \\
\hline Portugal & 1.21 & $(0)$ & 2,500 & (0) & 73 & (1) & 0 & 2,500 & (1) & 1 & 0 & 0.04 & (0) \\
\hline Romania & -0.12 & $(0)$ & Profit based & (1) & 73 & (1) & 1 & 13 & (0) & 0 & 0 & 0.13 & (0) \\
\hline Slovakia & 0.95 & $(0)$ & 600 & (0) & 74 & (1) & 0 & 664 & (1) & 0 & 0 & -0.06 & (0) \\
\hline Slovenia & 0.88 & $(0)$ & 125 & (0) & 51 & (0) & 0 & 125 & (0) & 0 & 0 & 0.32 & (1) \\
\hline Spain & 1.29 & (0) & Profit-based & (1) & 60 & (0) & 0 & 600 & (0) & 1 & 0 & 0.28 & (1) \\
\hline Sweden & 1.69 & (1) & No fine & (0) & 73 & (1) & 1 & 1,000 & (1) & 0 & 1 & 0.17 & (0) \\
\hline U nited K ingdom & 1.68 & (1) & No limit & (1) & 76 & (1) & 1 & No limit & (1) & 1 & 1 & 0.26 & (1) \\
\hline
\end{tabular}




\section{Table 4}

\section{Continued}

We measure the quality of prior regulation with the Regulatory quality index as of 2003, capturing the "ability of the government to formulate and implement sound policies and regulations" (K aufmann, K raay, and M astruzzi 2009). Higher values indicate higher regulatory quality. The three variables for strength of

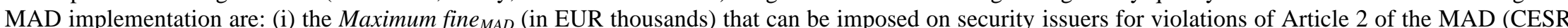
2008). If the fine is unlimited or indicated as a percentage of profits from violations, we set the indicator variable equal to ' 1 '. (ii) Supervisory power $S_{M A D}$ equals the number of positive replies (out of 86 ) by the local regulator to a questionnaire on the existence of specific supervisory powers regarding the translation of the MAD into local law (CESR 2007). Higher values indicate more supervisory powers. (iii) Shift in enforcement ${ }_{M A D}$ equals ' 1 ' if the local regulator has taken at least a single enforcement action under the MAD by the end of 2009 (see CESR Review Panel report on the implementation of the MAD; CESR 2010). The three variables for strength of TPD implementation are: (i) the M aximum fine TPD (in EUR thousands) that can be imposed on security issuers for violations of A rticles 4 to 6 of the TPD (CESR 2009a). If the fine is unlimited, we set the indicator variable equal to ' 1 '. (ii) Supervisory power STPD takes on the value of ' 1 ' if a country complies with all the enforcement principles outlined in CESR Standard No. 1 (see CESR peer review in 2008; CESR 2009b). (iii) Shift in enforcement TpD $_{\text {D }}$ equals ' 1 ' if local auditors and regulators indicate that the enforcement activity for the provision of financial information has substantially increased over the 2004 to 2009 period. This variable stems from a self-constructed survey that we sent to the technical departments of PricewaterhouseC oopers and the supervisory authority in each EU member state (see also Christensen, Hail, and Leuz 2013, Table 1). We measure the change in supervisory resources (Staff growth), which applies to both the MAD and TPD, with the percentage change in full-time employees working for the national securities regulator over the 2004 to 2009 period. If available, we use the growth of staff specifically assigned to the oversight of securities regulation. Otherwise, we use the staff growth for the joint regulator (i.e., including the banking and insurance sectors). Staff numbers are from the annual reports of the local regulators and Central B anking Publications (2009). For the analyses, we transform the continuous variables into binary indicators (show $\mathrm{n}$ in parentheses) splitting by the OECD median (Regulatory quality) or the sample median (implementation variables). 
Table 5

\section{Liquidity effects of tighter $\mathrm{E} U$ securities laws when prior regulation or implementation differs}

Panel A: Results for the MAD

\begin{tabular}{|c|c|c|c|c|c|}
\hline \multirow{2}{*}{$\begin{array}{l}\mathrm{Ln}(\mathrm{L} \text { iquidity factor }+1) \\
\text { as dependent variable } \\
(\mathrm{N}=112,260)\end{array}$} & \multirow{2}{*}{$\begin{array}{c}\text { Prior regulation } \\
\text { Regulatory } \\
\text { quality } 2003\end{array}$} & \multicolumn{4}{|c|}{ M AD implementation strength } \\
\hline & & $\begin{array}{l}\text { M aximum } \\
\text { fine }_{M A D}\end{array}$ & $\begin{array}{l}\text { Supervisory } \\
\text { powers }\end{array}$ & $\begin{array}{c}\text { Shift in en- } \\
\text { forcement }_{M A D}\end{array}$ & $\begin{array}{l}\text { Staff } \\
\text { growth }\end{array}$ \\
\hline \\
\hline High & $\begin{array}{l}-0.234 * * * \\
(-3.16)\end{array}$ & - & - & - & - \\
\hline Low & $\begin{array}{l}-0.000 \\
(0.00)\end{array}$ & - & - & - & - \\
\hline \multicolumn{6}{|l|}{ Implementation strength: } \\
\hline Strong & - & $\begin{array}{l}-0.151 * * * \\
(-2.73)\end{array}$ & $\begin{array}{l}-0.222 * * \\
(-2.28)\end{array}$ & $\begin{array}{l}-0.164 * * * \\
(-2.99)\end{array}$ & $\begin{array}{l}-0.139 * * \\
(-2.52)\end{array}$ \\
\hline W eak & - & $\begin{array}{l}-0.025 \\
(-0.57)\end{array}$ & $\begin{array}{l}-0.053^{*} \\
(-1.94)\end{array}$ & $\begin{array}{r}-0.000 \\
(-0.00)\end{array}$ & $\begin{array}{r}-0.051 \\
(-0.96)\end{array}$ \\
\hline \multicolumn{6}{|c|}{ F-test for differences across coefficients ( $p$-value): } \\
\hline High/strong $=$ L ow $/$ weak & 0.014 & 0.175 & 0.135 & 0.055 & 0.392 \\
\hline \multicolumn{6}{|l|}{ Panel B: Results for the TPD } \\
\hline \multirow{2}{*}{$\begin{array}{l}\mathrm{Ln}(\text { Liquidity factor }+1) \\
\text { as dependent variable } \\
(\mathrm{N}=112,260)\end{array}$} & Prior regulation & \multicolumn{4}{|c|}{ TPD implementation strength } \\
\hline & $\begin{array}{l}\text { Regulatory } \\
\text { quality } 2003\end{array}$ & $\begin{array}{c}\text { M aximum } \\
\text { fine }_{T P D}\end{array}$ & $\begin{array}{c}\text { Supervisory } \\
\text { powerSTPD }\end{array}$ & $\begin{array}{l}\text { Shift in en- } \\
\text { forcement }\end{array}$ & $\begin{array}{l}\text { Staff } \\
\text { growth }\end{array}$ \\
\hline \multicolumn{6}{|l|}{ Prior regulation quality: } \\
\hline High & $\begin{array}{l}-0.185^{* *} \\
(-2.40)\end{array}$ & - & - & - & - \\
\hline Low & $\begin{array}{c}0.034 \\
(0.77)\end{array}$ & - & - & - & - \\
\hline \multicolumn{6}{|l|}{ Implementation strength: } \\
\hline Strong & - & $\begin{array}{l}-0.108^{*} \\
(-1.95)\end{array}$ & $\begin{array}{l}-0.103^{*} \\
(-1.79)\end{array}$ & $\begin{array}{l}-0.191^{* *} \\
(-2.48)\end{array}$ & $\begin{array}{l}-0.135^{* *} \\
(-1.96)\end{array}$ \\
\hline W eak & - & $\begin{array}{l}-0.042 \\
(-0.73)\end{array}$ & $\begin{array}{l}-0.058 \\
(-1.12)\end{array}$ & $\begin{array}{c}0.032 \\
(0.75)\end{array}$ & $\begin{array}{l}-0.022 \\
(-0.39)\end{array}$ \\
\hline \multicolumn{6}{|c|}{ F-test for differences across coefficients ( $p$-value): } \\
\hline High/strong $=$ L ow $/$ weak & 0.039 & 0.486 & 0.619 & 0.032 & 0.334 \\
\hline
\end{tabular}

For details on the sample and a description of the dependent and control variables see Table 1 . We use M odel 4 in Table 2 as our base specification. For each model we partition the sample into two distinct groups by interacting the M AD (Panel A) or TPD (Panel B) variables with a binary indicator variable for the quality of prior regulation (high vs. low) or the strength of MAD and TPD implementation (strong vs. weak). For a description of the country-level partitioning variables see Table 4. We only report OLS coefficient estimates (t-statistics, based on robust standard errors clustered by country) for the main variables. We also report $p$-values from $W$ ald tests assessing the statistical significance of the differences across coefficients. $* * *, * *$, and $*$ indicate statistical significance at the $1 \%, 5 \%$, and $10 \%$ levels (two-tailed). 
Table 6

\section{Liquidity effects when combining prior regulation and implementation differences}

Panel A: Results for the MAD

\begin{tabular}{|c|c|c|c|c|}
\hline \multirow{2}{*}{$\begin{array}{l}\mathrm{Ln}(\text { L iquidity factor }+1) \\
\text { as dependent variable } \\
(\mathrm{N}=112,260)\end{array}$} & \multicolumn{4}{|c|}{ MAD implementation strength (IS) } \\
\hline & $\begin{array}{l}\text { Maximum } \\
\text { fine }_{M A D}\end{array}$ & $\begin{array}{l}\text { Supervisory } \\
\text { powers }\end{array}$ & $\begin{array}{l}\text { Shift in en- } \\
\text { forcement }\end{array}$ & $\begin{array}{l}\text { Staff } \\
\text { growth }\end{array}$ \\
\hline \multicolumn{5}{|l|}{ Regulatory quality (RQ): } \\
\hline High RQ/strong IS & $\begin{array}{l}-0.325^{* * *} \\
(-4.20)\end{array}$ & $\begin{array}{l}-0.335 * * * \\
(-3.32)\end{array}$ & $\begin{array}{l}-0.270 * * * \\
(-3.36)\end{array}$ & $\begin{array}{l}-0.312 * * * \\
(-3.75)\end{array}$ \\
\hline High RQ/weak IS & $\begin{array}{l}-0.079 * \\
(-1.74)\end{array}$ & $\begin{array}{l}-0.156 * * * \\
(-3.32)\end{array}$ & $\begin{array}{l}-0.067 \\
(-1.35)\end{array}$ & $\begin{array}{l}-0.098 * * \\
(-2.17)\end{array}$ \\
\hline Low RQ/strong IS & $\begin{array}{l}-0.006 \\
(-0.11)\end{array}$ & $\begin{array}{l}-0.082 \\
(-1.49)\end{array}$ & $\begin{array}{l}-0.007 \\
(-0.14)\end{array}$ & $\begin{array}{c}0.064 \\
(1.26)\end{array}$ \\
\hline Low RQ/weak IS & $\begin{array}{c}0.036 \\
(0.75)\end{array}$ & $\begin{array}{r}0.022 \\
(0.48)\end{array}$ & $\begin{array}{r}0.016 \\
(0.37)\end{array}$ & $\begin{array}{l}-0.066 \\
(-1.21)\end{array}$ \\
\hline \multicolumn{5}{|c|}{$F$-test for differences across coefficients ( $p$-value): } \\
\hline High RQ/strong IS = High RQ/weak IS & 0.001 & 0.075 & 0.018 & 0.004 \\
\hline High RQ/strong IS = Low RQ/strong IS & 0.000 & 0.011 & 0.010 & 0.000 \\
\hline Low RQ/strong IS = Low RQ/weak IS & 0.423 & 0.066 & 0.638 & 0.010 \\
\hline
\end{tabular}

Panel B: Results for the TPD

\begin{tabular}{|c|c|c|c|c|}
\hline \multirow{2}{*}{$\begin{array}{l}\mathrm{L} n(\mathrm{~L} \text { iquidity factor }+1) \\
\text { as dependent variable } \\
(\mathrm{N}=112,260)\end{array}$} & \multicolumn{4}{|c|}{ TPD implementation strength (IS) } \\
\hline & $\begin{array}{l}\text { Maximum } \\
\text { fine }_{T P D}\end{array}$ & $\begin{array}{l}\text { Supervisory } \\
\text { powers }\end{array}$ & $\begin{array}{l}\text { Shift in en- } \\
\text { forcement }_{T P D}\end{array}$ & $\begin{array}{l}\text { Staff } \\
\text { growth }\end{array}$ \\
\hline \multicolumn{5}{|l|}{ Regulatory quality (RQ): } \\
\hline $\mathrm{High} \mathrm{RQ} /$ strong IS & $\begin{array}{l}-0.233^{* *} \\
(-2.34)\end{array}$ & $\begin{array}{l}-0.267 * * * \\
(-2.78)\end{array}$ & $\begin{array}{l}-0.221 * * * \\
(-2.74)\end{array}$ & $\begin{array}{l}-0.274 * * * \\
(-3.36)\end{array}$ \\
\hline High RQ/weak IS & $\begin{array}{l}-0.090 * * \\
(-2.05)\end{array}$ & $\begin{array}{l}-0.075 \\
(-1.55)\end{array}$ & $\begin{array}{r}0.047 \\
(0.91)\end{array}$ & $\begin{array}{l}-0.022 \\
(-0.46)\end{array}$ \\
\hline Low RQ/strong IS & $\begin{array}{r}0.022 \\
(0.51)\end{array}$ & $\begin{array}{r}0.030 \\
(0.68)\end{array}$ & $\begin{array}{r}0.033 \\
(0.70)\end{array}$ & $\begin{array}{c}0.096^{*} \\
(1.91)\end{array}$ \\
\hline Low RQ/weak IS & $\begin{array}{r}0.094 \\
(1.43)\end{array}$ & $\begin{array}{l}0.143 \\
(1.39)\end{array}$ & $\begin{array}{c}0.033 \\
(0.72)\end{array}$ & $\begin{array}{l}-0.013 \\
(-0.22)\end{array}$ \\
\hline \multicolumn{5}{|c|}{$F$-test for differences across coefficients ( $p$-value): } \\
\hline High RQ/strong IS = High RQ/weak IS & 0.217 & 0.102 & 0.013 & 0.017 \\
\hline High RQ/strong IS = Low RQ/strong IS & 0.053 & 0.022 & 0.017 & 0.002 \\
\hline Low RQ/strong IS $=$ Low RQ/weak IS & 0.217 & 0.263 & 0.998 & 0.074 \\
\hline
\end{tabular}

For details on the sample and a description of the dependent and control variables see Table 1 . We use M odel 4 in Table 2 as our base specification. For each model we partition the sample into four distinct groups by interacting the M AD (Panel A) or TPD (Panel B) variables with a binary indicator for the quality of prior regulation (high vs. low) and another binary indicator for the strength of M AD or TPD implementation (strong vs. weak). For a description of the country-level partitioning variables see Table 4 . We only report OLS coefficient estimates (t-statistics, based on robust standard errors clustered by country) for the main variables. We also report $p$-values from Wald tests assessing the statistical significance of the differences across coefficients. $* * *, * *$, and $*$ indicate statistical significance at the $1 \%, 5 \%$, and $10 \%$ levels (two-tailed). 
Table A-1

Examples of national transposition timeline of $\mathrm{E}$ securities regulation

\begin{tabular}{|c|c|c|c|c|c|}
\hline Country & $\begin{array}{l}\text { Date of } \\
\text { initial } \\
\text { draft }\end{array}$ & Description & $\begin{array}{l}\text { Date of } \\
\text { signature or } \\
\text { publication }\end{array}$ & $\begin{array}{l}\text { Entry-into- } \\
\text { force date }\end{array}$ & $\begin{array}{c}\text { Length of } \\
\text { observable } \\
\text { process }\end{array}$ \\
\hline \multicolumn{6}{|c|}{ MAD (passage at EU level on 28-J an-2003): } \\
\hline France & $\begin{array}{l}27-0 c t- \\
2004\end{array}$ & Consultation period begins & $\begin{array}{l}21-J u l- \\
2005\end{array}$ & $\begin{array}{l}27-\mathrm{Jul}- \\
2005\end{array}$ & 9 \\
\hline Germany & $\begin{array}{l}10-M \text { ar- } \\
2004\end{array}$ & Preliminary draft published & $\begin{array}{l}29-0 \mathrm{ct}- \\
2004\end{array}$ & $\begin{array}{l}30-0 \mathrm{ct}- \\
2004\end{array}$ & 8 \\
\hline The N etherlands & $\begin{array}{l}27-0 \text { ct- } \\
2004\end{array}$ & $\begin{array}{l}\text { First Royal M essage } \\
\text { (K amerstuk 29827) }\end{array}$ & $\begin{array}{l}12-\mathrm{Jul}- \\
2005\end{array}$ & $\begin{array}{l}1-0 \text { ct- } \\
2005\end{array}$ & 11 \\
\hline Sweden & $\begin{array}{l}7-\mathrm{Jul}- \\
2004\end{array}$ & Consultation period begins & $\begin{array}{l}13-J \text { un- } \\
2005\end{array}$ & $\begin{array}{l}1-J \text { ul- } \\
2005\end{array}$ & 12 \\
\hline United K ingdom & $\begin{array}{l}\text { 1-Jun- } \\
2004\end{array}$ & Consultation period begins & $\begin{array}{l}\text { 23-Feb- } \\
2005\end{array}$ & $\begin{array}{l}\text { 1-J ul- } \\
2005\end{array}$ & 13 \\
\hline \multicolumn{6}{|c|}{ TPD (passage at EU level on 17-Dec-2004): } \\
\hline France & $\begin{array}{l}27-J u l- \\
2006\end{array}$ & Consultation period begins & $\begin{array}{l}\text { 18-Dec- } \\
2007\end{array}$ & $\begin{array}{l}19-D e c- \\
2007\end{array}$ & 17 \\
\hline Germany & $\begin{array}{l}\text { 3-M ay- } \\
2006\end{array}$ & Preliminary draft published & $\begin{array}{l}5-J a n- \\
2007\end{array}$ & $\begin{array}{l}20-J a n- \\
2007\end{array}$ & 9 \\
\hline The N etherlands & $\begin{array}{l}\text { 3-J ul- } \\
2007\end{array}$ & $\begin{array}{l}\text { First Royal M essage } \\
\text { (K amerstuk 31093) }\end{array}$ & $\begin{array}{l}20-\mathrm{N} \text { ov- } \\
2008\end{array}$ & $\begin{array}{l}1-J \text { an- } \\
2009\end{array}$ & 18 \\
\hline Sweden & $\begin{array}{l}\text { 26-A pr- } \\
2006\end{array}$ & Consultation period begins & $\begin{array}{l}13-J u n- \\
2007\end{array}$ & $\begin{array}{l}\text { 1-J ul- } \\
2007\end{array}$ & 14 \\
\hline United K ingdom & $\begin{array}{l}\text { 1-M ar- } \\
2005\end{array}$ & $\begin{array}{l}\text { White paper published by } \\
\text { the Department for Trade } \\
\text { and Industry }\end{array}$ & $\begin{array}{l}\text { 8-N ov- } \\
2006\end{array}$ & $\begin{array}{l}1-J a n- \\
2007\end{array}$ & 22 \\
\hline
\end{tabular}

The table lists various observable dates of the transposition of the MAD and TPD into national law for a select group of EU member states. The Date of initial draft is the first date for which a draft of the national law became publically available via official communication channels. Because the stage when the government releases the initial draft of a law varies across countries, we add a short description. The Date of signature or publication represents the date when the finalized law was officially published or signed by the head of state. The Entry-into-force date is what we use for the coding of the MAD and TPD variables (see Table 1, Panel A). The Length of Observable Process gives the number of months between when the initial draft of the national law was made publicly available and when the law came into force. All dates are from government websites or archives and other public sources. 


\title{
Internet A ppendix to
}

"C apital-M arket E ffects of Securities R egulation: Prior Conditions, Implementation, and E nforcement"

\author{
Hans B. C hristensen \\ University of Chicago, \\ B ooth School of Business \\ L uzi Hail \\ University of Pennsylvania, \\ The Wharton School \\ Christian Leuz \\ University of Chicago, \\ B ooth School of Business and NBER
}

M arch 2016 


\section{Additional Sensitivity Tests}

In this Internet appendix, we report a series of robustness checks. Specifically, we (1) gauge the robustness of our main specification as reported in Table 2 to various alternative research design choices, (2) evaluate the effects of the early implementation of select provisions from the TPD as a result of mandatory IFRS adoption in the EU, (3) further assess the 'sharpness' of the treatment effects with respect to the timing of the MAD and TPD, (4) develop a model predicting the length of the implementation timing, (5) consider alternative proxies for prior regulatory quality in the cross-sectional analyses, and (6) test for the existence of spillover effects from countries that implement the directives earlier and whether countries' implementation timing is related to the cross-sectional split variables. Overall, these analyses confirm our main findings and corroborate the interpretation provided in the paper.

\section{Research Design Choices for M ain Specification (R elated to Section 3.1)}

We begin with a series of robustness checks for the average market-liquidity effects of the MAD and TPD presented in Section 3 of the main text. ${ }^{1}$ We gauge the sensitivity of our findings to (i) the clustering of the standard errors; (ii) the choice of the fixed-effects structure as well as shocks that differentially affect firms and countries; (iii) the definition of the dependent variable including the construction of the liquidity factor; (iv) the sample composition and the use of firmquarters as our unit of analysis; and (v) the inclusion of share turnover and market value as control variables. Throughout this section, we use M odel 4 from Table 2 as our base specification, and report results for the coefficients on MAD and TPD in Table I-1.

\footnotetext{
We also conduct several robustness checks for the tests in Section 4 of the main text. We re-run the crosssectional analyses (i) with standard errors clustered by economic region instead of country, (ii) adding separate quarter-year-fixed effects for developed markets, (iii) replacing country- and industry-fixed effects with firmfixed effects, or (iv) controlling for macroeconomic factors. The results and inferences are similar to those in Tables 5 and 6.
} 
First, we consider alternative ways to cluster the standard errors. In our main specification, we use clusters by country. As the two rows under heading (1) in Table I-1 show, the inferences remain the same when we use two-way clustering by country and quarter-year, or when we cluster the standard errors by 18 economic regions. The latter approach combines several EU countries and in that sense is more conservative than country-level clustering.

Under the second heading of Table I-1, we expand the fixed-effects structure in our preferred empirical specification. When we replace the country- and industry-fixed effects with firm-fixed effects, the results are very similar, although the magnitude (but not the statistical significance) of the TPD effect is slightly attenuated. Next, we augment the current base model by adding separate quarter-year fixed effects for developed countries (as identified in the Morgan Stanley Capital International database). This specification accounts for the possibility that developed markets exhibit different liquidity trends or are differentially affected by economic shocks during the sample period. A long the same lines, we introduce separate size coefficients for each calendar quarter. This expansion of the fixed-effects structure should help absorb economic shocks that affect larger firms differently from smaller firms, and hence accounts for differences in the firm size distribution across countries. In both cases, the results are similar and the inferences remain the same as those in our main analysis, although the TPD effect is slightly smaller with separate quarter-year fixed effects for developed countries. In additional tests (not tabulated), we include separate volatility coefficients for each quarter-year, interactions between the country indicators and firm size, or interactions between the country indicators and industry. A gain, the results are similar to those reported in Table 2.

Under the third heading of Table I-1, we consider variations to our dependent variable. The objective of these tests is to assess the sensitivity of the results to the construction of the liquidity factor as well as to limited availability of individual liquidity measures. In our main specification 
we follow the prior literature and construct the liquidity factor from four observable variables (Bid-ask spread, Zero returns, Price impact, and Total trading costs). Of those, Bid-ask spreads and Zero returns can be viewed as proxies on opposite ends of a spectrum: Bid-ask spreads are conceptually appealing but more sensitive to market microstructure differences and not as widely available. Zero returns have less of a conceptual foundation, but are less sensitive to differences in market microstructure and give us the largest sample. Thus, in the first two rows, we report sensitivity tests using those two extremes, Bid-ask spreads and Zero returns, as the dependent variable. The results are very similar to those reported in Table 2 . Next, we assess the construction of the liquidity factor with respect to missing observations. One concern with requiring four observable liquidity variables is that the sample is biased towards more efficient and developed capital markets and systematically misses out on observations from smaller countries that might benefit the most from harmonized securities regulation. First, whenever one of the four liquidity variables is missing, we use a liquidity factor constructed from the three remaining measures. ${ }^{2}$ Second, we start with the sample of firm-quarters for which Zero returns are available and then impute missing observations for any of the other three variables using an expectationsmaximization (EM) algorithm (see e.g., Dempster, Laird, and Rubin 1977; K arolyi 2015, Chapter 3). This way, we end up with a sample of 145,090 firm-quarters with actual or imputed values for all four liquidity variables, which represents an increase in sample size by about 30 percent. These observations serve as input for the alternative liquidity factor, for which we report results in Table I-1. In both cases, the results remain largely unaffected, albeit the magnitude of the coefficients becomes slightly smaller when including imputed observations.

For instance, when the Bid-ask spread is missing in a firm-quarter, we use the factor scores from a liquidity factor for this particular observation, computed based on Zero returns, P rice impact, and Total trading costs. 
In additional tests (not tabulated), we consider several al ternative ways of constructing our main liquidity factor. The inferences remain unaffected when (i) we re-estimate the liquidity factor using median quarterly spreads and price impact (instead of means), (ii) with promax or varimax rotation in the factor analysis, (iii) using the (winsorized) raw scores of the liquidity factor without log transformation, or (iv) we aggregate the liquidity measures with principal component analysis (PCA) instead of factor analysis and then use the first principal component as the dependent variable. Table I-2 provides descriptive information on the construction of the aggregate liquidity measure using either factor analysis or PCA. Both methods yield a single factor or component that explains the vast majority of the variation in the observable liquidity variables with an eigenvalue of 2.6 and 3.0, respectively. The first principal component explains about 74 percent of the total variation, far above the commonly used threshold of 50 percent (e.g., Karolyi 2015, p. 39). When considering the scoring coefficients, both the factor analysis and PCA exhibit a similar pattern. Total trading costs and Bid-ask spreads have the highest weights, followed by Zero returns and Price impact. It is reassuring that four liquidity variables using different input data (bid and ask quotes, trading volume, stock returns) load strongly on the same underlying construct. Moreover, the correlation between the factor scores and the principal component scores in our sample is very high, and it is therefore not surprising that the estimated MAD and TPD treatment effects are essentially the same when using factor analysis or PCA to construct the liquidity factor.

Under the fourth heading of Table I-1, we assess the importance of sample composition and our unit of analysis. First, we exclude the countries that experienced the most serious economic downturn during the financial crisis. Specifically, we exclude firms from the so-called GIIPS countries (Greece, Ireland, Italy, Portugal, and Spain) as well as Cyprus. The results are not materially affected. Second, we include benchmark observations from non-EU countries in the 
sample. The idea is to also use firms that are unaffected by the introduction of the two directives as a benchmark instead of relying solely on the within-EU variation in entry-into-force dates. This identification strategy assumes that EU and non-EU countries have parallel liquidity trends absent the MAD and TPD, which is a strong assumption and the reason why we do not use this specification in our main analyses. Nevertheless, the results are quite similar. Third, we address the issue of oversampling and serial correlation in our control variables (e.g., Bertrand, Duflo, and Mullainathan 2004), which can occur because we do not measure all control variables on a quarterly basis (i.e., GDP per capita) and some controls are likely correlated over short windows. ${ }^{3}$ Thus, we randomly select one observation per firm-year (out of four possible) and re-estimate the regression with this reduced sample. The results are virtually the same, if not stronger. Fourth, we adjust the unit of analysis. Since the treatment occurs at the country-level one may argue that the effects should already be present in a country-level analysis. However, such an aggregate analysis ignores that firm characteristics like size or return variability are important firm-level determinants of liquidity. Thus, a country-level analysis would imperfectly capture and purge differences and time-series changes in these firm-level determinants. It would also make the analysis more susceptible to differences in the sample composition across countries (which arise, for instance, if the size threshold for going public differs across countries). Nevertheless, we adjust the unit of analysis from firm-quarters to the mean values of all the dependent and continuous independent variables in (i) a given country, year, quarter, and industry (giving rise to 4,941 observations), or (ii) a given country, year, and quarter (giving rise to 896 observations). In the latter specification, we compute a weighted average using the aggregate market capitalization (measured in US\$ for comparability) to make sure that the treatment effects are representative of the average liquidity

Note that an analysis using annual observations is not sensible for our purposes in light of the staggered implementation of the MAD and TPD over a time period of less than three years. Such a yearly analysis would leave little variation to identify the treatment effects and bring us closer to the single-country setting. 
effects for the EU capital market as a whole. The estimated coefficients obtained from these two aggregate analyses are almost identical to the coefficients from the firm-level analyses for the MAD, and smaller but statistically significant for the TPD.

Under the fifth heading of Table I-1, we consider the importance of particular control variables. First, we re-estimate our model after excluding Share Turnover from the set of controls. Turnover is conceptually close to some of the variables that enter the liquidity factor and, hence, it could be viewed as a proxy for liquidity as well. A gain, the results are very similar and the inferences remain unaffected. Second, we replace the M arket Value measured in quarter $\mathrm{t}-4$ with a fixed control variable using the market value as of 2001 (i.e., the beginning of our sample period) or whenever a firm enters the sample for the first time. Liquidity is likely priced in firms' market values and the directives could have increased firm valuation ahead of the entry-into-force dates; that is why we use lagged market values in the first place. Fixing market values prior to the directives still controls for size but at the same time ensures that the effects of the directives are not yet reflected in the control variables. The results remain largely unchanged.

\section{E arly Implementation of TPD Provisions (R elated to Section 3.1)}

In this section, we gauge to what extent our estimates for the TPD might have been affected by the prior passage of the IAS Regulation, which mandated IFRS adoption for firms listed on regulated EU markets with fiscal years ending on December 31, 2005, or later. The TPD focuses on supervisory regimes and the enforcement of periodic reporting of regulated information. Thus, the two regulatory initiatives are potentially connected. In fact, one important provision in the TPD requires that EU countries proactively review financial statements for compliance with IFRS. Because the IAS Regulation also highlights the importance of appropriate measures to ensure compliance with IFRS, several countries (Finland, Germany, the Netherlands, Norway, and the 
U.K.) implemented the TPD requirement of proactive reviews of financial reports before the official entry-into-force date of the TPD and in conjunction with IFRS adoption (see the appendix in Christensen, Hail, and L euz 2013 for details). As a consequence, the TPD should have less of an effect by the time it enters into force in those five countries, that is, the concurrent enforcement changes around IFRS adoption potentially attenuate the estimated treatment effect of the TPD.

To test these arguments, we explicitly control for IFRS adoption in the five EU countries that switched to IFRS and, at the same time, implemented substantive enforcement changes $\left(I F R S_{E_{-} E N F}\right)$ as well as the remaining EU countries without such concurrent enforcement changes around the introduction of IFRS (IF RS EU_nonENF $_{\text {n }}$ ). Table I-3 reports the coefficient estimates of this expanded model. We first repeat the main results from Table 2 , in which we estimate the treatment effects of the MAD and TPD with and without controls for the other EU directives, including IFRS adoption. As column (2) shows, only the coefficient on IFRS is significant and negative among the additional controls, but it leaves the main variables of interest largely unchanged. In column (3), we split the IFRS control variable into the two non-overlapping indicators IFRS $\mathrm{EU}_{-}$ENF and IFRS $\mathrm{EU}_{-}$nonENF. This model effectively controls (or accounts) for the early adoption of some TPD provisions. Consistent with Christensen, Hail, and Leuz (2013), we find a significant improvement in market liquidity only in countries with concurrent enforcement changes around IFRS adoption, but not in the remaining EU member states. At the same time, as predicted, the estimated treatment effect of the TPD is attenuated by about half (but it remains significant). Thus, once we account for the early adoption of some provisions, the estimated liquidity effects of the TPD declines, which further underscores that the enforcement provisions stipulated under this directive are indeed the drivers of our TPD findings. 


\section{Sharpness of Treatment E ffects (R elated to Section 3.2)}

In this section, we assess the 'sharpness' of the treatment effects using an alternative test design. In the paper, we argue that if the entry-into-force dates provide reasonably 'sharp' identification with respect to changes in market liquidity, meaning the change in liquidity is relatively abrupt, then any bias or threat to identification would have to come from omitted factors that are correlated with both the distribution of entry-into-force dates within the EU and concurrent changes in market liquidity. We already provide empirical evidence to support this argument (see Table 3, Panel A, and Figure 2). Here, we further gauge the sharpness by (counterfactually) shifting the assignment of the implementation dates by one quarter at a time for all EU countries, and each time re-estimating our base model from Table 2 noting the coefficient on M AD or TPD. If the liquidity effects are indeed caused by the directives, the estimated coefficients should be attenuated as we move away from the true implementation dates (in both directions).

As Table I-4 shows, the coefficients on MAD peak at the true entry-into-force dates and become smaller in magnitude (and significance) as we counterfactually move away from the true dates. This pattern shows that the implementation dates are indeed critical, consistent with a causal interpretation. For the TPD, the pattern is not centered at $t=0$. The coefficients continue to increase beyond the true entry-into-force dates before they start reversing (after quarter $t+5$ ). This delayed pattern suggests that it takes a few quarters from when the TPD comes into force until the regulatory changes become effective and translate into liquidity effects. But the pattern still shows that the onset of the liquidity effects is closely related to the entry-into-force dates. One explanation for the delayed response upon entry-into-force of the TPD is that part of the liquidity effects might be tied to the actual filing of the financial reports by the firms (and the beginning of the monitoring by the supervisory authority). The filing dates are determined by firms' fiscal year

ends and, hence, have to occur after the entry-into-force date of the TPD, potentially up to 12 
months later. A nother reason is that setting up a review process for financial information requires hiring and training additional staff, and likely involves a certain degree of learning. It therefore may take a while until the new supervisory agency is fully functional (see, e.g., Ernstberger, Hitz, and Stich 2012 for the case of Germany). The notion that enforcement activities under the TPD were gradually increased over time is also supported by answers we received in response to our survey of regulatory agencies and auditors. ${ }^{4}$

\section{Predicting I mplementation Timing (R elated to Section 3.2)}

Next, we analyze whether we can explain the relative transposition timing of the two directives with variables that indicate how early or late a country is implementing EU regulation in general. Specifically, we attempt to predict countries' relative timing of the MAD (TPD) in a regression model with the following variables: (i) the time (measured in months) it took a country to implement the other directive (i.e., the TPD for the MAD, and vice versa), counting from when the European Parliament and Council enacted the respective directive to its national entry-intoforce date, (ii) whether the country has a bicameral legislature, which might increase the administrative hurdles and thereby transposition length, and (iii) the median number of letters of formal notice that a country received in a given year between 2005 and $2011 .{ }^{5}$

As Table I-5 shows, the explanatory variables are significantly associated with countries' implementation timing (the F-statistics and $R^{2}$ values for the MAD and TPD models are 4.60 and

$4 \quad$ We note that a delayed response to the entry-into-force of the TPD is not in contradiction to our earlier finding of mitigated TPD liquidity effects once we control for the early implementation of certain TPD provisions during IFRS adoption (see Section 2 of this appendix). Table I-3 only shows that controlling for pre-implementation by some countries reduces the TPD coefficient, as one would expect. M oreover, the IF RS $\mathrm{S}_{E_{-} E N F}$ variable in Table I-3 is defined such that it accounts for the actual filing of the annual reports under the new monitoring regime. $Y$ et, we define the TPD variable based on countries' entry-into-force dates of the directive.

5 A letter of formal notice is a request by the European Commission for comments by national governments on issues of non-compliance with EU law and represents the first step in a formal procedure designed to resolve suspected violations, including tardiness or delays in the adoption of EU directives. 
4.75, and $39.6 \%$ and $40.4 \%$, respectively). ${ }^{6}$ This evidence suggests that countries' relative timing is persistent across different directives, consistent with the notion that the implementation dates are plausibly exogenous, for instance, driven by features of the national legislative process such as the existence of a bicameral legislature, rather than by endogenous considerations related to the specific directive. While we do not believe that the three variables are proper instruments in an instrumental variable (IV) sense, we still find about half of the treatment effects for each directive when we use the predicted dates based on the prediction models in Table I-5 (instead of the actual entry-into-force dates). These effects are economically and statistically significant using the distribution of placebo coefficients described in Section 2.1 of the main text.

\section{Alternative Regulatory Q uality M easures (R elated to Sections 4.1 and 4.2)}

In Section 4 of the main text, we examine heterogeneity in the treatment effects, in particular, due to differences in prior regulatory conditions. The argument is that countries with a proven track record of implementing regulation and government policies are expected to implement new regulation in an effective manner; others might do so to a lesser extent. Alternatively, countries with weaker securities regulation could benefit the most from EU-wide efforts to harmonize and improve extant regulation. We test these competing hypotheses using an index taken from Kaufmann, K raay, and M astruzzi (2009) that measures "the government's ability to formulate and implement sound policies and regulations that permit and promote private sector development" (Regulatory Q uality). We believe that this index conceptually captures the construct we have in mind. However, there are other commonly used proxies of regulatory quality in the literature that

6 In contrast, the five macro-economic variables used in the falsification exercise in column (5) of Table 3, Panel $B$, do not explain the relative timing of the M AD and TPD ( $F$-stats are 1.35 and 0.17 , respectively). This finding is again inconsistent with the concern that local economic factors drive implementation timing. Similarly, Table I-8 in this appendix presents contingency tables that show that implementation timing is not significantly related to regulatory quality and implementation strength. If the dates were endogenous, one might expect to see such associations. 
focus specifically on securities regulation and also capture facets of the same underlying construct. Thus, we assess the sensitivity of our cross-sectional tests to several alternative proxies of regulatory quality.

Table I-6 provides an overview of these alternative partitioning variables (and the resulting binary indicators) by EU member state. For comparison, we also report our preferred proxy, the Regulatory Q uality index, in the first column. First, we use the Rule of Law index measured as of 2003 from K aufmann, K raay, and M astruzzi (2009). This variable measures the "extent to which agents have confidence in and abide by the rules of society." The Public Enforcement index from La Porta, Lopez-de-Silanes, and Shleifer (2006) captures various aspects of supervisory characteristics and investigative powers of the public enforcement agencies responsible for securities regulation. The Anti-self-dealing index from Djankov et al. (2008) represents "private enforcement mechanisms, such as disclosure, approval, and litigation, that govern a specific selfdealing transaction." The fourth variable is an index measuring a country's Auditing and Reporting Quality as of 2002/03 and is taken from the Global Competitiveness Report (source: World Economic Forum). The index values represent the aggregate answers to the survey question: "In your country, how strong are financial auditing and reporting standards?" Finally, we construct an aggregate Regulatory Q uality F actor that represents the scores of a single factor obtained from factor analysis using all the country-level proxies (see also K arolyi 2015, Chapter 8, for such an approach to combine institutional variables). To avoid sample attrition, we impute missing observations of the individual institutional proxies using an EM algorithm before we estimate the factor scores. Throughout the table, higher values indicate higher regulatory quality. Similar to the main analysis, we split the sample by the OECD median when forming binary indicator variables. 
In Table I-7, we report the estimated treatment effects for high versus low regulatory quality countries using the alternative proxies. For comparison, we also repeat the results from Table 5. For both the MAD (Panel A) and TPD (Panel B), the results are very similar across the alternative proxies. $^{7}$ In each case, we find significant improvements in liquidity in countries with high prior regulatory quality, and no (or modest) liquidity effects in countries with low regulatory quality. The effects are statistically different from each other in all but one case. M oreover, the magnitude of the treatment effects is very similar across specifications. The only proxy for which the difference between the two groups of countries is insignificant is the Public Enforcement variable. But we note that this variable is missing for 14 sample countries and, hence, the power of the tests is likely much lower than for the other proxies.

\section{G auging the Existence of Spillover E ffects (R elated to Section 4.2)}

Finally, we examine whether the differential timing of the entry-into-force dates of the MAD and TPD across EU member states creates spillover effects from early-adopting countries to lateadopting countries. Such spillover effects could induce heterogeneity in the treatment effects, but this heterogeneity would have a very different interpretation. That is, if markets throughout the EU reacted at the time the first set of countries implements the directive, then the liquidity effects would be weaker or non-existent by the time the directive becomes effective in countries with later dates. In this case, the heterogeneity in the liquidity effects documented in Section 4 of the main text is an artifact of differential timing, rather than driven by differences in prior regulation, implementation, or enforcement.

$7 \quad$ We note that the partitions using the Rule of Law indicator and the Regulatory Quality Factor indicator are identical, consistent with the various proxies capturing the same underlying construct. This impression is further confirmed by the descriptive statistics of the factor analysis. The first factor is strongly dominant with an eigenvalue of 2.48 (compared to an eigenvalue of 0.50 for the second factor). The scoring coefficients on all five individual proxies going into the Regulatory Q uality F actor are positive, and the highest weights are assigned to the Regulatory Q uality and Rule of Law variables. 
We perform two analyses to address this concern. First, we examine the relation between implementation timing and our prior regulation and implementation strength proxies. To do so, we partition the EU countries into early and late MAD or TPD adopters using the median entryinto-force date as cut-off value and provide simple contingency tables with Chi Square tests. As Table I-8 shows, the early countries are not necessarily the ones with a stricter implementation (or vice versa). In fact, the observations are quite evenly distributed and the Chi Square tests are never significant. This evidence also supports the idea that the entry-into-force dates and, hence, the relative timing across countries is plausibly exogenous (see al so Footnote 6 in this appendix).

Second, we examine the liquidity patterns around the entry-into-force dates, separately for early and late countries (not tabulated). We find no evidence that late countries experience liquidity changes prior to the entry-into-force dates, which is inconsistent with spillover effects from earlier countries to later countries. Thus, it is unlikely that differential timing drives the cross-sectional results showing substantial heterogeneity in the treatment effects.

\section{R eferences}

Bertrand, M., E. Duflo, and S. Mullainathan. 2004. How much should we trust differences-in-differences estimates? Q uarterly J ournal of E conomics 119:249-75.

Christensen, H., L. Hail, and C. Leuz. 2013. M andatory IFRS reporting and changes in enforcement. J ournal of Accounting and Economics 56:147-77.

Dempster, A., N. Laird, and D. Rubin. 1977. Maximum likelihood from incomplete data via the EM algorithm. J ournal of the Royal Statistical Society 39:1-38.

Djankov, S., R. La Porta, F. Lopez-de-Silanes, and A. Shleifer. 2008. The law and economics of selfdealing. J ournal of F inancial E conomics 88:430-65.

Ernstberger, J., J. Hitz, and M. Stich. 2012. Enforcement of accounting standards in Europe: Capitalmarket-based evidence for the two-tier mechanism in Germany. European Accounting Review 21:25381.

K arolyi, G .A . 2015. Cracking the emerging markets enigma. Oxford: Oxford U niversity Press.

Kaufmann, D., A. K raay, and M. M astruzzi. 2009. Governance matters V III: Governance indicators for 1996-2008. W orld Bank Policy Research, W ashington, D.C.

La Porta, R., F. Lopez-de-Silanes, and A. Shleifer. 2006. What works in securities laws? Journal of Finance 61:1-32. 
Table I-1

Sensitivity analyses of the average M AD and TPD liquidity effects

M odel 4 in Table 2 serves

as base specification

N

(1) Alternative clustering:

- Two-way clustering by country and quarter-year

112,260

MAD

TPD

- Clustering by economic region

112,260

$(-4.63)$

$-0.093 * *$

$(-2.26)$

$-0.115^{* * *}$

$-0.093^{*}$

$(-3.92)$

$(-1.94)$

(2) Alternative fixed effects structures:

- Firm-fixed effects

$\begin{array}{lll}112,260 & -0.126 * * * & -0.069 * * \\ & (-5.09) & (-2.22) \\ 112,260 & -0.120 * * * & -0.056 * \\ & (-2.62) & (-1.84) \\ 112,260 & -0.114 * * * & -0.094 * * \\ & (-3.55) & (-2.33)\end{array}$

- A dd separate quarter-year fixed effects for developed markets

- A dd separate quarter-year fixed effects interacted with firm size

$(-3.55)$

$(-2.33)$

(3) Alternative dependent variables:

- Ln(Bid-ask spreads)

127,56

$-0.215^{* *}$

$-0.227 * *$

$(-2.60)$

$(-2.56)$

- Zero returns

145,094

$-0.035^{* * *}$

$-0.038 * * *$

$(-2.98)$

$(-2.71)$

- $L n($ Liquidity factor +1$)$ with a minimum of

135,016

$-0.114 * * *$

$(-3.86)$

$-0.099 * * *$ three liquidity variables

145,090

$-0.077 * * *$

$(-3.46)$

$(-2.75)$

- Ln(Liquidity factor +1$)$ with imputed missing values

$-0.075^{* * *}$

$(-2.60)$

(4) Alternative sample specifications:

- Excluding GIIPS countries plus Cyprus

94,501

$-0.116^{* *}$

$(-2.52)$

$-0.087 * *$

$(-2.06)$

- Including non-EU benchmark countries

695,156

$-0.099 *$

$(-1.81)$

$-0.090 * *$

$(-2.48)$

- Including only one quarter per firm-year

33,285

$-0.133 * * *$

$-0.088 * *$

$(-3.95)$

$(-2.65)$

- U sing country-year-quarter-industry means as unit of analysis

4,941

$-0.116 * * *$

$-0.060 *$

$(-4.27)$

$(-1.88)$

- U sing country-year-quarter means as unit of analysis

896

$-0.107 * *$

$(-2.67)$

$-0.043^{* *}$

$(-2.31)$

(5) Alternative control variables:

- N ot controlling for In(Share turnover $\left.\mathrm{t}_{-4}\right)$

112,260

$-0.121 * * *$

$-0.074 *$

$(-3.81)$

$(-1.97)$

- Controlling for In(M arket value 2001)

112,260

$-0.096 * * *$

$-0.073 *$

$(-3.55)$

$(-1.83)$ 


\section{Table I-1}

\section{Continued}

MAD and TPD are binary indicator variables that take on the value of ' 1 ' beginning in the quarter when the MAD or the TPD came into force. For further details on the sample and a description of the dependent and control variables see Table 1. We report results for the following specifications: First, we use alternative clustering criteria when computing standard errors. We apply (i) two-way clustering by country and quarter-year, or (ii) clustering by 18 economic regions (e.g., Southern Europe, Central Europe, etc.). Second, we use alternative fixed-effect structures. We (i) replace the country- and industry-fixed effects with firm-fixed effects, (ii) add separate quarter-year fixed effects for developed markets, or (iii) add quarter-year fixed effects that are interacted with the Market value of the firm. We identify developed markets based on the Morgan Stanley Capital International database. Third, we use alternative dependent variables. (i) We use the natural logarithm of the Bid-ask spread measured as the quarterly mean of the quoted daily spreads. (ii) Zero returns is the proportion of trading days with zero daily stock returns in a given quarter. (iii) We re-compute the Liquidity factor but require only three of the four liquidity variables (Bid-ask spread, Zero returns, Price impact, and Total trading costs) to be available for the factor analysis (i.e., when one liquidity variable is missing we use the factor scores from the three remaining liquidity variables). (iv) We maximize the sample by only requiring Zero returns data to be available and then impute missing observations for any of the three other liquidity variables using an expectations-maximization (EM) algorithm before estimating the factor scores (see e.g., Dempster, Laird, and Rubin 1977; K arolyi 2015, Chapter 3). We winsorize the imputed values based on the extreme observations of the original liquidity distributions. Fourth, we change the composition of the sample. (i) We exclude the so-called GIIPS countries (Greece, I reland, Italy, Portugal, and Spain) as well as Cyprus from the sample as they all experienced a serious economic downturn over the sample period. (ii) We add 582,896 firm-quarter observations from 31 non-EU countries as benchmark sample. In this specification we define the quarter-year fixed effects over all sample countries. (iii) For each firm-year, we only retain one randomly picked quarter in the sample to mitigate oversampling and serial correlation in the residuals (e.g., Bertrand, Duflo, and Mullainathan 2004). (iv) We use the means of the dependent and continuous independent variables in a given country, year, quarter, and industry as the unit of analysis. (v) We use country-year-quarter means instead. To account for differences in market size, we further weigh each observation by the aggregate US\$ market capitalization of the sample firms in a given country, year, and quarter. Fifth, we use alternative sets of control variables. We (i) exclude Share turnover from the model, and (ii) replace $M$ arket value measured in quarter $\mathrm{t}-4$ with $M$ arket value as of 2001 (i.e., the beginning of our sample period) or whenever a firm for the first time enters the sample. Unless indicated otherwise, we include the full set of control variables and fixed effects (see Model 4 in Table 2), but only report OLS coefficient estimates (t-statistics with country clustering) for the main variables. ${ }^{* * *}$, $* *$, and $*$ indicate statistical significance at the $1 \%, 5 \%$, and $10 \%$ levels (two-tailed). 
Table I-2

Descriptive statistics for the factor analysis and principle component analysis

\begin{tabular}{|c|c|c|}
\hline & $\begin{array}{c}\text { Factor } \\
\text { analysis } \\
\text { (1) }\end{array}$ & $\begin{array}{l}\text { Principle } \\
\text { component } \\
\text { analysis } \\
\text { (2) }\end{array}$ \\
\hline \multicolumn{3}{|l|}{ Eigenvalues: } \\
\hline First factor / component & 2.573 & 2.950 \\
\hline Second factor / component & 0.070 & 0.560 \\
\hline Third factor / component & -0.100 & 0.312 \\
\hline Fourth factor / component & -0.130 & 0.177 \\
\hline \multicolumn{3}{|l|}{ First factor/component scoring coefficients: } \\
\hline Bid-ask spread $t$ & 0.292 & 0.522 \\
\hline Zero returnst & 0.137 & 0.471 \\
\hline Price impact $t_{t}$ & 0.127 & 0.461 \\
\hline Total trading costs $s_{t}$ & 0.494 & 0.541 \\
\hline R ho first component $(2.95 / 4)$ & - & 0.738 \\
\hline $\begin{array}{l}\text { Pearson correlation coefficient between factor scores and principal } \\
\text { component scores for base sample }(N=112,260)\end{array}$ & \multicolumn{2}{|c|}{0.992} \\
\hline
\end{tabular}

The estimation sample for the factor analysis (FA) and principle component analysis (PCA) comprises the maximum number of observations with liquidity data available in Datastream over our sample period (i.e., first quarter of 2001 through second quarter of 2011). This selection gives rise to 956,977 firm-quarters from 62 countries. We use both the FA and the PCA to extract the underlying construct of "market liquidity" from the four observable variables Bidask spread, Zero returns, Price impact, and Total trading costs (see Table 1 for details). We report eigenvalues and scoring coefficients of the four liquidity variables for the two statistical techniques. For the PCA we also indicate the variance in the four liquidity variables explained by the first component (R ho). 
Table I-3

Controlling for IFRS adoption with or without bundled enforcement changes

$\mathrm{L} n($ Liquidity factor +1$)$ as dependent variable

\begin{tabular}{|c|c|c|c|}
\hline \multirow[b]{2}{*}{$(\mathrm{N}=112,260)$} & \\
\hline & $\begin{array}{c}\text { Without controls } \\
\text { for other EU directives } \\
\text { (M odel } 3 \text { in Table 2) } \\
\text { (1) }\end{array}$ & $\begin{array}{c}\text { With controls } \\
\text { for other EU directives } \\
\text { (M odel } 4 \text { in Table 2) } \\
\text { (2) }\end{array}$ & $\begin{array}{c}\text { IFRS adoption with } \\
\text { and without bundled } \\
\text { enforcement changes } \\
\text { (3) }\end{array}$ \\
\hline \multicolumn{4}{|l|}{ Test variables: } \\
\hline MAD & $\begin{array}{l}-0.116 * * * \\
(-3.70)\end{array}$ & $\begin{array}{l}-0.115^{* * *} \\
(-3.61)\end{array}$ & $\begin{array}{l}-0.134 * * * \\
(-2.77)\end{array}$ \\
\hline TPD & $\begin{array}{l}-0.087^{*} \\
(-1.87)\end{array}$ & $\begin{array}{l}-0.093 * * \\
(-2.20)\end{array}$ & $\begin{array}{l}-0.045^{*} \\
(-1.93)\end{array}$ \\
\hline \multicolumn{4}{|l|}{ O ther directives: } \\
\hline MiFID & - & $\begin{array}{c}0.033 \\
(0.51)\end{array}$ & $\begin{array}{c}0.049 \\
(0.78)\end{array}$ \\
\hline PROSP & - & $\begin{array}{l}-0.013 \\
(-0.56)\end{array}$ & $\begin{array}{l}-0.025 \\
(-1.14)\end{array}$ \\
\hline TAKEOVER & - & $\begin{array}{c}0.003 \\
(0.20)\end{array}$ & $\begin{array}{r}0.017 \\
(0.55)\end{array}$ \\
\hline IFRS & - & $\begin{array}{l}-0.101^{* *} \\
(-2.33)\end{array}$ & - \\
\hline IFRS $\mathrm{EU}_{-}$ENF & - & - & $\begin{array}{l}-0.261 * * * \\
(-4.49)\end{array}$ \\
\hline IFRS $\mathrm{EU}_{\text {EnnonENF }}$ & - & - & $\begin{array}{l}-0.015 \\
(-0.22)\end{array}$ \\
\hline \multicolumn{4}{|l|}{ Remaining control variables: } \\
\hline Ln(M arket value $\left.\mathrm{t}_{-4}\right)$ & $\begin{array}{l}-0.250 * * * \\
(-13.52)\end{array}$ & $\begin{array}{l}-0.248 * * * \\
(-13.48)\end{array}$ & $\begin{array}{l}-0.248 * * * \\
(-13.58)\end{array}$ \\
\hline $\operatorname{Ln}\left(\right.$ Share turnover $\left.r_{t-4}\right)$ & $\begin{array}{l}-0.155^{* * *} \\
(-19.11)\end{array}$ & $\begin{array}{l}-0.155^{* * *} \\
(-18.63)\end{array}$ & $\begin{array}{l}-0.160 * * * \\
(-20.29)\end{array}$ \\
\hline Ln(R eturn variability $\left.{ }_{t-4}\right)$ & $\begin{array}{l}0.172^{* * *} \\
(4.63)\end{array}$ & $\begin{array}{l}0.172^{* * *} \\
(4.67)\end{array}$ & $\begin{array}{l}0.184 * * * \\
(5.77)\end{array}$ \\
\hline Ln(GDP per capitat-4) & $\begin{array}{l}-0.013 \\
(-0.02)\end{array}$ & $\begin{array}{l}-0.046 \\
(-0.08)\end{array}$ & $\begin{array}{r}0.000 \\
(0.00)\end{array}$ \\
\hline \multicolumn{4}{|l|}{ F ixed effects: } \\
\hline Country & Yes & Yes & Y es \\
\hline Industry & Y es & Yes & Yes \\
\hline Quarter-year & Yes & Y es & Yes \\
\hline R-squared & 0.658 & 0.659 & 0.666 \\
\hline
\end{tabular}

$M A D$ and TPD are binary indicator variables that take on the value of ' 1 ' beginning in the quarter when the MAD or the TPD came into force. For further details on the sample and a description of the dependent and control variables see Table 1. In M odel 2 we include indicator variables for other regulatory changes in the EU, i.e., the M arkets in Financial Instruments Directive (M iFID), the Prospectus Directive (PROSP), the Takeover Directive (TAKE OVER), and the mandatory adoption of International Financial Reporting Standards (IFRS). In M odel 3 we split the IF RS observations into two non-overlapping subsets using binary indicators for firms from EU countries that bundled IFRS adoption with substantive changes in enforcement (IF RS $\left.\mathrm{EU}_{\mathrm{ENF}}\right)$ and firms from EU countries with no such

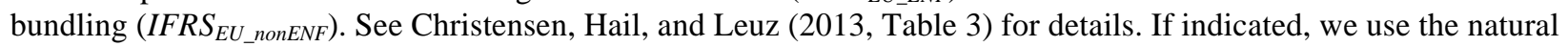
log of the raw values (plus one), and lag the variables by four quarters. We include country-, industry-, and quarteryear-fixed effects in the regressions, but do not report the coefficients. The table reports OLS coefficient estimates and (in parentheses) t-statistics based on robust standard errors that are clustered by country. ${ }^{* * *}, * *$, and $*$ indicate statistical significance at the $1 \%, 5 \%$, and $10 \%$ levels (two-tailed). 
Table I-4

C ounter-factually varying the entry-into-force dates of the M AD and TPD

\begin{tabular}{|c|c|c|c|c|}
\hline \multirow[b]{3}{*}{$(N=112,260)$} & \multicolumn{4}{|c|}{ Ln(L iquidity factor +1$)$ as dependent variable } \\
\hline & \multicolumn{2}{|c|}{ MAD } & \multicolumn{2}{|c|}{ TPD } \\
\hline & Coefficient & t-stat & Coefficient & t-stat \\
\hline $\begin{array}{l}\text { Shifting of entry-into-force dates relative to } t=0 \text { : } \\
t-6 \\
t-5 \\
t-4 \\
t-3 \\
t-2 \\
t-1\end{array}$ & $\begin{array}{l}0.039 \\
0.032 \\
0.016 \\
-0.005 \\
-0.020 \\
-0.080 * * *\end{array}$ & $\begin{array}{r}(1.21) \\
(1.04) \\
(0.65) \\
(-0.27) \\
(-1.01) \\
(-3.64)\end{array}$ & $\begin{array}{l}0.013 \\
-0.003 \\
-0.012 \\
-0.034^{* *} \\
-0.054^{* *} \\
-0.060 *\end{array}$ & $\begin{array}{l}(0.46) \\
(-0.16) \\
(-0.69) \\
(-2.11) \\
(-2.04) \\
(-1.75)\end{array}$ \\
\hline $\mathrm{t}=0$ ('true' entry-into-force date) & $-0.115^{* * *}$ & $(-3.61)$ & $-0.093 * *$ & $(-2.20)$ \\
\hline $\begin{array}{l}t+1 \\
t+2 \\
t+3 \\
t+4 \\
t+5 \\
t+6\end{array}$ & $\begin{array}{l}-0.103^{* *} \\
-0.083^{*} * \\
-0.064^{*} \\
-0.050 \\
-0.056 \\
-0.040\end{array}$ & $\begin{array}{l}(-2.73) \\
(-2.13) \\
(-1.69) \\
(-1.38) \\
(-1.94) \\
(-1.47)\end{array}$ & $\begin{array}{l}-0.121^{* *} \\
-0.130^{* *} \\
-0.137 * * \\
-0.154^{* *} \\
-0.165^{* *} \\
-0.165^{*}\end{array}$ & $\begin{array}{l}(-2.32) \\
(-2.12) \\
(-2.03) \\
(-2.11) \\
(-2.07) \\
(-1.93)\end{array}$ \\
\hline
\end{tabular}

For details on the sample and a description of the dependent and control variables see Table 1. The table reports the $M A D$ or TPD coefficients from 13 separate regressions. For each regression we counter-factually shift the 'true' MAD or TPD entry-into-force dates $(t=0)$ to a different quarter. That is, we set the binary MAD or TPD indicator variables equal to ' 1 ' beginning in each quarter from $t-6$ to $t+6$ relative to the 'true' entry-into-force date. Throughout the table, we include the full set of control variables and fixed effects in the models (see Model 4 in Table 2), but only report OLS coefficient estimates (t-statistics, based on robust standard errors clustered by country) for the main variables. $* * *, * *$, and $*$ indicate statistical significance at the $1 \%, 5 \%$, and $10 \%$ levels (twotailed). 


\section{Table I-5}

\section{Predicting the length of countries' implementation times for the M AD and TPD}

\begin{tabular}{|c|c|c|}
\hline \multirow[b]{2}{*}{$(\mathrm{N}=25)$} & \multicolumn{2}{|c|}{ Implementation time as dependent variable } \\
\hline & MAD & TPD \\
\hline \multicolumn{3}{|l|}{ Explanatory variables: } \\
\hline Intercept & $\begin{array}{l}15.148 * * * \\
(3.13)\end{array}$ & $\begin{array}{r}2.445 \\
(0.27)\end{array}$ \\
\hline Implementation time $\mathrm{MAD}_{\mathrm{A}}$ & - & $\begin{array}{l}0.636 * * \\
(2.09)\end{array}$ \\
\hline Implementation time & $\begin{array}{l}0.272 * * \\
(2.09)\end{array}$ & - \\
\hline Bicameral legislature & $\begin{array}{l}-1.833 \\
(-0.87)\end{array}$ & $\begin{array}{l}6.643^{* *} \\
(2.27)\end{array}$ \\
\hline Number EU notices & $\begin{array}{l}0.210 * \\
(2.00)\end{array}$ & $\begin{array}{c}0.131 \\
(0.75)\end{array}$ \\
\hline F-statistic & 4.60 & 4.75 \\
\hline R-squared & 0.396 & 0.404 \\
\hline
\end{tabular}

The sample comprises one observation per EU country. The dependent variable, Implementation time, measures the length of the total process (in months) from the enactment at the EU level of either the M AD (28-Jan-2003) or TPD (17-Dec-2004) to its entry-into-force date in each member state (see Table 1). We also include the implementation time of the other directive (indicated by the subscript) as a control variable. The other determinants are: (i) a binary indicator variable equal to one for countries with a bicameral legislature, and (ii) the annual median number of letters of formal notice that a country received from the European Commission (measured over the period 2005 to 2011). The table shows OLS coefficient estimates and t-statistics. $* * *, * *$, and $*$ indicate statistical significance at the $1 \%, 5 \%$, and $10 \%$ levels (two-tailed). 
Tablel-6

Alternative prior regulation variables by EU country

\begin{tabular}{|c|c|c|c|c|c|c|c|c|c|c|c|c|}
\hline \multirow{3}{*}{$\begin{array}{l}\text { Country } \\
\text { A ustria }\end{array}$} & \multirow{2}{*}{\multicolumn{2}{|c|}{$\begin{array}{c}\text { See Table } 4 \\
\text { Regulatory } \\
\text { quality } 2003\end{array}$}} & \multicolumn{10}{|c|}{ A Iternative proxies for prior regulatory quality } \\
\hline & & & \multicolumn{2}{|c|}{$\begin{array}{l}\text { Rule of } \\
\text { law } 2003\end{array}$} & \multicolumn{2}{|c|}{$\begin{array}{l}\text { Public } \\
\text { enforcement }\end{array}$} & \multicolumn{2}{|c|}{$\begin{array}{l}\text { A nti-self- } \\
\text { dealing }\end{array}$} & \multicolumn{2}{|c|}{$\begin{array}{l}\text { Auditing and } \\
\text { reporting quality } \\
2002 / 03\end{array}$} & \multicolumn{2}{|c|}{$\begin{array}{l}\text { Regulatory } \\
\text { quality factor }\end{array}$} \\
\hline & 1.52 & (1) & 1.79 & (1) & 0.17 & (0) & 0.21 & (0) & 6.0 & (1) & 1.12 & (1) \\
\hline Belgium & 1.36 & $(0)$ & 1.47 & (1) & 0.15 & (0) & 0.54 & (1) & 5.9 & (1) & 0.86 & (1) \\
\hline Bulgaria & 0.59 & $(0)$ & -0.09 & (0) & n.a. & n.a. & 0.65 & (1) & 4.1 & (0) & -0.57 & (0) \\
\hline Cyprus & 1.20 & $(0)$ & 0.85 & (0) & n.a. & n.a. & n.a. & n.a. & 5.6 & (0) & 0.38 & (0) \\
\hline Czech Republic & 1.12 & $(0)$ & 0.84 & (0) & n.a. & n.a. & 0.33 & $(0)$ & 4.1 & $(0)$ & 0.19 & (0) \\
\hline Denmark & 1.79 & (1) & 1.91 & (1) & 0.37 & (0) & 0.46 & (1) & 5.9 & (1) & 1.29 & (1) \\
\hline Estonia & 1.40 & (1) & 0.73 & (0) & n.a. & n.a. & n.a. & n.a. & 5.4 & (0) & 0.35 & (0) \\
\hline Finland & 1.90 & $(1)$ & 1.90 & (1) & 0.32 & (0) & 0.46 & (1) & 6.2 & $(1)$ & 1.35 & (1) \\
\hline France & 1.18 & (0) & 1.38 & (0) & 0.77 & (1) & 0.38 & (0) & 5.9 & (1) & 0.74 & (0) \\
\hline Germany & 1.51 & (1) & 1.65 & (1) & 0.22 & (0) & 0.28 & (0) & 5.8 & (1) & 1.01 & (1) \\
\hline Greece & 1.01 & $(0)$ & 0.82 & (0) & 0.32 & (0) & 0.22 & $(0)$ & 4.4 & $(0)$ & 0.17 & (0) \\
\hline Hungary & 1.08 & $(0)$ & 0.87 & (0) & n.a. & n.a. & 0.18 & $(0)$ & 5.5 & $(0)$ & 0.33 & (0) \\
\hline Iceland & 1.67 & (1) & 2.06 & (1) & n.a. & n.a. & 0.26 & (0) & 6.2 & (1) & 1.36 & (1) \\
\hline Ireland & 1.66 & (1) & 1.51 & (1) & 0.37 & (0) & 0.79 & (1) & 5.7 & $(0)$ & 0.97 & (1) \\
\hline Italy & 1.02 & $(0)$ & 0.76 & (0) & 0.48 & (1) & 0.42 & (0) & 5.4 & $(0)$ & 0.24 & (0) \\
\hline Latvia & 1.03 & (0) & 0.53 & (0) & n.a. & n.a. & 0.32 & (0) & 4.7 & (0) & 0.03 & (0) \\
\hline Lithuania & 1.10 & $(0)$ & 0.50 & (0) & n.a. & n.a. & 0.36 & $(0)$ & 4.4 & $(0)$ & 0.00 & (0) \\
\hline Luxembourg & 1.94 & (1) & 1.91 & (1) & n.a. & n.a. & 0.28 & (0) & 6.0 & (1) & 1.34 & (1) \\
\hline M alta & 1.27 & $(0)$ & 1.54 & (1) & n.a. & n.a. & n.a. & n.a. & 5.8 & (1) & 0.86 & (1) \\
\hline The N etherlands & 1.76 & (1) & 1.71 & (1) & 0.47 & (1) & 0.20 & $(0)$ & 6.1 & (1) & 1.16 & (1) \\
\hline Norway & 1.39 & $(0)$ & 1.91 & (1) & 0.32 & (0) & 0.42 & (0) & 5.7 & (0) & 1.13 & (1) \\
\hline Poland & 0.61 & $(0)$ & 0.56 & (0) & n.a. & n.a. & 0.29 & $(0)$ & 4.5 & $(0)$ & -0.12 & (0) \\
\hline Portugal & 1.21 & $(0)$ & 1.26 & (0) & 0.58 & (1) & 0.44 & (1) & 5.0 & $(0)$ & 0.58 & (0) \\
\hline Romania & -0.12 & $(0)$ & -0.23 & (0) & n.a. & n.a. & 0.44 & (1) & 3.7 & $(0)$ & -0.95 & (0) \\
\hline Slovakia & 0.95 & (0) & 0.36 & (0) & n.a. & n.a. & 0.29 & (0) & 4.4 & (0) & -0.14 & (0) \\
\hline Slovenia & 0.88 & (0) & 0.94 & (0) & n.a. & n.a. & n.a. & n.a. & 5.2 & $(0)$ & 0.28 & (0) \\
\hline Spain & 1.29 & $(0)$ & 1.29 & (0) & 0.33 & (0) & 0.37 & $(0)$ & 5.1 & (0) & 0.64 & (0) \\
\hline Sweden & 1.69 & (1) & 1.89 & (1) & 0.50 & (1) & 0.33 & (0) & 6.1 & (1) & 1.26 & (1) \\
\hline United Kingdom & 1.68 & (1) & 1.70 & (1) & 0.68 & (1) & 0.95 & (1) & 6.5 & (1) & 1.19 & (1) \\
\hline
\end{tabular}


Tablel-6

\section{Continued}

In the main analysis, we measure the quality of prior regulation with the Regulatory quality index as of 2003, capturing the "ability of the government to formulate and implement sound policies and regulations" (K aufmann, K raay, and M astruzzi 2009). In the sensitivity tests, we use the following alternative proxies: (i) the Rule of law index as of 2003 from K aufmann, K raay, and M astruzzi (2009), (ii) the Public enforcement index from La Porta, L opez-de-Silanes, and Shleifer (2006), (iii) the Anti-self-dealing index from Djankov et al. (2008), and (iv) an index measuring a country's Auditing and reporting quality as of 2002/03 and based on survey results from the Global Competitiveness Report (source: World E conomic Forum). W e further construct a Regulatory quality factor that represents the scores of a single factor obtained from factor analysis with all the above country-level measures (see also Karolyi 2015, Chapter 8). B efore estimating the factor scores, we impute missing observations of the individual institutional proxies using an EM algorithm. Throughout the table, higher values indicate higher regulatory quality. For the analyses, we transform the continuous variables into binary indicators (shown in parentheses) splitting by the OECD median. The OECD countries not included in our sample are: A ustralia, Canada, Chile, Israel, Japan, South K orea, M exico, N ew Zealand, Switzerland, Turkey, and the U nited States. 
Tablel-7

\section{Sensitivity analyses of the MAD and TPD liquidity effects when prior regulation differs}

Panel A : R esults for the M AD

\begin{tabular}{|c|c|c|c|c|c|c|}
\hline \multirow[b]{2}{*}{$\begin{array}{l}\operatorname{Ln}(\text { Liquidity factor }+1) \\
\text { as dependent variable }\end{array}$} & \multirow{2}{*}{$\begin{array}{c}\text { See Table 5, Panel A } \\
\text { R egulatory } \\
\text { quality } 2003\end{array}$} & \multicolumn{5}{|c|}{ A Iternative proxies for prior regulatory quality } \\
\hline & & $\begin{array}{l}\text { Rule of law } \\
2003\end{array}$ & $\begin{array}{c}\text { Public } \\
\text { enforcement }\end{array}$ & $\begin{array}{l}\text { A nti-self- } \\
\text { dealing }\end{array}$ & $\begin{array}{l}\text { A uditing and } \\
\text { reporting quality } \\
2002 / 03\end{array}$ & $\begin{array}{l}\text { Regulatory } \\
\text { quality factor }\end{array}$ \\
\hline \multicolumn{7}{|l|}{ Prior regulation quality: } \\
\hline High & $\begin{array}{l}-0.234 * * * \\
(-3.16)\end{array}$ & $\begin{array}{l}-0.200 * * * \\
(-2.95)\end{array}$ & $\begin{array}{l}-0.174 * * \\
(-2.25)\end{array}$ & $\begin{array}{l}-0.261^{* *} \\
(-2.75)\end{array}$ & $\begin{array}{l}-0.209 * * * \\
(-2.96)\end{array}$ & $\begin{array}{l}-0.200 * * * \\
(-2.95)\end{array}$ \\
\hline Low & $\begin{array}{l}-0.000 \\
(0.00)\end{array}$ & $\begin{array}{r}0.001 \\
(0.02)\end{array}$ & $\begin{array}{l}-0.067 \\
(-1.13)\end{array}$ & $\begin{array}{l}-0.061^{* *} \\
(-2.35)\end{array}$ & $\begin{array}{r}0.040 \\
(0.89)\end{array}$ & $\begin{array}{r}0.001 \\
(0.02)\end{array}$ \\
\hline \multicolumn{7}{|c|}{ F-test for differences across coefficients ( $p$-value): } \\
\hline $\mathrm{High}=\mathrm{Low}$ & 0.014 & 0.027 & 0.266 & 0.073 & 0.006 & 0.027 \\
\hline $\mathrm{N}$ & 112,260 & 112,260 & 100,868 & 110,244 & 112,260 & 112,260 \\
\hline
\end{tabular}

Panel B: Results for the TPD

\begin{tabular}{|c|c|c|c|c|c|c|}
\hline \multirow[b]{2}{*}{$\begin{array}{l}\operatorname{Ln}(\text { Liquidity factor }+1) \\
\text { as dependent variable }\end{array}$} & \multirow{2}{*}{$\begin{array}{c}\text { See Table 5, Panel B } \\
\text { Regulatory } \\
\text { quality } 2003\end{array}$} & \multicolumn{5}{|c|}{ A Iternative proxies for prior regulatory quality } \\
\hline & & $\begin{array}{c}\text { Rule of law } \\
2003\end{array}$ & $\begin{array}{c}\text { Public } \\
\text { enforcement }\end{array}$ & $\begin{array}{l}\text { A nti-self- } \\
\text { dealing }\end{array}$ & $\begin{array}{l}\text { A uditing and } \\
\text { reporting quality } \\
2002 / 03\end{array}$ & $\begin{array}{l}\text { Regulatory } \\
\text { qual ity factor }\end{array}$ \\
\hline \multicolumn{7}{|l|}{ Prior regulation quality: } \\
\hline High & $\begin{array}{l}-0.185^{* *} \\
(-2.40)\end{array}$ & $\begin{array}{l}-0.161^{* *} \\
(-2.30)\end{array}$ & $\begin{array}{l}-0.119 * * \\
(-2.36)\end{array}$ & $\begin{array}{l}-0.237 * * \\
(-2.56)\end{array}$ & $\begin{array}{l}-0.157^{* *} \\
(-2.41)\end{array}$ & $\begin{array}{l}-0.161^{* *} \\
(-2.30)\end{array}$ \\
\hline Low & $\begin{array}{c}0.034 \\
(0.77)\end{array}$ & $\begin{array}{l}0.040 \\
0.82\end{array}$ & $\begin{array}{r}0.025 \\
(0.42)\end{array}$ & $\begin{array}{c}-0.011 \\
(-0.25)\end{array}$ & $\begin{array}{l}0.091 * \\
(1.91)\end{array}$ & $\begin{array}{l}0.040 \\
0.82\end{array}$ \\
\hline \multicolumn{7}{|c|}{$F$-test for differences across coefficients ( $p$-value): } \\
\hline High $=$ Low & 0.039 & 0.044 & 0.164 & 0.064 & 0.007 & 0.044 \\
\hline $\mathrm{N}$ & 112,260 & 112,260 & 100,868 & 110,244 & 112,260 & 112,260 \\
\hline
\end{tabular}

For details on the sample and a description of the dependent and control variables see Table 1 . We use M odel 4 in Table 2 as our base specification. For each model we partition the sample into two distinct groups by interacting the M AD (Panel A) or TPD (Panel B) variables with a binary indicator variable for the quality of prior regulation (high vs. low). For a description of the country-level partitioning variables see Table I-5. W e only report OLS coefficient estimates (t-statistics, based on robust standard errors clustered by country) for the main variables. We also report $p$-values from Wald tests assessing the statistical significance of the differences across coefficients. $* * *, * *$, and $*$ indicate statistical significance at the $1 \%, 5 \%$, and $10 \%$ levels (two-tailed). 


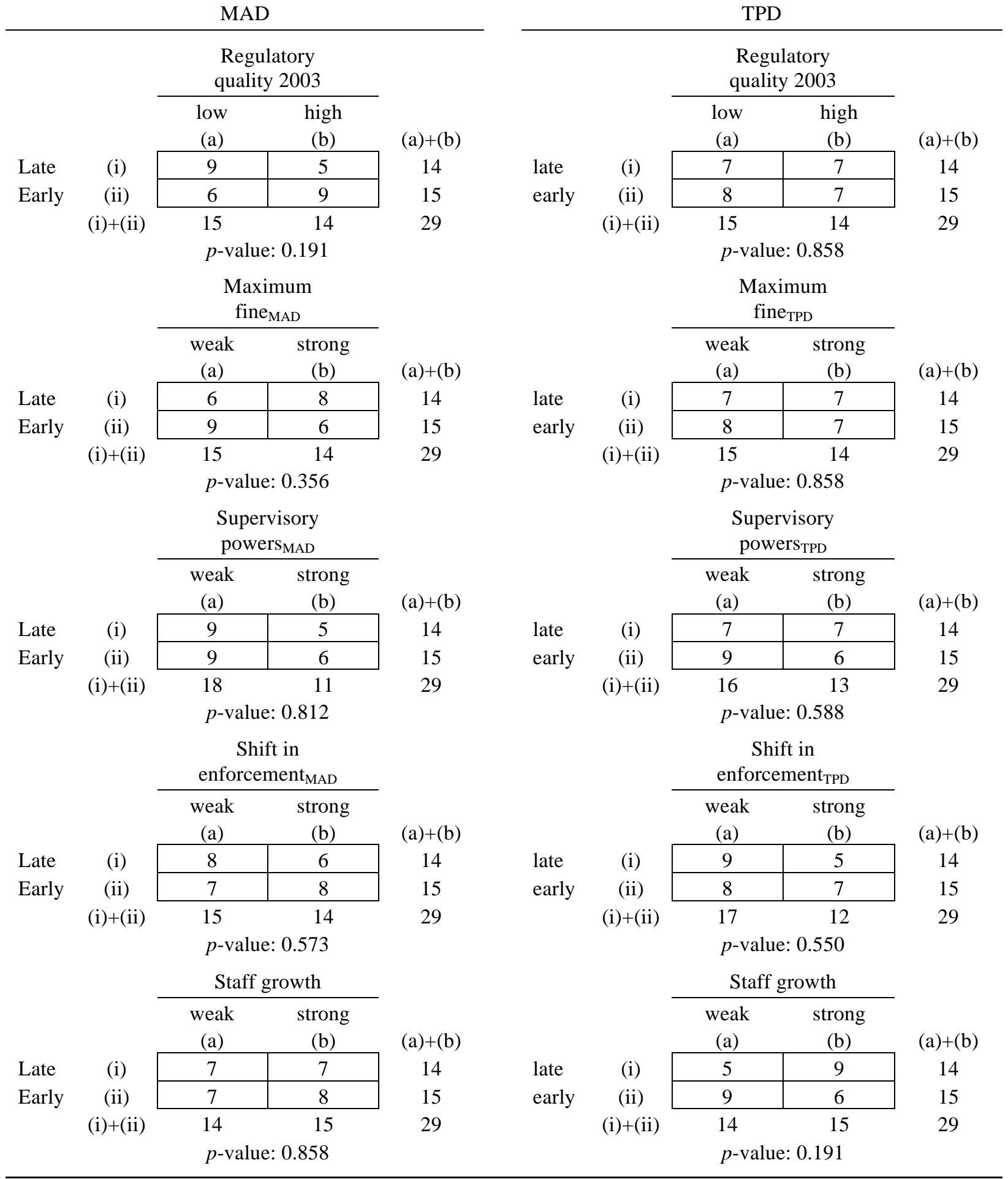

The table presents cross-tabulations of the MAD or TPD adoption timing (late vs. early) with either the quality of prior regulation (low vs. high) or the implementation strength of the MAD and TPD (weak vs. strong). The sample comprises country-level observations for the $29 \mathrm{EU}$ member states listed in Table 1 . We classify a country as late (early) if the adoption of the MAD or TPD occurred after (before) the median entry-into-force date of the respective directive. For a description of the country-level partitioning variables see Table 4 . W e also report $p$-values from chisquared tests assessing the statistical significance of the frequencies across cells for each contingency table. The analysis shows that prior regulation and implementation strength do not capture implementation timing. 